Portland State University

PDXScholar

$1-1-1987$

\title{
A Descriptive Study of an Alternative Process of "Learning-To-Teach"
}

Nancy Terry Nagel

Portland State University

Follow this and additional works at: https://pdxscholar.library.pdx.edu/open_access_etds Let us know how access to this document benefits you.

\section{Recommended Citation}

Nagel, Nancy Terry, "A Descriptive Study of an Alternative Process of "Learning-To-Teach"'" (1987). Dissertations and Theses. Paper 854.

https://doi.org/10.15760/etd.854

This Dissertation is brought to you for free and open access. It has been accepted for inclusion in Dissertations and Theses by an authorized administrator of PDXScholar. Please contact us if we can make this document more accessible: pdxscholar@pdx.edu. 


\title{
A DESCRIPTIVE STUDY OF AN ALTERNATIVE \\ PROCESS OF "LEARNING-TO-TEACH"
}

\section{by}

NANCY TERRY NAGEL

A dissertation submitted in partial fulfillment of the requirements for the degree of

\author{
DOCTOR OF EDUCATION \\ in \\ EDUCATIONAL LEADERSHIP
}

Portland State University

1987 
TO THE OFFICE OF GRADUATE STUDIES AND RESEARCH:

The members of the Committee approve the dissertation of Nancy Terry Nagel presented June 26, 1987.

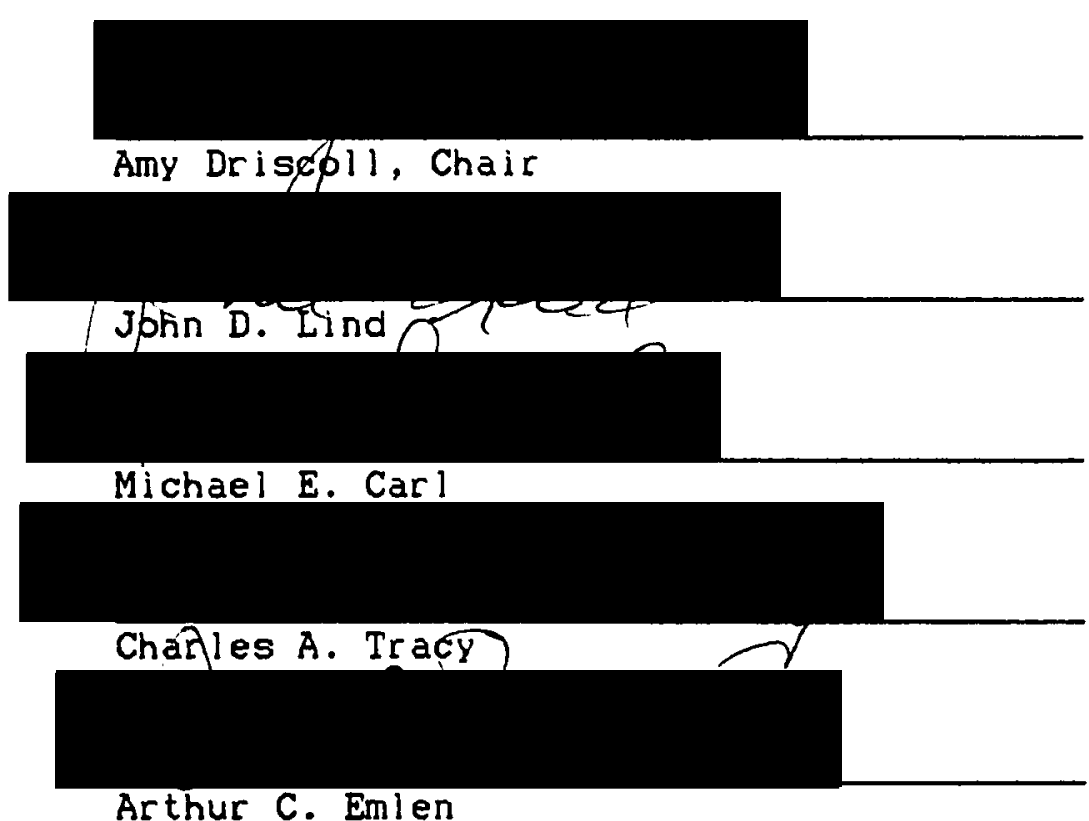

APPROVED :

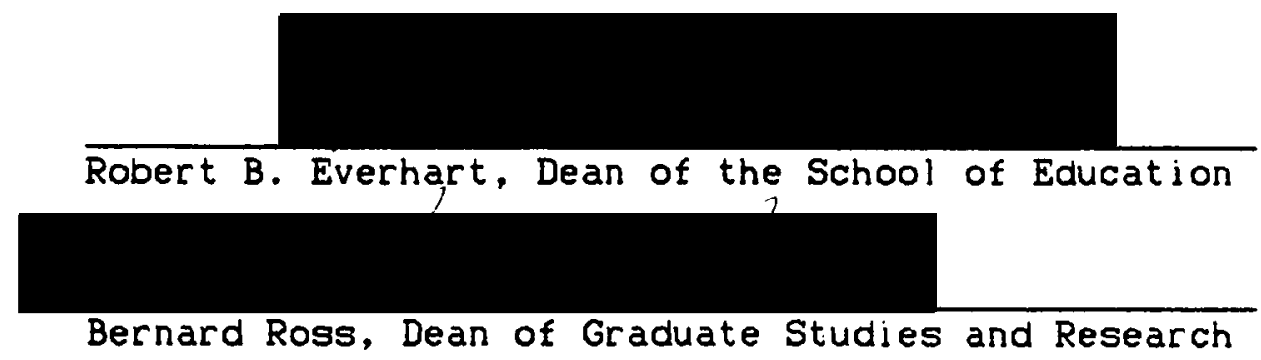




\begin{abstract}
AN ABSTRACT OF THE DISSERTATION OF Nancy Terry Nagel for the Doctor of Education in Educational Leadership presented June $26,1987$.
\end{abstract}

TITLE: A Descriptive Study of an Alternative Process of "Learning-To-Teach" .

APPROVED BY MEMBERS OF THE DISSERTATION COMMITTEE:

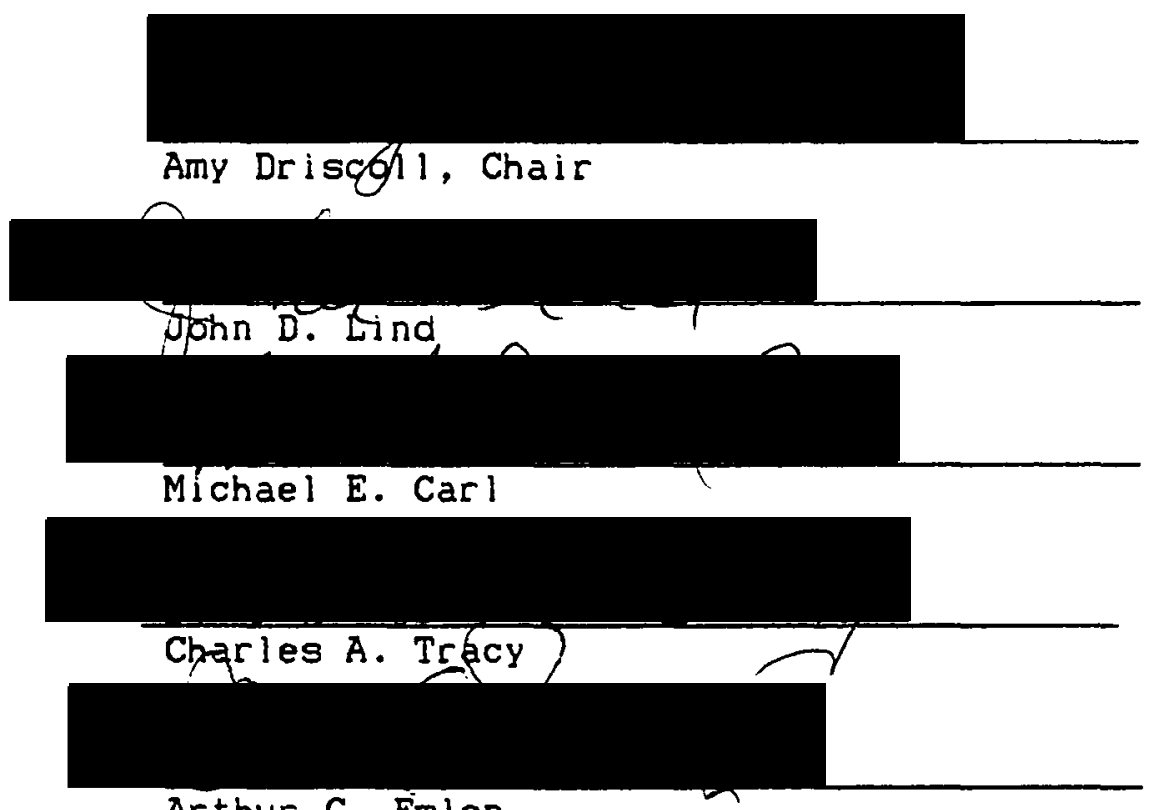

Arthur C. Emlen

The purpose of this study was to examine the "learning-to-teach" process in an alternative teacher education program. Three research questions were addressed to probe the "learning-to-teach" process: 1. To what sources do the interns attribute learning and use of 
specific teaching behaviors and skills? 2. What are the professional concerns of interns, and are there changes in concerns as they progress through the field experience? 3 . How do interns assess themselves as they progress through the field experience, and what is the rationale of the assessment?

Qualitative research allows the study of subjects in the natural setting, and enables emergent findings to be utilized in directing the focus of the study. Integrating qualitative and quantitative data strengthened the description of "learning-to-teach" in this study. Research methods included use of multiple collections of data from observations, interviews, and questionnaires with the intensive subjects, and questionnaires with the general sample of subjects. A descriptive analysis approach was utilized to present and discuss the findings. The intensive sample of subjects included six interns enrolled in the Cooperative Teacher Education Program (CPEP) at Portland State University, with a general sample of twenty-two CPEP interns providing additional data.

Interns reported multiple sources of influence on their teaching behavior. Exposure to multiple "models" of teaching in conjuction with application during the field experience provided interns with the opportunity to analyize, syntheslze, and Integrate these ideas into their personal teaching. 
Professional concerns of CPEP interns followed the pattern of concerns reported by student teachers in traditional programs. Extending the field experience did not cause the interns to move to concerns-with-students at a faster rate. Concerns-with-self must be addressed and resolved before preservice teachers can move to concerns-with-students.

Interns reported the self-assessment process enabled them to evaluate and improve their teaching. Teaching preservice teachers to assess their instruction and the purpose and use of this assessment, enhances professional growth. Preservice teachers can learn to reflect upon their teaching, and use this information to improve future inseruction.

These conclusions lead to the recommendation of incorporating reflection of "models" of teaching, professional concerns, and self-assessment of teaching in teacher education curriculum. Preparing "reflective" teachers facilitates professional movement beyond "survival" and "imitation". Reflective teachers advance to the level of making instructional decisions based on careful considerations of beliefs and knowledge, and create personal "models" of teaching. 


\section{ACKNOWLEDGMENTS}

I am indebted to several people who have supported ana assisted me in this project.

The group of interns in the Cooperative Professional Education Program deserve recognition for spenaing the time necessary to participate in this study.

I would like to acknowledge the interest and enthusiasm expressed by friends and colleagues during my dissertation process.

My doctoral advisory committee was extremely helpful, providing valuable recommendations and support for this study. Grateful appreciation is extended to the chalrperson of my committee. Dr. Amy Driscoll, who expended many hours of discussion and feedback sessions during this study. Her expertise in the field of teacher education providea exceptional guidance.

I wish to thank my parents for teaching me the values of "hard work" and patience, which were necessary during the project.

Finally, I am most appreciative of the love and encouragement from my husband, Ralph, and our sons. Marc and Scott. They provided the balance during "dissertation life." 
TABLE OF CONTENTS

PAGE

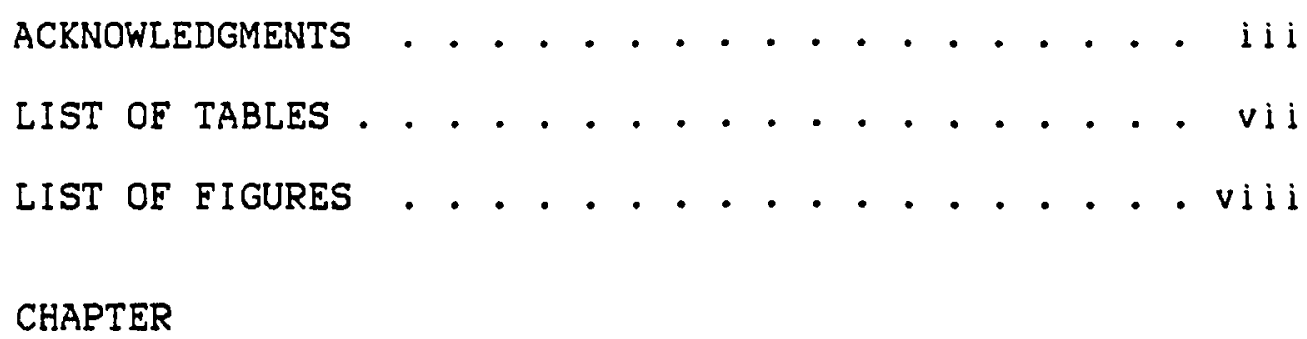

I INTRODUCTION . . . . . . . . . . . 1

Rationale for Study ........ 1

Purpose of Study . . . . . . . 3

Significance of the Study...... 3

Methodology ........... 5

Summary . . . . . . . . . 6

II REVIEW OF THE LITERATURE ........ . 8

Introduction ......... 8

Teacher Education........ . 8

Reform Issues

Reform Agenda

Teacher Education Research

Field Experiences . . . . . . 12

Prominence of Field Experience

Field Experience Concerns

Major Influences

Field Experience Research

Critique

Review of Literature Related to

Study's Methodology . . . . . . . . 23 
Qualltative Research in Education Qualitative Research Characteristics Methodology Literature

Review Summary

Summary . . . . . . . . . . 29

II I METHODOLOGY . . . . . . . . . . . . 31

Introduction . . . . . . . . . 31

Research Design . . . . . . . . 31

Context of Study . . . . . . . . 34

Data Collection and Data Analysis . . 37

Schedule of Data Collection

Observations and Interviews

Teaching Concerns Questionnaire

Self-Assessment Quest i onna ire

Reliability......... 44

Limitations ......... . 46

Summary . . . . . . . . 47

IV PRESENTATION AND DISCUSSION OF DATA... 49

Introduction ......... 49

Reported Sources of Influence . . . . 53

Presentation of Data Introciuction

Sources of Influence

Analyzed by Month

Source of Influence

Analyzed by Category

Influences on Specific Categories

of Teaching Behavior

Discussion of Findings by Category

Summary of Reported Sources

of Influence

Professional Concerns of Interns ...

Presentation of Data

Presentation of Data

within Concerns Categories 


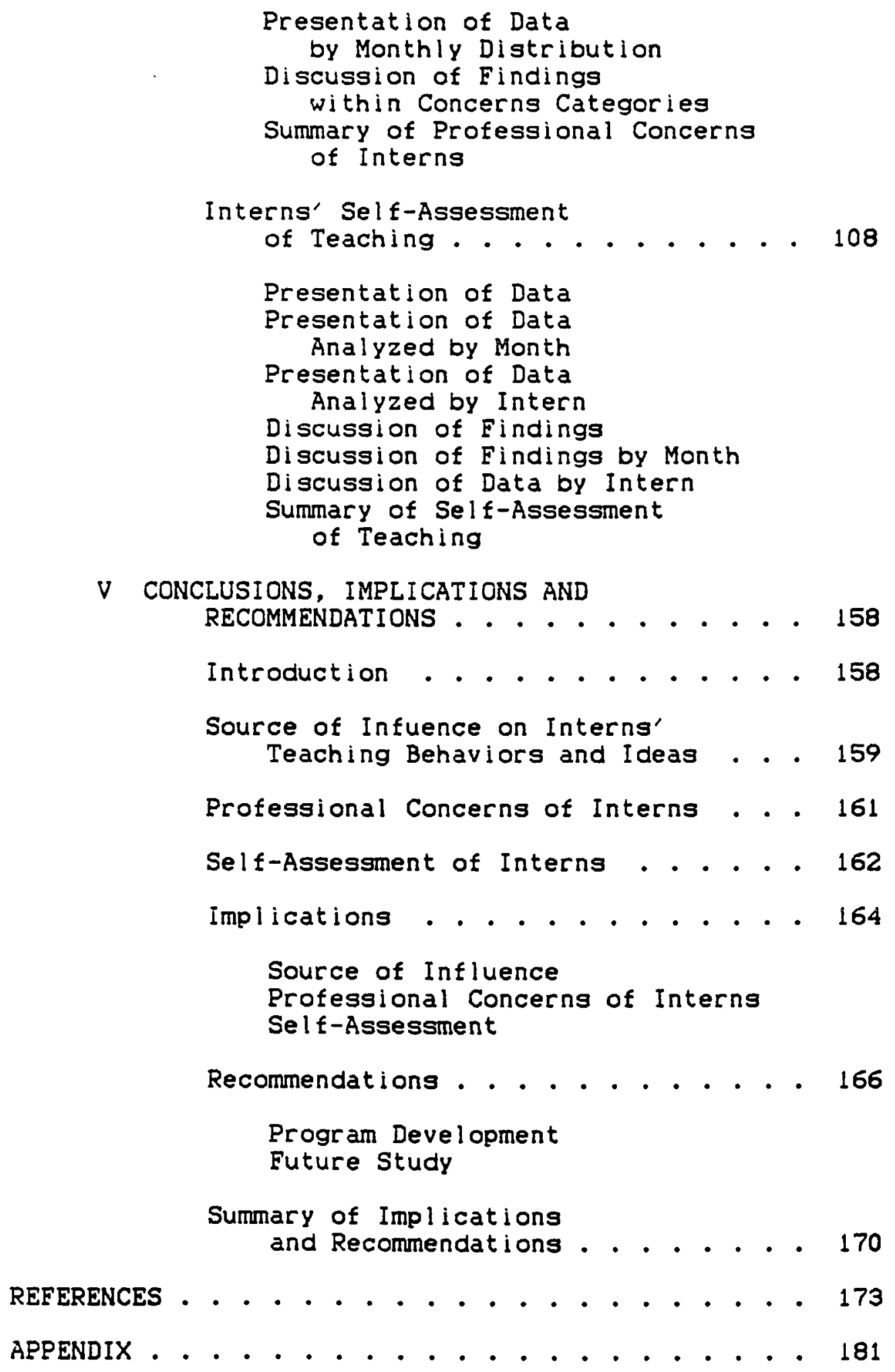




\section{LIST OF TABLES}

TABLE

PAGE

I Reported Source of Influence on Observed Teaching . . . . . . . . 55

I Content of Reported Source of Influence on Observed Teaching . . . . . . . . 61

II Professional Concerns of Interns . . . . . 84

IV Interns' Self-Assessment of Teaching . . . 110

$V$ Content of Rationale of Interns'

Self-Assessment of Teaching . . . . . 111

VI Self-Assessment Profile of Intern \#1 . . . 137

VII Self-Assessment Profile of Intern \#2 . . . 141

VIII Self-Assessment Profile of Intern \#3 . . . 144

IX Self-Assessment Profile of Intern \#4 . . . 147

$X$ Self-Assessment Profile of Intern \#5 . . . 150

XI Self-Assessment Profile of Intern \#6 . . . 153 


\section{LIST OF FIGURES}

1. Timelines, Research Processes, and Multi-Levels of Subjects..... . 40

2. Teaching Concerns Questionnaire . . . . . 43

3. Self-Assessment Questionnaire . . . . . 45

4. Timeline of CPEP Activities . . . . . . . 51 
CHFPTER I

INTRODUCT ION

RATIONALE FOR STUDY

This study examines the "learning-to-teach" process during the field experience in order to contribute to teacher education policy and program development. It provides critical information in advance of initiation of major program changes. According to Zeichner (1984), the unsatisfactory state of the knowledge of field experience is a result of inadequate exploration of the interrelationship between student teacher and the field experience environment. Careful descriptions of programs are needed before attempting to alter existing practice (Koehler, 1985). The findings of this research add to the knowledge used in reform decisions in teacher education.

In 1983, A Nation at Risk (National Commission of Excellence in Education) informed the public about the state of schooling in America. With statements such as, "the educational foundations of our sociey are presently being eroded by a rising tide of mediocrity that threatens our very future as a Nation and a people" (p. 5), included in thls publication, the public soon grew alarmed over the reported state of the schools. In response to the findings 
in the report, demands for reform in educatlon were initiated. Teacher education was not immune to these calls for reform, and the criticism that had focused on education has now shifted to teacher education (Warren, 1985). The idea that teacher education should be changed is not novel. Despite changes occurring through the last two centuries, teacher education has retained an essence of low opinion. During the last forty years, the strength of the focus of attention on reform in education and teacher education has varied considerably, often according to the level of national economic and social stability.

The Holmes Group and the Carnegie Task Force are two of several groups with current agendas promoting change in teacher education. Both of these groups agree that teacher education needs to be dramatically changed (Keppel, 1986), to Include reform ldeas such as eliminating undergraduate education degrees and a restructuring of the certification requirements. Before instituting major change in teacher education programs, a close and careful examination of existing programs is warranted. Change in education programs should do more than satisfy an urge for action or reaction. Studying the history and research on teaching, teacher education and teachers provides a resource useful in developing change strategies to build effective teacher education programs (Warren, 1985). 


\section{PURPOSE OF STUDY}

The purpose of this study was to examine the "learning-to-teach" process of interns enrolled in the Cooperative Professional Education Program (CPEP) at Portland State University. The following questions were addressed:

1. To what sources do the interns attribute learning and use of specific teaching behaviors and skills?

2. What are the professional concerns of the interns, and are there changes in concerns as they progress through the field experience?

3. How do interns assess themselves as they progress through the experience, and what is the rationale of the assessment?

The preceding questions provide the organizing framework for this study, and are focused on the interns' behaviors and thoughts occurring during the process of "learning-to-teach." The answers to these questions will create a comprehensive, hollstic portrayal of processes occurring during the field experience.

\section{SIGNIFICANCE OF THE STUDY}

A major result of this study was knowledge gained about the process of becoming a teacher, learned through the field experience from the view of the intern. This information 
was useful in designing and structuring field experiences more effectively. Since field experlences are the major commonality of teacher education programs, information derived from this study is useful in evaluating existing programs, as well as facilitate in the development of new programs.

Knowledge gained from reported sources of influence on interns' teaching behaviors and skills benefits developers of teacher education programs. For example, if interns frequently attribute source of teaching influence to skills gained through concurrent seminars, this information could assist in determing components of a teacher education program.

Many studies look at pre- and post-test results of the field experience, yet do not explain the process of learning-to-teach (Zeichner, 1984). Employing qualitative techniques in this study provided rich, descriptive data about the field experience process. Tabachnick \& Zeichner (1984) find few researchers have studied the process of events occurring during the fleld experience, and conclude the "actions and interactions of student teachers during the experlence" should be a focus of study. Through a descriptive examination of various processes occurring during the field experience, a comprehensive picture emerges, which increases the understanding of the event of 
"learning-to-teach", thus enabling educators to make wise decisions affecting the education of teachers.

\section{METHODOLOGY}

A qualitative research approach was deemed the appropriate choice of method, in order to allow the most significant information relating to the study of the field experience to be presented. Zeichner (1980) states that the constructivist approaches to research (e.g., participant observation, case study and ethnography) allow findings related to the field experlence to emerge, and offer a method for understanding the process of becoming a teacher. Techniques used in this study included participant observation, interviews, and questionnaires.

The intensive sample consisted of 6 interns enrolled in the Cooperative Professional Education Program (CPEP) at Portland State University. This program (CPEP) is an alternative teacher education program, which includes a year-long field placement and concurrent weekly seminars focused on methods course content and topics pertinent to current educational issues and research in teacher education. Another feature of CPEP is the collaborative program development and responsibilities assumed between two local school districts and the university. In addition to the 6 irterns who supplied the major data for the study, 16 
additional interns in the CPEP program completed questionnaires.

Observations were conducted at the school site of each of the $\sigma$ interns in the intensive sample. Data were collected during each observation in addition to interviews following the observation. Interns completed four questionnaires for 1 week each month from January through May. The questions focused on teaching behaviors, skills, arid self assessment of the teaching. Monthly questionnaires were completed by the general sample (22 interns) relating to teaching concerns. Combining these data created a descriptive analysis of the field experience process.

Data analysis included organizing, interpreting, and making sense of the collected material. A coding system was developed to sort the data. The data from the observations were coded according to the sources of influence on teaching and terminology used in the self assessments. The teaching concerns were coded and sorted into appropriate catagories. This information was analyzed and interpreted to produce the findings of this study.

\section{SUMMARY}

This study was a response to the reform proposals. It provides the kind of process and data currently absent in the teacher education literature; such data are critical to the analysis that must precede ceform. The purpose of the 
study was to examine the actual "learning-to-teach" process within the context of the field experience. Qualitative methods were used to investigate what is occurring during the "learning-to-teach" process, with quantitative data added to create additional support and description. Finally, the significance of this study was to address relevant questions and provide essential information needed in reviewing and revising teacher education policies and programs. 
CHAPTER II

REVIEW OF THE LITERATURE

INTRODUCTION

This chapter reviews the current knowledge emerging from research and development literature on teacher education and field experiences. To provide a rationale for this work, a discussion of specific critical information missing in the existing field experience literature is presented. In addition, an examination of the functions of qualitative research and descriptive studies, and the relation of these methods to the purpose and questions in this study is included. This study provides a description of the field experience and attends to research currently absent in the literature. It also responds to concerns emerging from the current teacher education literature base.

\section{TEACHER EDUCATION}

\section{Reform Issues}

National interest in the subject of education has alternately intensified and waned since the introduction of public education. Currently, teacher education is a focus of public attention and criticism, with calls for reform coming from within and outside the profession (Egbert, 1985; 
Joyce \& (lift, 1984). "The graduates, current students, faculty, and administrators generate at least as much fury toward teacher education as do the politicians, pundits, and serious scholars who reside outside it" (Joyce \& Clift, 1984, p. 5). On the national level, the well-publicized National Commission on Educations's report, Nation at Risk (National Commission of Excellence in Education, 1983) addresses numerous concerns about the relationship of education to the future advancement of our country. In international comparisons of student achievement on 19 academic tests, American students never placed first, and were last seven times (National Commission on Excellence in Education, 1983). With dramatic findings of the steady decline in student achievement in American schools or half the population of gifted students is not achieving at the tested tested ability level (National Commission on Excellence in Education, 1983), concern about the quality of education increases.

According to Hall and Hord, (1981) teacher education receives increased criticism in relation to the decline in student achievement. In order to increase the quality of education for students in schools, the quality of teacher preparation must be addressed. Findings of this study yield implications for the quality issues. 


\section{Reform Gaenda}

Current suggestions and proposals for change in teacher education range from abolishment of an undergraduate degree in education to closer cooperation between the universities and school districts in the education of teachers, and to the development of a National Board for Professional Teaching Standards (Carnegie Forum on Education and the Economy, 1986; Goodlad, 1984; Holmes Group Report, 1986). National reports published by groups including the National Commission on Excellence in Education, the Education Commission of the States, the Holmes Group and the Carnegie Foundation for the Advancement of Teaching, have addressed certification requirements, length and type of teacher preparation program requirements. Voices within the profession raise caution, however, that substantial changes must be preceded by examinations of existing practices. This study contributes to the recommended scrutiny in advance of major changes by conducting a descriptive examination of some teacher education practices.

\section{Teacher Education Research}

In reviewing the current knowledge base in teacher education, Schalock (1983) finds the situation essentially without tradition when it comes to teacher education research. Others who have reviewed the literature reach similar conclusions (Denemark \& MacDonald, 1967; Peck \& 
Tucker, 1973). Curriculum and program requirements for teacher education tend to be based on "hunches" and political biases instead of research findings. Koehler (1985) characterizes current teacher education literature as "fragmented, particularistic and often cutting corners." Schalock (1983) concludes that teacher education research does not have an influential history, and in addition has received limited emphasis due to the focus in research on teacher effectiveness during the last ten years. Although the teacher effectiveness research is significant in providing important information in education, within the field of teacher education remain many unanswered questions. According to Koehler (1985), research is needed that assists in conceptualizing the relationship between teacher education and teaching practice in order to provide information useful in developing goals and objectives that have the potential to improve teaching. Studying the prospective teacher during the process of learning to teach may provide essential information for reforming teacher education. Howey (1983) recommends that further research is needed to more completely describe what is occurring, why this is occurring, and to better assess the effects of these efforts. This study responded to Howey and other teacher educators' proposals.

Strengthening existing programs and providing answers to the questions and problems in education is a major 
purpose for educational research. Finding answers to questions about how best to educate teachers for tomorrow, may also yield answers in the realm of improving education in the schools. Research to learn more about the preparation of teachers in turn affects the quality of education children receive (Schalock, 1983). This study examined the field experience and added descriptive information to the teacher education research base.

\section{FIELD EXPERIENCES}

\section{Prominence of Field Experiences}

Teacher education programs and practices vary widely, with field experiences representing the sole commonality. When examining teacher education programs at over 1,200 colleges and universities, Egbert (1985) denoted classroom experience as a "given" in each teacher education program. The number and type of required courses and course content vary, along with the portions of the teacher education program designated as inside the school of education or in other departments, but all programs require a field placement. In The Education of American Teachers, James Conant (1963) describes student teaching as "the one indisputably essential element" (p. 142) in the professional teacher preparation.

A common assumption that field experiences are "necessary and useful components" in teacher education 
programs is held by educators, laypeople and students (Joyce, Yarger \& Howey, 1977). In examining the rationale for requiring the field experience, the belief most teacher education programs promote is that field experiences are "worthwhile" (Applegate \& Lasley, 1982). From the students" perspective, field experiences are valuable and provide an opportunity to be involved in the "real" world of teaching (Ryan, et al., 1980). Silberman (1971) noted the "strongest proponents of teaching practice are preservice teachers " (p. 451). Peck and Tucker (1973) report both college students and experienced teachers rate the field experience as the most important part of the teacher education program. In reviewing diaries of beginning teachers, Lortie (1975) found experienced teachers stressed the importance of field experience for learning the practical and useful classroom skills.

In the current educational reform literature, both the Holmes Group and the Carnegie Task Force recognize that the field experience, along with the first years of teaching, are the most effective preparation for learning to teach (Keppel, 1986). The Carnegie Task Force recommendation includes a minimum of one year of field-based preparation in the teacher education program.

Haberman (1983) describes student teaching as "the heart and mind of teacher preparation" (p. 105), and emphasizes the value of understanding its development in 
order to gain the entire perspectlve of the professional development of teachers. As numerous studies cite the critical importance of the field experience in learning to teach, it becomes clearer why there is a need for further research to expand the current knowledge base in teacher education. This study addressed the concern about the lack of information in the field experience, by conducting an examination of the "learning-to-teach" process.

A comprehensive study of field experiences was conducted by Griffin, et al., (1983), based on the rationale that the "persistence and pervasiveness of the expressed belief that student teaching is the most beneficial component of the teacher education program suggests the need to better understand it" (p. 3). The sample included 93 student teachers, 87 cooperating teachers, and 17 university supervisors. Both qualitative and quantitative data were collected through the use of observations, interviews, questionnaires and numerous instruments. Subjects were also asked to record a journal, during this period. The major findings revealed that cooperating teachers wanted to teach the student teachers about specific tasks of instruction, a major concern for the student teachers was their personal relationship with the cooperating teacher, and the cooperating teacher dominated the supervisory communication with the student teachers. One of the numerous conclusions derived from the study is that the existing knowledge of 
schooling has made little impact on the student teaching practice. Questions were raised about influences and ideological concerns on the student teacher. This study of the CPEP interns "learning-to-teach" addressed these questions by describing concerns and influences on internsduring the field experience.

\section{Eield Experience Concerns}

A contrasting view related to the impact of the field experience questions the continuation of the practice in its present form (Popkewitz, 1977; Sanders, 1974). Most of the criticism is focused on the conservative nature of the schools, and whether the field experience is merely promoting the assimilation of the student teacher into the world of existing beliefs and convictions in education (Salzillo \& Van Fleet, 1977). Zeichner (1978) calls for additional research to "probe into the subtle processes" of the field experience, in order to answer questions about the contrasting views of the impact and influence of the field experience. In addition, Zeichner recommends using the proposed studies as a basis for improvements in field experiences.

In response to the question of the impact of the field experience, Tabachnick and Zeichner (1984) examined the role field experience plays in the development of the teacher. Thirteen student teachers enrolled in a elementary student 
teaching program were the subjects for this study. The data collection consisted of interviews with student teachers, supervisors and cooperating teachers, observations of the teaching and student teacher conferences, and administration of the Teacher Belief Inventory (TBI). The TBI attempts to assess student teacher beliefs and perspectives. Data analysis involved developing individual profiles for the thirteen student teachers. The results indicate the student teachers continue to expand upon their personal beliefs held when beginning the fleld experience. Thus, the influences exerted by others did not significantly alter the preexisting beliefs. Tabachnick and Zelchner call for further investigation on the impact of the field experience on the development of teachers, utilizing research designs that examine the "actions and interactions of student teachers" durling the experience. The methodology in this study responded to Tabachnick and Zeichners' request for research designs appropriate for examining the dynamics of the field experience.

\section{Major Influences}

Cooperating Teachers. Existing research on field experiences reveals several sources of significant influences on the student teacher during the fleld experience. First, the cooperating teacher has more influence over the student teacher than college supervisors 
or other sources of influence KFriebus, 1977; Karmos \& Jacko, 1977; Seperson \& Joyce, 1973; Yee, 1969). Friebus (1977) describes the trend of field experience literature as the assessment or investigation of the influence of the cooperating teacher. Haberman (1983) concludes his literature review with the bellef that the cooperating teacher has the greatest influence on future skills and teachling styles.

University Supervisor. Zimpher, deVoss and Nott (1980) conducted a descriptive study including three student teachers, three cooperating teachers and one university supervisor. Data consisted of interviews, observations and written documentation occurring during the field experience. The findings of this study describe the forms of influence attributed to the University supervisor. The specific roles of the supervisor included setting the goals and expectations for the student-teaching experience, establishing a sequence for field experience activities, providing useful criticism, increasing communication and introducing concepts and Ideas that might have been dismissed as impractical by the cooperating teacher or student teacher. The supervisor's role provides essential elements in the fleld experience, yet many of these functions (ie., the teaching of concepts and principles) are more covert, thus less measurable than the specific teaching behaviors observed in a classroom. 
Another study assessing the iniluence of the supervisor was conducted by Llpton and Lesser (1978), who concluded not only that the supervisor's influence is minimal, but possibly negative, impeding the student teacher's progress. Due to the relatively minor influence of the university supervisor in comparison with that of the cooperating teacher Patty (1973) recommends elimination of the university supervisor position. Again, conflicting findings address the need for further study into the process of the field experience.

Student Teacher Backaround. Veldman (1970) conducted a study examining the role of the student teacher's personality in relation to the development of an individual teaching style. Fifty-five student teachers were compared to their cooperating teacher by pupil perceptions evaluated with the use of the Pupil Observation Survey Report. The result of the study found no "evidence that cooperating teachers influence the behavior of their student teacher appreciably" (p. 167). Lortie (1975) argues that biography (or what student teachers bring with them to the field experience) is the major element in determining their socialization as student teachers. According to Lortie, the development of teaching skills and behaviors is a result of the internalization of the many hours the student teacher spent in a classroom observing teacher behavior. Silvernail and Costello (1983) support this belief with data 
from a study conducted with 60 elementary education students enrolled in field experiences. Three instruments were administered both pre- and post-field experience. The results indicate major influences in teacher development occur prior to formal training, with a recommendation by Silvernail and Costello that field experiences "need greater scruting and study prior to the institution of massive changes in teacher preparation programs" (p. 32).

Seminars. In reviewing the research conducted on seminars in the preparation of teachers, seminars have been described as situations where students have the opportunity to relate educational theory into practice, solve problems, and discuss the field experience, thus developing more insights into their role as a teacher (eg., Combs, Blume, Newman \& Wass, 1978; Feiman, 1979; Sarason, Davidson \& Blatt, 1962; Zeichner, 1981). Goodman (1983) designed a case study to explore the purpose and meaning of the seminar, examining and exploring the role the seminar played in an elementary education teacher program. The sample consisted of five seminar groups, each with 20 to 30 randomly assigned students. Observations and interviews were the two major methods of collecting information, with the purpose established to discover what actually happened In the seminar meetings, and to ascertain the function of the seminar in teacher education (Goodman, 1983). The findings of the study indicated there are three major 
functions of semlnars durling the sield experience. The flrst function is the ljberalizing role. Seminar leaders presented a more "liberal view" of education than the public school setting and often suggested alternatives to the present educational practices. The second function of seminar was to collaborate with the field experience setting through addressing immediate classroom concerns. Student teachers often discussed skills and techniques useful in helping each other in their field experience. The collaborative function tended to dominate the seminar experience. The third function of seminar was to provide a setting for Inguiry about educational issues. These seminar sessions would center on critical thinking related to teaching, children, education and schools. Discussions on the "meaning" of the field experience or the value of individualized instruction are examples of topics occurring during an "inquiry" seminar. Goodman concludes if we desire to "educate" prospective teachers, instead of "training" them in the existing structure of schooling, seminars provide a setting where the relationship between theory and practice can be explored and questioned, allowing students to analyze and evaluate educational practices.

A major focus of this study was to assess and describe the reported influences on the interns' teaching behaviors and ldeas during the fleld experience. These findings 
contribute to the research base of influences on student teachers and interns while learning to teach.

\section{Field Experience Research Critique}

\section{Eield Experlence Research Base. In assessing the}

methodology of the studies of field experiences, Popkewitz, Tabachnik, \& Zeichner (1979) found most studies "rely almost entirely on the pre- and post-administration of questionnaires and surveys (self-reports) for data" ( $p .12$ ). Due to the types of studies conducted, many of the important issues related to the field experience have been ignored. The restricted focus of these studies is associated with the concensus regarding the present 1 imits of the field experience knowledge base. Zeichner (1984) argues that the current research base in field experiences is limited due to the neglect of studies to focus on the "complex, dynamic, multidimensional nature of the settings and people" (p. 3), and future research must utilize methods that explore the processes of field experiences as they evolve over time. A similar suggestion was made by Davies and Amershap (1969),

A review of the research leaves one with a great feeling of urgency to expediate the study of student teaching; given its ascribed importance in teacher education, it is alarming to find so little systemic resarch related to it. Discussion and descriptive reports are plentiful, but comprehensive basic study of the processes involved is lacking. Studies of what really happens to the student teacher are vital (p. 1384). 
This overview of the state of research on field experiences is similar to findings by Sarason, Davidson, and Blatt, (1962), Howey (1977) and more recently Griffin, et al., (1983). The research methods of the proposed study are designed to provide comprehensive information of "what really happens" during the field experience.

Haberman (1983) characterizes the study and research related to student teaching as "meager, diverse, and trivial."

$$
\begin{aligned}
& \text { is a function of the fact that those who do an } \\
& \text { occasional study are unfamiliar with the basic nature } \\
& \text { of student teaching and regard it as teaching behavior } \\
& \text { rather than learning behavior (p. } 98 \text { ). }
\end{aligned}
$$

Haberman (1983) also addresses the paucity of research on the content of student teaching, concluding that the current knowledge base is not derived from research. While studies have examined segments of the field experience, Zeichner (1984) finds the purpose and content of the field experience remain obscure.

Field Experience Research Methodology. Existing studies have rarely looked at the process or interrelated dynamics of the field experience. They have not reported the complex Interactions that occur during the field experience. Few Insights into the influence or change which occurs during the field experlence have been derived from existing studies (Zelchner, 1984). In addition, Howey (1983) flnds that decisions about student teaching rarely 
stem from research findings. A possible reason for such lack of lmpact is the existence of weak and irrelevant research data. Methodological flaws, poor direction, and Inappropriate questions may also contribute to the lack of credibility. The task of future research then is to examine and describe the processes which characterize field experiences. Alternative methodological approaches have been recommended to yield a more complete and comprehensive picture of field experiences. For these reasons this study examined the actions and interactions of interns during the field experience, providing a descriptive, holistic view of understanding the process of becoming a teacher.

REVIEW OF LITERATURE RELATED TO STUDY'S METHODOLOGY

\section{Qual itative Research in Education}

The purpose and questions in this study required indepth, descriptive data. The following section reviews literature relevant to qualitative research in education, discuss the characteristics of qualitative methodology and relate these characteristics to the questions posed in this study. In addition, the rationale for adding quantitative data to strengthen the study's descriptive findings is discussed.

Understanding the context and meaning of situations from the perspective of the people (human behavior) in the study is a goal of qualitative research. Human behavior is 
significantly influenced by the setting in which it occurs. Thus. studying the sub.jects while in the setting allows ata about the interactions and actions of behavior to emerge (Wilson, 1977). Therefore, the researcher goes to the site and collects data through direct contact with the people Interacting in their setting, utilizing naturalistic approaches with a minimal amount of interference from the researcher. Bogdan and Biklen (1982) consider particlpant observation and in-depth interviewing as "the best known representatives of qualitatıve research." Qualitative research embraces many different research strategles and techniques, yet all share similar functions. Terms such as rich, descriptive, indepth, hol istic, and comprehensive are used in defining the techniques and findings in qualiltative research. Another similarity found in qualitative research designs is the role of the researcher, who is the main "instrument" in the study, and must work at becoming aware of the perspectives of the subjects (Wilson, 1977).

"Constructivist" approaches (e.g., participant observation and ethnography) in education research encourage the data and information to emerge over the course of the study, producing a more thorough and accurate description. Magoon (1977) defines the constructivist approach as "descriptive and interpretive" in explaining the compexitity of human behavior. Descriptions resulting from on-site observations, interviews, open-ended questionnaires provide 
more complete knowledge of human behavlor and facilitate Interpretation of program impact, in order to assist in developing policies and programs.

The use of qualitative research in education has recently begun to be recognized as a viable research method, producing important and interesting information that may be unobtainable through the use of traditional quantitative methods (Scriven, 1972). Beginning in the late sixties and extending into the seventies, federal funding was allocated to qualitative studies of schools. Research in education has now reached the point where both quantitative and qualitative research methods are acceptable and important.

\section{Qual itat ive Research Character istics}

Although there exists great diversity in the qualitative approach to research, there are common characteristics that help define qualltative research. Listed below are the five characteristics developed by Bogden and Biklen (1982), with an explanation of how each characteristic relates to the intent of this study:

1. The natural setting is the source of data, and the researcher is the key instrument. In studying interns and field experiences, the school, classroom, and the workplace of the intern is the data collection site. There is no artificial laboratory, as Information is collected in the field. In order to understand the process of the field 
experience, the context of the process can be best understood in the setting where it occurs. Thus, participant observation and interviewing on site are data collection methods utilized in this study. Zeichner (1984) views direct observations of field experiences necessary to understanding the nature and quality of the experience, as well as essential in increasing the usefulness of the research findings.

2. The data collected is in the form of words, hence is descriptive. When relating the process of the field experience, a descriptive study yields much more information. The basic function of the researcher is description; the richest, fullest, most comprehensive description (Rogers, 1984). It is very difficult to tell the story of the field experience through numbers only. Thus, a descriptive study utilizing both qualitative and quantitative methods became the method of choice to use in studying and disseminating the findings regarding the process of the field experience.

3. Process is the major concern of the investigation, rather than outcomes or products. When a researcher is interested in finding out the how or why of a situation, employing qualltative techniques to tell the meaning of the change is essential. Teaching and learning are ongoing processes, therefore a comprehensive study of what really happens in the field experience (process) will be conducted 
with qualitative methods. Zeichner (1978) concludes that the lack of a research base in the field experience literature is related to the absence of descriptive studies examining the field experience process as it evolves over a period of time.

4. The focus of the study is not entirely predetermined before entering the field. Qualitative researchers allow some of the theory to develop as the research progresses. Data collection and analysis are structured to allow for emergent issues to develop throughout the study. Zeichner (1980) recomnends the use of participant observation, case study, and ethnography techniques in studying field experiences as they enable the pursuit of emergent phenomena and offers a means of understanding the process of becoming a teacher. Tabachnick (1981) states that the process of fleld experiences will include "unanticlpated as well as anticipated" events, and in order to understand teacher development, the researcher must examine "the evolution of the event". This study has three basic questions creating the framework for the research focus and direction. Concurrently, the relevance of importance and inclusion of essential findings and implications will be formed as the study advances.

5. The search for meaning is a central concern to a qualitative researcher. In examining the field experience through the observations, interviews and journal of the 
participants, meaning will be constructed. The perspective of the intern is essential to the development of the meaning in the field experience process.

"Relatively few researchers have actually examined what takes place during the experience itself and how professional life is interpreted and acted upon as students participate in its ongoing affairs. . the actions and interactions of student teachers during the experience must be treated as problematic if we are to understand the impact of student teaching upon prospective teachers" (Tabachnick \& Zeichner, 1984, p. 29).

In summary, all five preceding characteristics of qualitative methodology form the research design in this study; through use of the natural setting as the data source, examining and describing the process of the field experlence, analyzing the data inductively and pursuing the search for the meaning (1.e.,"participants" perspective", Bogdan \& Biklen, 1982) of the field experience.

\section{Methodology Literature Review Summary}

The three questions in this study provide the organization for the research design and data analysis. While qualitative research is the major research method, guantitative findings are included. The addition of quantitative data strengthens the description of the field experience processes, and provides another source in answering the questions of this study. This methodology enables the purpose (examining the field experience portion of the learning to teach process) and questions of the study 
to be appropriately addressed. The three questions in the study inquired about influences on intern's teaching behavior, intern's teaching concerns, and self-assessment. Answers to these questions were sought through collection and analysis of qualitative and quantitative data to allow a comprehensive, holistlc picture of the field experience to emerge. (Cruickshank \& Armaline, 1986; Hall \& Hord, 1981; Zelchner, 1984).

\section{SUMMARY}

This chapter reviewed the current teacher education and fjeld experience literature, and found that the most persistent theme emerging from this review related to field experiences is the call for further research. Much of the existing research base contains contradictory findings. Existing studies of $f i e l d$ experiences have not presented information that describes the complex processes and Interactions occurring during "learning-to-teach". This study provides descriptions and data that are absent in the field experience literature. Applying qualitative research techniques along with collecting quantitative data enables the process and interactlons occurring within the field experience process to emerge. The use of qualitative methodology in thls study creates a rich description of the field experience. Observations, interviews and questionnaires will be utillzed to gain insights into the 


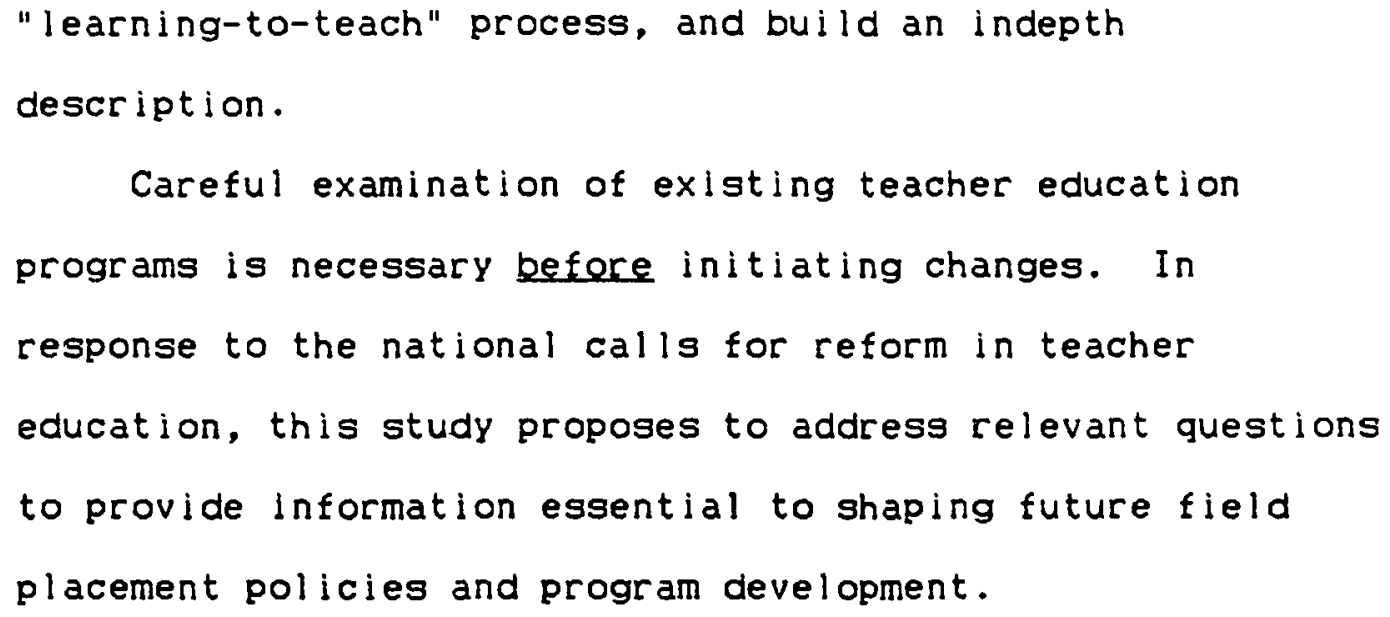


CHAPTER III

METHODOLOGY

\section{INTRODUCTION}

This chapter is a presentation of the research design in the study, along with the purpose and rationale for selecting this research methodology. The discussion includes a specific description of the study context, with an overvlew of the teacher education program. Further, this chapter describes each data collection procedure, with a description of subjects specific to each procedure, instrumentation and data analysis included within the appropriate data collection procedure. Finally, reliability, limitations, and a chapter summary are provided.

\section{RESEARCH DESIGN}

Schatzman and Strauss (1970) suggest that an inquiry method is well-chosen when the design is logically consistent with the study's questions, and when the design adapts to the Individual characteristics of the thing or event being examined. The match between the focus and questions in the study and the research design must be congruent in order to produce valuable and accurate 
Information. For these reasons, this research design utilizes multiple methods. Integrating qualitative and quantitative methods is an appropriate response to this study's questions.

This descriptive research design is built on a loosely stuctured plan. The framework is developed from the specific research questions directing the focus of the study. The questions serve as the advance organizer for determining the data collection procedures, categorizing the data, data analysis and presentation of the findings. Data collection and ongoing data analysis affected the questions and procedures. The study itself created directions therefore structuring the research (Bogdan \& Biklen, 1982). The design in this study was also built upon theoretical concepts such as; collecting descriptive data is essential, on-site observation is necessary, and meaning and process of the field experience must be explored in order to understand the "learning to teach" process. Data collection techniques included participant observation, interviews, and open-ended questionnaires. Design decisions were made continuously through the study due to the dynamic interaction of the data collection, data analysis, and emergent findings in the study. The constant-comparative method described by Glaser (1978) contains elements adopted in this study. Glaser describes the steps as the following:

1. Begln collecting data 
2. Look for key issues, recurrent events, or activities in the data that become categories of focus.

3. Collect data that provide many incidents of the categries of focus with an eye to seeing the diversity of the dimensions under the categories.

4. Write about the categories being explored, attempting to describe and account for all the incidents in data while continually searching for new incidents.

5. Work with the data and emerging model to discover basic social processes and relatjonshlps.

6. Engage in sampling, coding, and writing as the analysis focuses on the core categories (Glaser, 1978). These procedures occur simultaneously, creating a dynamic interactive method.

Combining the qualitative and quantitative $f$ indings create a mixed-method research study, resulting in data that strengthen the description. Integration of quantitative data with the qualitative data allows the construction of a rich description of the field experience process. Utilizing both methodologies takes "advantage of the strengths of each approach", while minimizing the limitations (Griffin, et al., 1983). The qualitative data answer how and why, while quantitative methods tell how often and how many. The basic framework of the study is qualitative, with the quantitative data providing additional information useful in describing the field experience process. Miles and Huberman (1984) 
find the use of numbers (quantitative) with words (qualitative) keep one another "analytically honest".

\section{CONTEXT OF STUDY}

The Cooperative Professional Education Program (CPEP) was developed in 1982, when school district personnel and unlversity faculty recognized the need to strengthen cooperation between teacher training institutions and local school districts in the selection and preparation of prospective teachers (Carl, 1985; Driscoll \& Strouse, 1986). During the 1982-83 schooi year, interns and support teachers were selected and the CPEF program began in one school district. Three years later CPEP expanded to include a second school district. In 1987, CPEP was selected in national competition as the first runner-up of outstanding teacher education programs by the Association of Teacher Educators.

Major components of CPEP include a 9 month field experience, weekly seminars, Individualized Learning Plan (ILP) and a support team, which consists of the university supervisor, support teacher, bullding administrator, and the intern's university advisor (Carl, 1985). One of several differences between the traditional student teaching experience and the field experience of a CPEP intern is found in the numerous enrichment experiences required through the Individuallzed Learning Plan (ILP) objectives. 
Each intern develops an ILP during the first months of the school year. ILP objectives include all curriculum areas (i.e., reading, math, social science, etc.), and professional skills (classroom management, elements of instructions, etc.). Interns have not completed traditional teacher education coursework before entering the program, thus the ILP serves as the framework for organizing and completing the coursework at an individual level. In order to complete ILP objectives, interns observe and assist teachers in numerous classrooms and schools, including varied cultural and socio-economic settings. Interns determine the grade levels, subjects, schools and teachers that will enable them to meet ILP objectives. Past experiences and interns' learning styles are also addressed in planning activities to meet objectives. The ILP becomes a document for interns' professional growth, and is completed during the school year.

Each intern has a support team, consisting of the support teacher, school administrator, university supervisor and academic advisor from the university. The function of the support team is to assist in developing and approving the ILP, in addition to monitoring the progress of the intern. The team approach enables interns to have access to several sources of support and resources during their program, while continuing the liaison between the university and school distrlet. 
Another unique characteristic of CPEP is the presentation of traditional coursework, current education issues and research in education in weekly seminars, workshops and inservice programs. Both the university and school district provide instructors for the seminars, selected for their expertise and instructional quality in their specialized field. As interns return to Portland State University each Friday for an 8 hour seminar session, education coursework is presented concurrently with the field experience (see Appendix). In addition to the coursework, seminar also includes a weekly meeting time between supervisors and their group of interns. The smallgroup seminar topics include concerns about classroom management, the relationship between the support teacher and the intern, to reflection about instructional strategies, styles and philosophies. Interns are encouraged to analyze and compare different teaching styles.

The function of the university supervisor was to communicate program objectives to the support teacher and intern, supervise the teaching of the intern, and conduct small group seminar meetings. Additional responsiblities Included assisting interns in completing ILP requirements and coordinating support team meetings.

The selection process for CPEP is another source of distinction between CPEP and traditional teacher education programs. After admittance to the education program, 
interested students apply for admittance to CPEP. Selected candidates are interviewed after an initial screening. Program Coordinators interview candidates, looking for self-direction, commitment and motivation in relation to an intensive year-long program and a teaching career, communication skills, and ablility to organize and complete projects. Support teacher and university supervisor candidates are also interviewed. Both of these roles require knowledge and demonstration of exemplary teaching ability, communication skills and supervisory capacities. Critical differences between a traditional teacher education program and CPEP are found in the collaboration between the university and the school district, emphasis on observing and learning-to-teach in a variety of classrooms and with a number of teachers, use of Individual Learning Plans to plan and document professional growth (including traditional coursework content), concurrent seminars, and extended field placement in the CPEP program. Students enter the field experlence with varied backgrounds, develop an Individual Learning Plan, and spend an entire school year in an intensive "learning-to-teach" program.

\section{DATA COLLECTION AND DATA ANALYSIS}

While the basic framework of this study consisted of qualitative methodology, quantitative data have been integrated in order to provide a broader description, thus 
creating a mixed-method procedure to probe into the field experience. A mixed-method research procedure contributes tc triangulation, increasing reliabilty of a study through the use of several methods, sources, and subjects (Guba, 1978). A weakness in a single method is compensated for by the counter-balancing strengths of other methods, each method providing assets and liabllities to the total study. The general sample included 22 student interns enrolled in the Portland State University CPEP teacher education program. The grade level of field experience placement ranged from Kindergarten to senior high school. A more Intenslve group of subjects included 6 of these interns who completed additional surveys, and were the focus of observations and interviews. Two of these interns were placed in a high school setting, and four were in elementary schools. As different subjects were utilized according to the purpose of various questions in the study, a multi-level of subjects was created, which again added to the triangulation of the study. Issac (1971) finds the multiplicity of data sources strengthen the validity of results.

Following are descriptions of each data collection procedure and analysis, with the sample described in terms of each speciflc data collection procedure. A schedule of the data collection is also presented. 


\section{Schedule of Data Collection}

The first meeting with the CPEP interns began in late August, 1986. During the first portion of the school year, most of the interns spent their time observing and assisting the support teacher and developing the Individual Learning Plan (IIP), therefore the observations, interviews, and questionnaires began in January, 1987 and continued through May, 1987 (see Figure 1). This study's hueristic (Figure 1) was developed to display the timelines, research processes and multi-levels of subjects in this study. The display is a modification of a data collection schedule presented in a study by Griffin, et al., (1983). Individual schedules for each instrument and procedure are presented within each data collection procedure discussion.

\section{Qbservations and Interviews}

The classroom teaching of the 6 interns in the intensive sample group was observed during the school year. Beginning in January, 1987, the intern's specific teaching behavior was recorded at 5 minute intervals during an observation period. The recorded teaching behavior included verbatim (what the intern said) and or a description of the actual teaching behavior taking place. Due to the different grade levels and subjects the interns were teaching, the observation perlod varled from 20 minutes to 50 minutes. Each intern was observed a minlmum of 8 times during the 5 


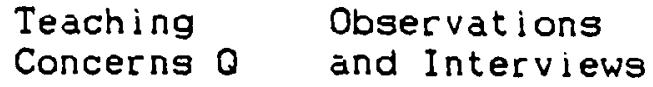

January

February

March

Apri 1

May
Concerns 0 and Interviews
Intensive
Sample

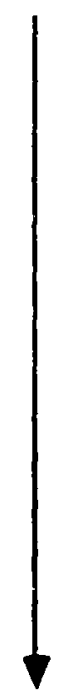

Self-

Assessment

\section{Intensive}

Sample

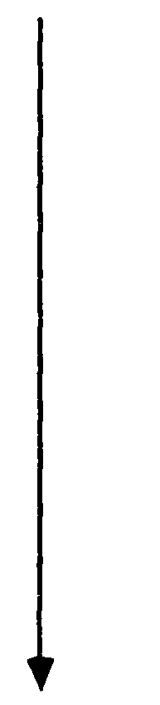

Eiqure 1. Timeline, research processes, and multi-levels of subjects. 
month period. The classroom observations were designed to document teaching behaviors upon which to base interview questions.

Immediately following each observation, the intern was interviewed and asked to describe the source of each recorded teaching behavior. Interns were asked, "Where did you get the idea for doing.. . ?" Occasionally an intern responded, "I don't know" during the first month of interviewing and observations. The investigator then asked the intern to attempt to determine a source for the recorded teaching behavior. After the first month interns responded on their own initiative to the question about the source of their teaching behaviors or ideas. The average interview time was 10 to 15 minutes, including recording of responses. The interview procedure was designed to elicit the intern's perspective of idea sources for their teaching behavior, and to probe for underlying factors or relationships (Tuckman, 1972).

Data analysis began with categorizing the interview responses. Due to the open-ended structure of the questions, interns were able to attribute the source of the teaching idea to any person, material, workshop, course or other appropriate influence. The second step included describing the categories, using the language and meaning relayed by the intern. Finally, determining and displaying 
the frequency of each category created an additional layer of data.

Teaching Concerns Questionna ire

The general group of 22 interns completed a questionnaire (Figure 2) once a month from January to May. The first Friday of each month during seminar was selected as the data collection date. Minor variations occurred due to vacations or a period when all interns were teaching full-time. The question on the form asked the interns to state their teaching concerns at this time, in reiation to the fleld experience. The form was open ended, with one question and writing space for their comments. The teaching concerns question was aimed at assessing potential changes in the movement from concerns-with-self to concerns-withstudents. Concerns-with-self includes concern with self-adequacy, classroom management, knowledge of subject matter and ability to meet expectations of cooperating teacher and supervisor (Fuller, 1969). These concerns could also be classified as "survival" skills for the interns. Concerns-with-students includes concerns about students: learning, individual needs and abilities and the impact of interns' instruction on students. When the intern expresses concerns about the student the focus is directed on the student, learning, andior instruction. 
In relation to your teaching, what are your concerns at this time?

[Intern's open-ended response]

Eiqure 2. Teaching concerns questionnaire. 


\section{Selt-össessment Questionnère}

The intensive sample group of 6 interns completed a questionnaire form (see Figure 3) for self assessment of their classroom teaching. The form was completed dally for one week each month during the January through May, 1987 period. The second week of each month was selected as the data collection period for this question, due to school schedules and vacation periods. The self-assessment form consisted of a rating scale and a probe for rationale for the rating. The rating scale range was from 1 to 5 , with 1 rated as an outstanding lesson, and would make no changes if the same lesson was taught again. During the week, questionnaires were filled out independently. Open-endea responses were required. The data were collected over a 5 month period, allowing for changes in self-assessment to energe.

Data anaiysis of the self-assessment forms included the rationale interns used to base their self-assessment on, and the content of this rationale. The data resulting from the self assessment ratings over the duration of the 5 month were examined for signs of change in rationale or ratings during the field experience.

\section{RELIABILITY}

Reliability in a quantitative study is achieved when another researcher working to answer the questions in a 
Circle the number that describes how you would rate the lesson(s) you taught:

1. Very satisfied, would make no changes if presented again

2. Satigfied, would make minimal changes

3. Acceptable, would make some changes, while retaining some portions of the lesson

4. Dissatisfied, would make major changes

5. Very dissatisfied, would change everything

Why?

[Intern's open-ended response]

Eiqure 3. Self-assessment questionnaire 
study replicates the findings. In qualitative research, reliability has different expectations. A major goal in descriptive research is to add to the knowledge base about a particular setting, not to evaluate or determine cause and effect. The researcher attempts to acknowledge personal biases, and to 1 imit prejudices and opinions as much as possible (Bogdan \& Biklen, 1982). Employing mixed-methods with multi-levels of subjects is an attempt to reduce researcher bias in this study. Adding quantitative techniques to the descriptive base lends objectivity to the data. Reliability was strived for in this study through accurate and holistic descriptions of the fleld experience process.

\section{LIMITATIONS}

Listed below are limitations of this study:

1. The number of questions included in the questionnaires was 1 imited due to time constraints and sensitivity to the intern's role.

2. Qualitative data were subjectively reduced, therefore personal interpretation or perception may have influenced the categorization of data.

3. Self-reporting was a major source of data collection, and perceptions of the interns must be accounted for in interpretation of the data. 
4. The investlgator (particlpant observer) in this study was the university supervisor of the interns in the intensive sample from August, 1986 to June, 1987.

5. This study was conducted within one teacher education program, with a small sample of subjects.

6. This study was conducted from January through May, and did not study the interns from September to January.

7. The findings from the descriptive study of one program may not generalize to other field experiences or teacher education programs.

\section{SUMMARY}

This descriptive study of the field experience process relied on both qualitative and quantitative research findings. Mixed-method design has the potential to provide a more complete description. Multi-level of subjects provide layers of data useful in interpreting the process of the field experience. The mixed-methods and multi-levels of subjects create triangulation, increasing the accuracy of research findings. Most of the data were collected from an intensive group of subjects (a small population). Relying on a small population creates an indepth description of important and recurring variables (Green \& Wallat, 1981).

This chapter presented the rationale for utilizing the research questions to provlde data organization, collection procedures, categorlzation and analysis, with interpretation 
and presentation of the findings. An overview of the context of the population was included. Each data collection procedure was described, accompanied by subjects and data analysis specific to each procedure. Discussion of reliability and limitations concluded this chapter of the study. A major theoretical assumption of this study is found in the purpose of descriptive research, which is to describe the field experience process, rather than judge or determine success or failure of a program. 


\section{CHAPTER IV}

\section{PRESENTATION AND DISCUSSION OF THE DATA}

\section{INTRODUCTION}

The purpose of this study was to examine the

"learning-to-teach" process of interns enrolled in the Cooperative Professional Education Program (CPEP) at Portland State University. Three research questions were addressed, with presentation of data and discussions of findings reported for each question. The three questions were the following:

1. To what sources do the interns attribute learning and use of specific teaching behaviors and skills?

2. What are the professional concerns of the interns, and are there changes in concerns as they progress through the field experience?

3. How do interns assess themselves as they progress through the experience, and what is the rationale of the assessment?

Qualitative research attempts to examine the complete picture of an event or process (Bogdan \& Biklen, 1982). This study examined "learning-to-teach" over a five month 
period. The content analysis of the data in this siudy yielded both qualitative and numerical patterns. The numerical data served to clarify and further explain the qualitative description. Consistent with the use of qual itative methodology, a comprehensive description of "learning-to-teach" includes relating the findings to specific time periods in the CPEP program and the activities occurring during each month. A schedule of the CPEP activities during the school year was included (see Figure 4).

In late August, interns began attending seminars, met their support teacher, and assisted in setting up the classroom for the school year. When the public schools began in September, interns continued to attend seminars, assist their support teacher, and began developing their Individual Learning Plan (ILP). The ILP provides the framework for the interns' professional growth programs for the year. In October, the intern continued with the previously mentioned activities and added observations in other classrooms along with beginning to teach small groups of students. The major actlvity for interns in November was completion of the ILP draft, including development of proposed enabling activities to meet ILP objectives. The enabling activities were completed during the school year. A support team meeting was held with each intern, with the purpose of reviewing and approving the ILP draft. The 


\begin{tabular}{|c|c|c|c|c|c|c|c|c|c|}
\hline Month & Seminar & $\begin{array}{l}\text { Assist } \\
\text { Support } \\
\text { Teacher }\end{array}$ & Ooserve & $\begin{array}{l}\text { Develop } \\
\text { ILP }\end{array}$ & $\begin{array}{l}\text { Work on } \\
\text { ILP } \\
\text { Activities }\end{array}$ & $\begin{array}{l}\text { Teach: } \\
\text { (Several } \\
\text { Lessons/ } \\
\text { Week) }\end{array}$ & $\begin{array}{l}\text { Teach: } \\
\text { (Several } \\
\text { Lessons/ } \\
\text { Day) }\end{array}$ & $\begin{array}{l}\text { Teach: } \\
\text { Full- } \\
\text { Time }\end{array}$ & $\begin{array}{l}\text { Complete } \\
\text { ILP }\end{array}$ \\
\hline August & $x$ & $x$ & $x$ & $x$ & & & & & \\
\hline September & $x$ & $x$ & $x$ & $x$ & & & & & \\
\hline October & $x$ & $x$ & $x$ & $x$ & $x$ & $x$ & & & \\
\hline November & $x$ & $x$ & $x$ & & $x$ & $x$ & & & \\
\hline December & $x$ & $x$ & $x$ & & $x$ & $x$ & & & \\
\hline January & $x$ & $x$ & $x$ & & $x$ & & $x$ & & \\
\hline February & $x$ & $x$ & $x$ & & $x$ & & $x$ & & \\
\hline March & & & & & $x$ & & & $x$ & \\
\hline April & $x$ & $x$ & $x$ & & $x$ & & & $x$ & \\
\hline May & $x$ & $x$ & $x$ & & $x$ & $x$ & & & $x$ \\
\hline June & & $x$ & $x$ & & & $x$ & & & \\
\hline
\end{tabular}

Figure 4. Timeline of CPEP activities. 
support team consists of the intern's advisor, support teacher, building administrator, and university supervisor. Additional activities in November included assisting the teacher, observing, and attending seminars. December found the interns teaching several lessons each week. Several interns instructed a reading group each day and were responsible for the planning and implementation of the students' learning activities. Interns were also observing other classrooms, attending seminars, and working on ILP objectives. In January, many interns began to teach on a regular basis. For example, one intern assumed responsibility for the social studies unit. Observations, work on the ILP, and seminars continued. During February, a few of the interns began to teach full-time, while most of the interns were now teaching several lessons each day, progressing toward full-time teaching. Again, observations, ILP work and seminars continued. Interns were all involved in full-time teaching during March. Observations and seminars were suspended during this month, although interns continued to complete ILP objectives. In April, several interns continued to teach full-time, while most interns were observing and teaching in other grade levels and schools, while assisting their support teacher. Seminars continued in Aprll and May. During May, a major focus was the completion of the ILP objectives. Interns were observing, teaching, and assisting in many classrooms to 
complete the ILP objectives, as their support teams met in May to revjew and approve the final ILP. In June, interns assisted their support teacher as well as other teachers in the school. Several interns continued teaching a subject or reading group and worked collaboratively with the support teacher in planning and instruction. The major activities and focus changed throughout the program, creating a sequentlal "learning-to-teach" experience.

\section{REPORTED SOURCES OF INFLUENCE}

\section{Presentation of Data Introduction}

Data related to this question were obtained through observations and follow-up interviews with the six interns In the intensive sample. Each intern was observed and interviewed every three weeks during the January to May period, with minor variations due to schedule differences. Each intern was observed during a 20-50 minute time period, depending on the grade level or subject taught. Teaching behaviors and or verbatim (what the intern was saying during the teaching) were recorded at 5 minute intervals. In order to decrease observer bias, the 5 minute interval was established to ensure teaching behaviors were intermittently recorded and not selected by the observer. An interview was conducted immediately following each observation. Interns were asked, "Where did you get this ldea?", as the observer read each item orally from the observation record. The 
answer was recorded on the observation record and later coded. After the first month of observations and interviews, the data were examined, and eight preiliminary categories were established (see Table I). These categories were the following:

1. Observations (Classrooms other than the one the intern is assigned)

2. Self (Ideas or behaviors the intern attributes to self-origination)

3. Support teacher (Teacher with whom intern works)

4. Seminar (Related to content presented in concurrent CPEP presentations and workshops)

5. Past experiences (Experiences before entering the CPEP program)

6. Supervisor from the University

7. Manual or Teacher's Guide

8. Course work (Education classes taken before entering the CPEP program)

A total of 330 responses from 44 observations were recorded during the January through May data collection period. The distribution of teaching behaviors was 3 to 136, with the lowest incidence of 3 teaching behaviors or ideas attributed to teacher's guides or manuals as the source of influence, and the highest incidence of 136 teaching behaviors or ldeas influenced by seminars. In 4 of the 5 months, seminar was reported as the most frequent 
TABLE I

REPORTED SOURCE OF INFLUENCE ON OBSERVED TEACHING

\begin{tabular}{|c|c|c|c|c|c|c|c|c|c|}
\hline & Observations & Self & Teacher & Seminar & $\begin{array}{c}\text { Past } \\
\text { Experfence }\end{array}$ & Supervisor & $\begin{array}{l}\text { Manual } \\
\text { T. OuIde }\end{array}$ & $\begin{array}{l}\text { Course } \\
\text { Work }\end{array}$ & Total \\
\hline January & 5 & 6 & 9 & 32 & 5 & 5 & 3 & 4 & 69 \\
\hline February & 14 & 14 & 13 & 24 & 7 & 11 & 0 & 3 & 86 \\
\hline March & 4 & 8 & 10 & 28 & 7 & 6 & 0 & 2 & 65 \\
\hline April & 3 & 13 & 12 & 11 & 1 & 0 & 0 & 0 & 40 \\
\hline May & 8 & 8 & 9 & 41 & 0 & 2 & 0 & 2 & 70 \\
\hline TOTAL & 34 & 49 & 53 & 136 & 20 & 24 & 3 & 11 & 330 \\
\hline
\end{tabular}

Intensive sample of Interns $n=6$ 
source of influence. The exception was in April, when the category of "self" was the most frequent source of influence. The category of teacher's guide or manual consistently received the lowest frequency rating, with 3 teaching behaviors or ideas attributed to the teacher's guide in January, and none ( 0 ) in each of the following 4 months.

\section{Sources of Influence Analuzed by Menth}

January. A total of 69 teaching behaviors or ideas were recorded during 13 observations in January. The range of the number of teacher behaviors and ideas in each category was from 3 in teacher's guide category to 32 in the seminar category. Coursework was designated a source of influence 4 times, and past experiences, supervisor, and observations attribured as a source of teaching influence 5 times. Interns claimed the support teacher was an influence on 9 of their teaching behaviors and 6 of the teaching behaviors were attributed to themselves as the source of influence.

Eebruary. Nine observations were conducted in February, resulting in a total of 86 recorded teaching behaviors and ideas. The range was from 0 in teacher's guide category to 24 teaching ideas and behaviors reportedly influenced by seminars. 
March. Sixty-five teaching behaviors and ideas were recorded during 9 observations. The range was from 0 in teacher's guide category to 28 teaching behaviors and ideas attributed to seminar as the source of influence.

April. During April, most interns were spending time completing ILP activities instead of teaching in their assigned classroom, therefore 6 observations occurred. Of the 40 recorded teaching behaviors and ideas, 13 chighest number) of these were attributed to the "self" category as the source of influence. Three categories received ratings of 0 ; supervisor, teacher's guide, and coursework, resulting in a range of 0 to 13 .

May. A total of 7 observations were made in May, with 70 teaching behaviors and ideas recorded. The range was from 0 in the categories of past experience and teacher's guide to 41 teaching behaviors and ideas influenced by seminar.

\section{Source of Influence Analyzed by Category}

Qbservations. Of the 330 total teaching behaviors and ideas recorded during the 5 month period, 34 were attributed to observations in other classrooms as the source of influence. The range of the number of teacher behaviors and ideas attributed to observations included the lowest incidence of 3 in April and the highest incidence of 14 in Eebruary. 
Self. Forty-nine teaching behavlors and ldeas were attributed to "self" as the source of influence during the January through May data collection period. The range was from 6 teaching behaviors or ideas attributed to "self" in January to 14 in February. During April, "self" was the most frequently reported source of influence.

Support Teacher. A total of 53 teaching behaviors and Ideas were attributed to the support teacher as the source of influence. The range was from 9 behaviors and ideas attributed to the cooperating teacher in January and May to 13 in February.

Seminars. A total of 136 teaching behaviors and ideas were attributed to seminar as the source of influence, causing the seminar category to be the most frequently reported source of influence in this study. The range was from 11 teaching behaviors and ideas attributed to seminar in April to 41 in May. In 4 of the 5 months, seminar was most frequently reported as the major source of influence on the Interns' teaching behaviors and ideas.

Past Experience. Interns designated 20 of their teaching behaviors and ideas to their past experience as the source of influence. The range was from 0 of the teaching behavlors attributed to past experiences in May to 7 in February and March.

Supervisor. The unlversity supervisor was listed as the source of influence on 24 of the interns' observed 
teaching behaviors or ideas. The range of the number of teaching behaviors and ideas atributed to the supervisor included the lowest incidence of 0 in April and the highest incidence of 14 in February.

Teacher's Guide or Manual. Only 3 of the 330 recorded teaching behaviors designated teacher's guide or manual as the source of influence. The range was from 0 teaching ideas or behaviors attributed to this category in February, March, April and May to 3 behaviors coded to teacher's guide in January. The teacher's guide or manual was the lowest frequency of source of influence in this study.

coursework. Interns attributed education coursework as the source of influence on their teaching behavior 11 times during the 5 months of data collection. The range was 4 , with 0 of the recorded teaching behaviors influenced by coursework in April, and 4 in January.

Influences on Specific Categor ies of Teaching Behavior In order to obtain additional information about the source of influence on interns' teaching, the 330 teaching behaviors were categorized again, according to the content or theme of the teaching behavior. Each observation record was read, and teaching behaviors were coded according to the "theme" of the teaching idea. For example, an intern said, "Daniel, turn your chair to face the front of the class." This teaching behavior was coded as classroom management. 
The four final categories that emerged from reading and categorization include the following: (1) Instructional techniques which included specific teaching techniques interns used during a lesson; (2) classroom management which included interns' teaching behaviors focused on discipline and "controlling" students; (3) classroom routines which included teaching behaviors associated with establishing procedures; (4) subject matter (curriculum content) which included teaching behaviors related to the content or curriculum of a subject matter area. Table II displays the 4 categories of content of influences and the number of responses included in each category of source of influence. Of the 330 total recorded teaching behaviors and ideas, the range was from the lowest incidence of 49 teaching behaviors demonstrating classroom routines to the highest incidence of 140 focused on instructional techniques.

Instructional Techniques. The highest frequency of the reported sources of influence content categories was instuctional techniques, with 140 teaching behaviors demonstrating instructional techniques. The range of the number of teaching behaviors containing instructional techniques was from 0 in the source of influence category of teacher's guide to 96 in the seminar category.

Clagsroom Management. Sixty-one of the total 330 teaching behaviors contained classroom management teaching behavlors. The range was from 0 in teacher's guide and 
TABLE II

CONTENT OF REPORTED SOURCE OF INFLUENCE ON OBSERVED TEACHING

\begin{tabular}{|c|c|c|c|c|c|c|c|c|c|}
\hline & Observations & Self & Teacher & Seminar & $\begin{array}{c}\text { Past } \\
\text { Experlence }\end{array}$ & Supervisor & $\begin{array}{l}\text { Manual } \\
\text { T. Qu Ide }\end{array}$ & $\begin{array}{l}\text { Course } \\
\text { Work }\end{array}$ & Total \\
\hline $\begin{array}{l}\text { Instructional } \\
\text { Techniques }\end{array}$ & 8 & 13 & 12 & 96 & 3 & 7 & 0 & 1 & 140 \\
\hline $\begin{array}{l}\text { Classroom } \\
\text { Management }\end{array}$ & 5 & 5 & 7 & 26 & 1 & 17 & 0 & 0 & 61 \\
\hline $\begin{array}{l}\text { Classroom } \\
\text { Routines }\end{array}$ & 7 & 12 & 18 & 7 & 4 & 0 & $\mathbf{0}$ & 1 & 49 \\
\hline $\begin{array}{l}\text { Subject } \\
\text { Matter }\end{array}$ & 14 & 19 & 16 & 7 & 12 & 0 & 3 & 9 & 80 \\
\hline TOTAL & 34 & 49 & 53 & 136 & 20 & 24 & 3 & 11 & 330 \\
\hline
\end{tabular}

Intensive sample of interns $n=6$ 
coursework to 25 classroom management teaching behaviors reportedly influenced by seminar.

Classroom Routines. Forty-nine teaching behaviors were concerned with classroom routines. The lowest incidence of influence on classroom routine teaching behaviors was 0 from both the supervisor and teacher's guide to 18 behaviors influenced by the support teacher.

Subject Matter. A total of 80 teaching behaviors demonstrated subject matter or curriculum content. The range was from 0 teaching behaviors influenced by the supervisor to 19 behaviors influenced by the intern's "self".

Discussion of Findings by Category

Qbservations Category. Throughout the school year, interns spent several days each month observing teachers in other classrooms. The Interns reported observations as a source of influence on their teaching 34 times, with a higher frequency during February and May, which were months when more time was spent observing teaching outside of the assigned classroom. In March, interns were involved in full-time teaching in their assigned classroom, and observation as a source of influence was noted 4 times. During May, interns were completing ILP activities, which required more observations in other classrooms, along with a decrease in the amount of teaching in their assigned 
classroom. Interns noted observations as a source of influence on their teaching 3 times in May, which was the lowest number reported in this category during the 5 month period.

Of the 34 teaching behaviors influenced by observations, the content representation was highest for subject matter, 14; followed by instructional techniques, 8; classroom routines, 7 ; and classroom management, 5. One intern had observed an English class, where the teacher was using questioning techniques during a discussion period. The intern returned to her class and during an English Literature discussion asked the the students, "Do you agree with this statement?" The intern was "trying out" instructional techniques learned through the observation. In experimenting with a classroom routine of having the students count lunch tickets orally each morning, an intern stated, "Let's count out loud together." She had observed this activity in another class and was using it with her students. A classroom management teaching behavior was reported as influenced by an observation of a Child Development Specialist. The intern said, "Everyone in their seat, and I'll decide who earns the penny award." The intern had watched the Child Development Specialigt use this clasgroom management technique with students and was trying it out in her class. An example of an intern using a subject matter idea from an observation occurred in a first 
grade durling a unlt on telling time. The intern sald, "The little hand is between the 12 and 1, so we say 12:30." The intern had recently observed another first grade class and had incorporated the "teaching time" ideas into her class. Observations as a source of influence was the fourth highest reported category. According to reports by CPEP interns, observations did influence their teaching. In revlewing the field experience literature on observations, no literature was found discussing or researching the purpose or benefits of observations in other classrooms during the field experience. However, Goodlad (1983) suggests that prospective teachers need multiple experiences that expose them to varied instructional techniques. Clift and Warner (1986) agree with Goodlad and propose field experiences should also include "culturally diverse settings". The Individualized Learning Plan (ILP) in CPEP requires observations in numerous classes, grade levels, and settings. Therefore, the CPEP requirements may account for observations reported as an influence on the teaching behavior of interns in this study. In traditional student teaching programs, students complete classroom observations durling the early portions of the teacher education program, before entering the field experlence. Once these students enter the fleld experience, their teaching "model" is Iimited to the cooperating teacher. Joyce and Clift (1984) found that in some field experience situations, student 
teachers would follow the teaching example of the cooperating teacher even when the behavior negated their personal beliefs or practices learned at the University. The cooperating teacher has the major responsibility for the activities of the prospective teacher (Friebus, 1977) in traditional programs, providing only one model of teaching. In contrast, CPEP interns are involved in observations and teach in several classrooms concurrently with the field experience. This requirement may result in interns relating the observed teaching with their personal teaching experiences and expanding the number of models and styles of successful teaching the intern experiences. Differences between traditional teacher education programs and CPEP in relation to required observations during the field experience may account for the presence of the reported influence of observations on CPEP interns' teaching behaviors.

Self Category. The "self" category had the highest frequency of all reported sources of influence in April. Several explanations are possible. First, after 7 months of field experience, teaching, observing other teachers, and seminars, interns might have synthesized teaching techniques, behaviors and information. Such synthesis may have resulted in a personal sense of ownership of teaching behavior and ideas they display. Second, it may be separating their own behavior from the ideas and teaching 
behavior of others becomes more difíicuit as the interns became more immersed and experienced in teaching. Third, after utilizing someone else's ideas, interns incorporated the new idea with previous learning, and created a personal teaching idea or behavior. Veldman (1970) notes student teachers bring their personal beliefs into the field experience, and rely heavily upon this belief system when learning to teach. Combining Veldman's idea with the preceding explanations creates a possible rationale for interns reporting themselves as a source of influence on their teaching 49 times during the study, which was the third highest category.

of the 49 teaching behaviors attributed to intern's self as the source of influence, 19 were focused on subject matter; 13 were instructional techniques; 12 were classroom routines; and 5 were classroom management behaviors. There were 80 teaching behaviors focused on subject matter, and 19 of those were influenced by the interns' self, resulting in more subject matter teaching ldeas influenced by the intern's self than any other source. A possible explanation may be the interns were integrating their observations, seminar information and past experiences to develop personal teaching ideas for a specific subject matter. Also, as most interns had not completed education methods courses before entering CPEP, they were possibly drawing subject matter or curriculum ldeas from general university courses and 
attributing these ideas as coming from themselves. An example of a subject matter teaching behavior an intern reported as "self-influenced" was, "I think Shakespeare was being more critical than that in this passage." The intern reported herself as the source for this teaching idea, as she has worked extensively with Shakespearean literature. Interns did rely upon their personal ideas (self) in teaching, particularly in the subject matter or curriculum area.

Support Teacher Category. The category of support teacher as a source of influence on the interns' teaching remained fairly constant during the study, with a range of 9 in May and January to 13 in February. The support teacher was reported as the second most influential source on the interns' teaching, (although the total number was 53, compared to seminar with 136). Haberman (1983) concluded that the cooperating teacher has the greatest influence on the student teacher. In this study, the support teacher was reported as an important source of influence on teaching, yet not as the major source of influence. A possible explanation for the difference in findings may be attributed to the numerous sources of influence on an intern in CPEP and to the qualitative approach employed in this study. These interns attended concurrent seminars, learned subject matter and intructional techniques, met regularly with their supervisor, and were exposed to numerous teaching examples 
through their observations in other classrooms. In comparison, a student teacher in a traditional program will often work with the cooperating teacher only, and have limited additional experiences.

The breakdown of the content categories of the teaching behaviors influenced by the support teacher were as follows: classroom routines, 18; subject matter, 16; instructional techniques, 12; and classroom management, 7 . Of the 49 teaching behaviors categorized as classroom routines, 18 of those were influenced by the cooperating teacher. The most dominant content of teaching ideas influenced by the support teacher was classroom routines. The intern is teaching in the classroom setting which was developed by the support teacher. Although interns were able to experiment and develop some new teaching ideas and routines, often the established routines were accepted as the norm. A plausible reason for continuing the support teacher's established classroom routine may be attributed to the security of following an established pattern with the students. It may be easier to continue a routine than teach the students a different routine. Interns had also observed the support teaching meeting success with this routine, and may have concluded that the same routine would also be successful for the intern. Another possible reason for continuing a routine instead of altering the established practice may be interns' reluctance to "rock the boat" or disturb the accepted 
practice, which may result in conflict between the support teacher and the intern. Thus, interns often continued with the ideas previously established by the support teacher. An example of a classroom routine established and, consequently, adopted by an intern occurred during math. The intern told the students, "Each student tell one correct answer as we go around the class, and I will write the problem on the overhead projector." The intern had watched the support teacher correct math problems using this approach and had adopted this technique. The support teacher had also suggested to the intern that this routine would be the most effective approach to correcting the math problems. After watching a support teacher model a classroom routine and after listening to suggestions of continuing this approach, interns may feel pressure to continue with established classroom routines.

Seminars. Seminars were the most often reported source of influence for interns. Of the 330 recorded teaching behaviors, interns reported 136 were influenced by seminars. In 4 of the 5 months, seminars were reported as the most influential teaching source. Goodman (1983) suggests seminar should serve as a tool to "educate, rather than train" prospective teachers, and seminar content should address immediate classroom concerns during the field placement. CPEP seminars followed this suggestion, as seminar topics corresponded to educational needs of interns (see Appendix). 
Elements of instruction (writing objectives, lesson plans, units, instructlonal strategies and models) and classroom management were topics introduced in the beginning seminars, and addressed continually through the program. Reading, math, social studies, science, art, music, special education, physical education, health, technology in the classroom and language arts composed the content or subject area in the seminars. These topics were presented by a large number of university faculty, school district personnel, and community resource people. Seminars also included a one hour small group meeting with the interns and their supervisor. One of the major and recurring topics in the small group seminars addressed simllarities and contrasts of instructional styles, and the results specific teaching behaviors caused in students and their learning. Therefore, seminar topics were related to the concrete day-to-day teaching of the intern as well as abstract and philosophical questions about the effects and relationship of teaching and learning. Interns returned to Portland State University each Friday for an 8 hour seminar session. The exception was during March, when seminars were suspended, due to interns' full-time teaching.

In contrast, student teachers in traditional field experiences spend less time in seminar, generally 1-3 hours per week. These seminars typically include "how-to-do" toplcs such as bulletin boards, parent conferences, 
discipline, lesson planning, units, and record keeping. The seminar is conducted by one person, often a faculty member or graduate student. Goodman (1983) found the most common function of seminars was collaboration with the field experience setting by addressing immediate classroom concerns. Therefore, traditional fleld experience seminars tend to focus on short range skills that facilitate success in the field experience. In comparison, CPEP seminars focus on both short range (success in the field placement) and long range goals (analysis, synthesis and evaluation of instructional styles, techinques and settings).

In respect to content, both instructional techniques and classroom management teaching behaviors were reportedly influenced more by seminar than other sources. A total of 140 teaching behaviors were coded as instructional techniques, and 96 of these were attributed to seminar as the source of influence. An example of an instructional technique learned in seminar occurred when an intern said, "Come to the chalkboard and show me what you mean." The Intern reported this idea came from seminar because she was including active particlpation in the lesson and had learned this ldea in seminar. Another observed teaching behavior Included an Intern "walking around the classroom, checking the students' handwriting assignment." The teaching behavior of monitoring students' seatwork was learned in seminar according to this intern. An additonal example of 
an instructional technique attributed to seminar occured during a class discussion. The intern asked, "Let's see if you were listening and can tell me the name of the poem we just read?" The intern said the idea for checking to see if students were attending to the reading along with keeping them accountable came from a seminar. Classroom management was the other content area where seminar was reported as the major Influence on the interns' teaching. Twenty-six of the 61 recorded teaching behaviors in the classroom management category were influenced by seminar. Interns participated in several seminar session on classroom management skills and techniques. Describing specific behavlors for feedback and positive reinforcement were seminar ideas an intern used during a lesson. She stated. "I like the way you are counting out loud so he can tell what you are doing", during a cardiopulmonary resuscitation activity. In a first grade class, an intern asked a student, "What kind of voice should you be using?" as a classroom management technique. She attibuted this idea to seminar.

Perhaps the large number of teaching behaviors and ideas attributed to seminar as the source of influence is a result of the CPEP interns' lack of prior educational knowledge before entering the program. Interns had not completed traditional education courses, and thus, were learning the theory and skills of instruction and classroom 
management concurrently while applying them in the field experience.

Rast Experiences. Silvernail and Costello (1983) found that major influences on teaching behavior occur prior to entering the field experience. The findings in this study did not support those of Silvernail and Costello, as 20 of the 330 reported influences were attributed to past experience. The teaching behaviors influenced by past experiences were divided into the following categories: Subject matter, 12; classroom routines, 4; instructional techniques, 3 ; and classroom management, 1 . The category of subject matter was the most frequently reported content of teaching ideas influenced by past experiences. Perhaps, interns recalled subject matter knowledge from their own school years, and integrated these past experiences into teaching in the field experience. Also, most CPEP interns had completed their undergraduate degree before entering CPEP. The previous university coursework in liberal arts or general studies may have provided subject matter or curriculum information to draw upon as a past experience and relate to their teaching. An example of a teaching behavior that was focused on subject matter and influenced by past experiences occurred when an intern told the students, "You should know the parts of an essay and the order they come in." She had learned this information as a college student, and was relating her teaching to a past experience. 
University Supervisor Categery. According to Patty (1973) the University Supervisor has little influence on the teaching behavior of a student teacher. While the source of influence of the university supervisor in this study is not as frequent as other sources, the range was from 0 in April and May to 11 in February. During February, interns were preparing to assume the responsibility of full-time teaching and were eager for feedback and direction related to their teaching. The supervisor was able to provide some of this information on an individual basis for the interns in February. The supervisor also made more classroom observations during Eebruary, which may have increased the number of teaching behaviors influenced by the supervisor. In April and May, most interns had completed full-time teaching and were spending their time completing ILP objectives. The supervisor met with each intern, discussed ILP objectives, and developed time-lines for completion of the document. Although the supervisor continued to supervise the teaching of each intern, the intern did not attribute sources of influence to the supervisor in April or May.

The content of the teaching behaviors influenced by the supervisor were classroom management and instructional techniques. The university supervisor was the second highest frequently reported source of influence on interns' classroom management behaviors. Interns reported no 
influence from the supervisor on their classroom routines or subject matter knowledge teaching behaviors. The university supervisor worked with the interns on "general" teaching behaviors and ideas, such as implementing teaching models and styles, and effective classroom management strategies. The support teacher had definite ideas about classroom routines and subject matter, thus assumed responsibility for these teaching areas.

An example of a classroom management teaching behavior influenced by the supervisor follows: An intern told her class, "You have all worked so hard and were quiet during reading. If you continue this for the next five minutes, we will leave for recess early and be the first class on the playground." The intern had asked the supervisor for assistance in developing classroom management techniques, and had followed through with the suggestions in her teaching. Although the university supervisor did not provide a major source of influence on the interns' teaching, the interns did report that the supervisor influenced their classroom management and instructional techniques.

Teacher's Manual or Guide Category. This category received the lowest number of ratings ( 3 out of 330 ). January was the only month interns reported the teacher's guide as a source of teaching idea. All 3 of these teaching behaviors were placed in the subject matter or curriculum category. Samples of interns' teaching ldeas attributed to 
the manual or teacher's guide were found to be specific to the lesson the intern was teaching at that time. For example, one intern instructed the class to "look at the ' $C$ ' group of words, and $f$ ind the $l$ ist of suffexes, and use these at the end of the word." The intern was working with the students in teaching the parts of a word and had referred to the teacher's guide as a source of information for this lesson. In a math lesson on telling time, an intern asked the students, "What do you normally do at midnight?" She reported the teaching idea came from the mathematics teacher's guide, and she was following the suggested teaching ideas. The low frequency reported in the use of the manual or teacher's guide may be related to the support teachers involved in the CPEP program. Through observations it was noted that 3 of the 6 support teachers did not use a teacher's manual. The teachers who did use the manual relied upon it for reading instruction and a source for subject matter ideas in other curricular areas. An additional possibility for the reported low frequency of teacher's guides influencing the interns' teaching may be found in the curriculum development in their classrooms. The curriculum tended to be developed from numerous sources, and the interns followed the direction established by the cooperating teachers. Also, the interns were involved in learning curriculum content in the seminars concurrently, and brought subject matter ideas to the classroom from 
seminars. In contrast to the CPEP interns, student teachers in a traditional program spend less time in the field experience (10-12 weeks compared to 38 weeks in CPEP) and possibly need to rely upon teacher's guides. In a traditional field experience, there is not enough time to observe and develop curriculum, therefore; a teacher's manual or guide offers expedient assistance in planning instruction.

Coursework, Interns in CPEP were not required to complete traditional education courses before entering the program. Some interns had taken several education courses, while other interns entered the CPEP program with a degree in another field (i.e., Nutrition, English, Far Eastern Languages) and had completed little education coursework. Eleven teaching behaviors were reported to be Influenced by previous coursework. The content representation was subject matter, 9; instructional techniques, 1; classroom routines, 1; classroom management, 0 . Most of the teaching behaviors or Ideas the interns attributed to coursework focused on specific subject matter ideas, rather than teaching techniques or classroom management ideas. For example, during a science lesson, an intern told the class "I found all of the things needed for the science experiment around my house". She related that during a science course she had learned it was important to let students know that science is practical, and that it does not always require 
speclalized equipment. Another intern directed the class to, "Find which number is larger, then mark the largest number on your paper". She felt the idea for identifying the largest number came from a "math methods" class which she had previously completed. The small number of education courses completed prior to the field experience may explain the low frequency reported of coursework as a source of influence on teaching. If interns had relatively little background in education coursework, they are unable to attribute the source of their teaching to this category. In a traditional program, student teachers generally complete all education coursework before the field experience. Both prospective and inservice teachers have criticized the value of education coursework (Joyce \& Clift, 1984), and suggestions for reform in teacher education programs include changes in education coursework.

\section{Summary of Reported Sources of Influence}

Seminar was the most frequently reported source of influence on interns' teaching with 136 of the total 330 recorded teaching behaviors attributed to seminar. The presentation of seminar concurrently with practice application may contribute to the high incidence of seminar influence reported by interns. This finding is in contrast with the field experlence literature origlnating in traditional programs. According to Haberman (1983), an 
accepted conclusion is that the cooperating teacher has the greater influence on a prospective teacher. The interns in CPEP observed and participated in several classrooms, along with attending a weekly seminar. Therefore, these interns were exposed to a greater number of teachers and experiences than a student teacher in a traditonal program. Seminars presented education coursework in subject areas as well as elements of instruction and classroom management. Interns were given the opportunity to discuss and question existing teaching practices during small group sessions in seminar. CPEP interns also spent 8 hours each week in seminar, in addition to homework assignments originating from seminar. The combination of these factors possibly increased the influence seminar exerted on CPEP interns.

The influence of the support teacher was rated as the second most reported influence ( 53 of 330 ) on the teaching behavior of the interns. Teaching behaviors likely to be influenced by the support teacher were related to classroom routines and subject matter or curriculum areas. Field experience literature finds this to be the major influence on student teachers, and while a strong influence in this study, it was not the major influence. There are several possible explanations for the lower rating of the influence of the support teacher. CPEP interns taught and observed in several classrooms throughout the school year; therefore, they observed several teacher "models". University 
supervisors stressed the importance or "trying out" different teaching strategies and experimenting with instructional ideas, and discussed this philosophy with support teachers and interns. Interns were encouraged to explore, question and discuss advantages and disadvantages found in different teaching styles. These elements of CPEP enable interns to experience varied models of instruction, thus broadening their base of "models" of instruction beyond the supppot teacher.

The source of influence frequencles reported in other categories included: self, 49; observations, 34;

supervisor, 24; past experiences, 20; coursework, 11; and teacher's guide or manual, 3. The findings in this study indicate interns attribute themself as a frequent source of influence in their teaching, particularly in the area of subject matter. As no literature was found describing the influence of observations on prospective teachers' behavior, it is interesting to note that CPEP interns reported observations as influencing their teaching behavior. The supervisor was also reported as a source of influence more frequently during January, February, and March, when interns were preparing to teach full-time. Interns also brought their past experiences into the classroom, reporting this a source of influence in their teaching. Using their past experlences was most prominent in the area of subject matter. Education coursework was a minor influence on the 
interns' teaching. CPEP Interns completed a minimal amount of courses before entering the field experience, along with learning this information in the concurrent seminars. Teacher's guides and manuals were reportedly a minor influence on interns' teaching. CPEP interns used numerous resources in teaching and relied minimally on teacher's guides.

In summarizing the content of the observed teaching behaviors (see Table II, p. 61), 140 of the 330 teaching behaviors demonstrated instructional techniques; 61 were classroom management techniques; 49 were classroom routines; and 80 were related to subject matter. Seminar was reported as most influential on instructional techniques and classroom management. The support teacher was the major source of influence on interns' classroom routines, and the interns" "self" was most influential in the area of subject matter. The varied experiences and requirements of CPEP may have contributed to the range of influence on their teaching behaviors and ideas.

\section{PROFESSIONAL CONCERNS OF INTERNS}

\section{Presentation of Data}

Introduction. The concept of teacher concerns is based on Fullers' (1969) Concerns Theory. Fuller found that student teachers' concerns Initially revolved around 
themselves, and later concerns focused on the effects of the student teachers' instruction with students. In a later study (1971) Fuller concluded prospective teachers progress from concerns about self as students, then about tasks in the field experience, and finally about the impact of their instruction. In examining the "learning-to-teach" process in this study, analyzing interns' professional concerns as they progress through the field experience provided information from the interns' perspective. Fuller's work provided a foundation and rationale for including this question in the study.

A questionnalre was developed for this study which included the question, "In relation to your teaching, what are your concerns at this time?" A space was provided on the form to answer this question with an open-ended response. The general sample of interns $(n=22)$ completed the questionnaire once a month from January to May, generally during the first week of the month.

After reading and analyzing the concerns, two initial categories emerged: concerns-with-self and concerns-withothers. These categories were found to be too general, so additional analysis and categorization (classifying similar responses) resulted in the emergence of nine categories. As some of the emergent categories overlapped with Fuller's work, several of these category names were used. The final nine categorles contained seven categories in "concerns- 
with-self", and two categories in "concerns-with-students." The seven categories of "concerns-with-self" included the following:

1. Meeting expressed and non-expressed expectations from support teacher, including teaching expectations and support teacher-intern relationship expectations;

2. Self-adequacy including self-questioning of teaching ability, time management, and survival potential;

3. Cooperative Professional Education Program (CPEP) concerns, including completing program requirements;

4. School situation including policies, rules and established practices of classroom or school;

5. Classroom management including discipline and "gaining control" of students;

6. Knowledge of subject matter including competence and lack of competence in curriculum areas;

7. Future employment concerns. The "concerns-with-students" categories included the following:

1. General concerns about students' problems, individual needs or abilities;

2. Instruction of students including impact of ingtruction on students.

Table III displays the data on professional concerns of the interns from January to May. There were a total of 149 concerns reported during this time period. Of these, 132 
TABLE. III

PROFESSIONAL CONCERNS OF INTERNS

\begin{tabular}{|c|c|c|c|c|c|c|c|c|c|c|}
\hline \multirow[b]{2}{*}{ Month } & \multirow[b]{2}{*}{ Total } & \multicolumn{7}{|c|}{ Concerns with Self } & \multicolumn{2}{|c|}{ Concerns with Students } \\
\hline & & $\begin{array}{l}\text { Expectations } \\
\text { Support } \\
\text { Jeacher }\end{array}$ & $\begin{array}{l}\text { Self- } \\
\text { Adequacy }\end{array}$ & CPEP & $\begin{array}{l}\text { School } \\
\text { Situation }\end{array}$ & $\begin{array}{l}\text { Classroom } \\
\text { Management }\end{array}$ & $\begin{array}{l}\text { Knowl edge } \\
\text { Subject } \\
\text { Matter }\end{array}$ & $\begin{array}{c}\text { Future } \\
\text { Employment }\end{array}$ & $\begin{array}{l}\text { Individual } \\
\text { Students }\end{array}$ & $\begin{array}{l}\text { Impact of } \\
\text { Instruction }\end{array}$ \\
\hline Jan. & 28 & 6 & 6 & 7 & 5 & 3 & 1 & 0 & 0 & 0 \\
\hline Feb. & 34 & 7 & 12 & 2 & 7 & 5 & 1 & 0 & 0 & 0 \\
\hline Mar. & 30 & 2 & 10 & 1 & 4 & 7 & 1 & 0 & 1 & 4 \\
\hline April & 23 & $\mathbf{0}$ & 9 & 2 & 1 & 3 & $\mathbf{0}$ & 1 & 2 & 5 \\
\hline May & 34 & $\underline{0}$ & 7 & 8 & $\underline{2}$ & $\underline{2}$ & $\mathbf{0}$ & 10 & 1 & 4 \\
\hline TOTAL & 149 & 15 & 44 & 20 & 19 & 20 & 3 & 11 & 4 & 13 \\
\hline
\end{tabular}

Ceneral Sample of Interns

$n=22$ 
concerns were reported in "concerns-with-selt" categories, and 17 concerns were reported in "concerns-with-students" categories. In January and February, interns reported 0 concerns with students, while during March, April, and May interns reported 17 concerns with students. The range of reported professional concerns was from 3 (the lowest amount of concerns reported in the category of knowledge of subject matter), to 44 (the highest amount of concerns reported in self-adequacy $>$.

\section{Presentation of Data within Concerns Categories}

\section{Concerns about expectations of the support teacher.}

This category included concerns interns had about meeting the teaching expectations of the support teacher and expectations interns held about the relationship between the support teacher and intern. In addition, concerns the support teacher had expressed and concerns the intern had assumed were expectations of the support teacher are included in this category. There were 15 concerns reported in this category during the 5 month data collection period. The range of concerns reported was from 0 concerns reported in April and May (lowest number) to 7 concerns reported in February (highest number). Early concerns reported during January focused on "experiencing resistance to having to conform to someone else's expectations (support teacher)" while concerns in March reported, "Getting along with my 
support teacher is a concern--my teaching sometimes suffers because of our relationship." The concerns about expectations of the support teacher consistently reported difficulty in conforming to the support teacher's style ("During my full-time teaching it will be teaching in her style, just me doing it, so it doesn't come naturally") or problems in the working relationship between the intern and the support teacher ("I want to implement many ideas and concepts from seminars, but I am having difficulty due to my support teacher's beliefs").

Concerns about Self-Adequacy. These concerns were centered on interns" successes, failures, "survival" anxieties and time management problems during the field experience. Concerns about self-adequacy had the highest frequency of reported concerns, with 44 concerns reported with a range of 6 to 12 . Six concerns were reported in January (lowest amount), and 12 concerns were reported in February (highest amount). Early concerns in January included, "I am still so inexperienced", or "Will I be able to manage the class..." In February, interns reported, "My teaching concerns are being able to teach and be observed, I have a real difflcult time keeping my attention on the class" or "Keeping up with all the content as well as with evaluation of essays is my concern." Examples of self-adequacy concerns in March were the following: "Being able to keep up with orchestrating all the details of every 
day teachlng" and "I teel I can teach, but I don't have enough different ways to present material." Later concerns in April and May stated, "Everything I do takes hours to prepare and I feel like I am never done" and "I need to work on making sure that I actually teach what I intended to teach."

\section{Concerns about CPEP Requirements. CPEP concerns} included comments about the CPEP program and completing the Individual Learning Plan (ILP) objectives. In a traditional teacher education program, these objectives would be met in the education coursework. Each intern developed and completed an ILP. The developmental process consisted of identifying and sequencing enabling activities and evaluations to meet the objectives in the ILP. Once developed, the ILP acts as a professional development plan for the year of internship.

Total concerns reported in the CPEP category were 20 , with a range from 1 in March to a hlgh of 8 in May. Twenty of the 20 CPEP concerns were related to the ILP. CPEP concerns in January reported, "My major concern is my ILP and getting it organlzed" or "Not working on ILP requirements definitely is a major concern." Later concerns in May were agaln focused on the ILP and included statements such as, "My concern is finishing the ILP in the time that remains before the end of the program. I'll make it, but it will be tight." 
Concerns about the School Situation. These concerns included policies, rules, and established practices and routines in the classroom or school. A total of 19 responses were in this category with a range from 1 (reported in April) to 7, (the highest amount, reported in February). An example of a concern in February is, "I feel uneasy about how to grade the students' work. I am tempted to grade heavily on effort or individual progress, but I don't think the school grades that way." A later concern expressed in April stated, "I'm putting some thought into how to fit smoothly back into the classroom in terms of the existing management structure."

Classroom Management Concerns. Concerns about classroom management included student discipline and establishing and maintaining "control" in the classroom. A total of 20 concerns were reported in this category, with a range of 2 reported in May (lowest amount) to 7 concerns reported in March (highest amount). Early concerns focused on, "Will I be able to manage the class?" or "Of course, classroom management!" (the answer to the question about major teaching concern at this time). Later concerns in May reported, "My concerns about teaching at this time are effective classroom management--establ lishing (maintalning) good rapport with students."

Cencerns about Subject Matter. These concerns included knowledge of the curriculum or subject matter. There were 3 
concerns reported in this category with a range of 0 concerns reported in April and May to 1 (highest number in this category) reported in January, February, and March. A typical concern about knowledge of subject matter expressed, "Right now I think my major concern is that I will be "soloing" soon and may not be as familiar with all the subjects as I should be."

Concerns about Future Employment. Future employment concerns revolved around obtaining a teaching position for the following school year. A total of 11 concerns were reported in this category, with a range from 0 in January, February and March to 10 in May. Many of the concerns were similar to the following: "...concerned about employment and the uncertainty of employment", "As the end of the year approaches I $f$ ind my concerns are centering on the process of being hired" and "I'm concerned about the job hunt."

Concerns about Students' Problems, Individual Needs and Abilities. The total number of concerns in this category was 4 , with a range of 0 reported in January and February to 2 concerns reported in April. An intern concerned about students expressed, "Students come with such different emotional, social, and academic starting points." Another intern noted, "It's interesting to see how a student's behavior is affected the days before vacation."

Concerns about Impact of Instruction on Students. This category centered on the intern questioning themselves about 
the impact of their instruction on students. $A$ total of 13 concerns were reported in this category, with a range from 0 in January and February to 5 in April. Examples of concerns about the impact of ingtruction on students occurred when interns stated: "I'm concerned about finding a way in which to teach writing that will allow the student some freedom to express himself", "How do I teach students and develop realistic academic expectations for them as individuals?", and "How can I best evaluate their work and give them feedback?"

\section{Presentation of Data by Monthly Distribution}

Before looking at the monthly distribution of expressed concerns, it is important to review the timeline of activities in Figure 4 ( $p .51$ ) and the description of activities interns were involved in monthly (p. 50).

January. In January, a total of 28 concerns were reported, with a range of 0 to 7 . Concerns within the category of students' problems, individual needs and abilities, the category of instruction of students and the category of future employment were expressed least ( 0 ) and those within the category of concerns about CPEP were expressed most often ( 7 ).

Eebruary. A total of 34 concerns were reported this month, with a range of 0 to 12 . No concerns were expressed in the "concerns-with-students" categories and with future 
employment, while the most concerns (12) were reported in the self-adequacy category.

March. Thirty concerns were reported in March, with a range of 0 to 10 . No concerns were expressed in the future employment category, and concerns were expressed most often (10) about self-adequacy. In the "concerns-with-self" categories there were a total of 25 concerns, and in "concerns-with-students", a total of 5 concerns were reported.

April. A total of 23 concerns were reported in April, with a range of 0 to 9. No concerns were expressed in the categories of expectations from the support teacher and knowledge of subject matter, and 9 concerns were reported in the self-adequacy category. A total of 16 concerns were expressed about "concerns-with-self", and 7 concerns were reported about "concerns-with-students".

May. Thirty-four concerns were reported in May, with a range from 0 to 10 . The lowest number of concerns ( 0 ) was reported in the categories of expectations from the support teacher and knowledge of subject matter. Ten concerns were expressed about future employment, resulting in the most often reported concern in May. Of the 34 concerns in May, a total of 29 were "concerns-with-self" and a total of 5 "concerns-with-students". 


\section{Discussion of Eindings within Concern Categories}

Concerns-With-Self and Concerns-With-Students. With

132 concerns reported in the categories of concern-with-self and 17 concerns reported about students, an obvious finding is that throughout the intership concerns-with-self dominated the professional concerns expressed. Fuller, Parsons, and Watkins (1973) found that prospective teachers' concerns move from self to students during the field experience, with a shift back to self (as a student again) near the end of the field experience. This study reports a similar trend. Silvernail and Costello (1983) found student teachers to move toward concerns about students during the middle of the field experience, and then reversing towards self-concerns as the field experience ended. Interns in this study were concerned about completing program requirements and obtaining a teaching position at the end of the field experience; therefore, concerns shifted to concerns-with-self. This finding is consistent with those of Fuller, Parsons, and Watkins (1973), and Silvernail and Costello (1983).

A possible explanation for the limited number of concerns-with-students expressed may be found in the intensity and demands of CPEP. Students were responsible for developing and completing individual learning activities for their ILP, which required time and energy that might have been directed toward concerns-with-students in a 
traditional student teaching experience. In the traditional field experience, student teachers complete full-time teaching near the end of the 10-12 week field experience and have no further responsibilities after completion of full-time teaching. In CPEP, interns were teaching full-time in March and Aprll, but also faced completion of the Individual Learning Plan activitites by the end of May. In addition, the end of the data collection period coincided with the time period for applying for teaching positions. Interns were concerned about future employment. Both of these concerns (program requirements and future employment) were not reported in the literature about teaching concerns, yet emerged in this study.

Concern with Expectations from Support Teacher. The range of reported concerns of expectations from the support teacher was from 0 in April and May to 7 in February. Durlng January and February, the months with the highest number of concerns about expectations from the support teacher reported, interns were beginning the progression of teaching one or two lessons per day to gradually assuming responsibility for planning and teaching for the entire day. A possible reason for the high number of concerns about expectations from the support teacher at this time may be found in the timeline and activities in CPEP. Interns were preparing to teach full-time and were apprehensive about assuming responsibllity for the students. Interns were also 
in the process of deveioping their personal styie and phllosophy of teaching, and comparing this with the support teachers' styles. Both of these activities may have added to the concerns interns had about expectations from the support teacher.

According to Zeichner (1978), there is agreement that the cooperating teacher has a major influence on the student teacher; yet, it is not known what the effect of the cooperating teachers' expectations are, or how these expectations are transmitted (Wright, Silvern, \& Burkhalter, 1982). Examining the descriptive statements from the interns provides insight into interns' perceptions of these expectations. Examples of the concerns expressed in January focused on differences in teaching style or philosophy between the intern and support teacher. One intern stated, "I'm concerned about taking over the class from my support teacher. Will I need to manage the class according to her expectations or with my own style?" A concern about working around the support teacher's "style" was expressed by another intern in, "How will I get around the overload of seatwork in English that the support teacher has set up?" The theme from the preceding concerns continued into February, when an intern expressed the following concern, "I sometimes feel that I am a puppet performing the tasks that my support teacher wants accomplished, but that I don't desire to put the energy 
into." This intern was aware of the expectations and interests of the support teacher, and possibly doubted if this matched the intern's interests. The frequency of interns' concerns about the expectations of the support teacher decreased each month (during the later months). Perhaps, this decrease is explained by the timeline. Interns had completed full-time teaching and possibly became more confident about themself and their teaching.

Concerns about Self-Adequacy. This category contained the highest number (44) of reported concerns. A possible explanation for the large number of concerns with self-adequacy may be found in examining the activities on the CPEP timeline. In February, the month with 12 reported concerns (the highest number per month), interns were preparing to teach full-time. In preparation for assuming responsiblity for the entire planning and instruction in a classroom, interns may have begun to experience anxiety and doubt about their ability to successfully teach full-time. In the category of self-adequacy, a wide variation of types of concerns is found. Although the concerns are about self-adequacy, it was difficult to group them into "monthly themes" as the concerns expressed a wide range of thoughts. Interns were "learning-to-teach" at their own rate, and the individuality was expressed in concerns about self-adequacy. For example, in January interns reported concerns about "getting enough sleep", "seeing some improvement", "finding 
enough time to digest, evaluate, reconsider my teaching", and "getting enough continuity so that I feel like I am able to follow through on an activity." The first concern, getting enough sleep, is a basic "survival" concern, while the concern of getting enough continuity in order to follow through in teaching reveals an intern's concern about improving her teaching. In February, interns were closer to their full-time teaching requirement, and they reported concerns about their teaching skills. An intern stated, "My planning skills are still a formidable hurdle." Other interns found "I'm feeling apprehensive about maintaining momentum through longer chunks of teaching time" and "I'm concerned about my ability to teach the kids what they're required to know." All of these concerns point to the personal thoughts of interns in relation to their self-adequacy during "learning-to-teach", yet are related to teaching and improving teaching skills. Interns were aware of the areas in which they needed improvement and were expressing concern about their professional growth.

By May, most interns had completed their full-time teaching. Concerns expressed during May changed focus from classroom teaching during the field experience to concerns about themself as a teacher. The focus of concerns in this category shifted as interns moved through the field experience, moving from concerns of "surviving" or succeeding in the field experience to concerns about 
self-adequacy in relation to the teaching profession. Interns were now looking at the larger picture of the teaching profession, and thinking about the future. In the earlier months, interns expressed concerns about succeeding in day-to-day components of the field experience. Examples of concerns of interns thinking about the future follow: "I an worried about the work load of teaching and the time it takes me for lesson planning, grading and preparation...I am wondering if the monetary rewards of teaching will be enough to justify the amount of time spent" and "being a first year teacher will be very time consuming."

Changes in concern with self-adequacy also occurred in the frequencies reported each month. From February through May, concerns about self-adequacy dropped each month as interns progressed through the field experience. A possible explanation for the decrease may be found in the confidence gained by interns as they gain additional experiences and successes in teaching each month.

Concerns about CPEP. Of the 20 concerns reported about CPEP, all 20 were about completing the Individual Learning Plan (ILP) requirements. The ILP contains specific program objectives, and each intern develops and completes activities to meet the requirements of the objectives. The completion of the ILP involves a year-long process and several hundred activities. Examples of enabling activities include the following: Teaching full-time ( 4 week minimun), 
observing and assisting in a multi-cultural school setiting for 1 week; teaching at several different grade levels; planning and teaching lessons in each subject area at more than 1 grade level; and developing a wrltten philosophy of education. As these activities and objectives are usually met in the education coursework in a traditional teacher education program, CPEP interns were actually completing the field experience and the education coursework simultaneously. This required an intensive commitment from each intern, which may have been expressed in their reporting of concerns about the ILP.

Perhaps, concerns were not reported about other components of CPEP due to implementing the concern's questionnaire in January. Interns had been involved in the program since August and concerns other than ILP concerns may have been resolved or accepted before the concerns questionnaire was administered.

During January and May, interns reported the highest number of concerns about the ILP. These were the months interns were not teaching full-time and were spending more time working on the activities outlined in their ILP. In May, when the ILP had to be completed, interns were spending many days teaching and observing in other classes, as well as completing reading and other assignments. In February, March and April, interns reported lower numbers of concerns about the ILP. During these months, all interns were 
engaged in teachling activities, and were not spending as much time directly on the ILP activities required out of their assigned class. There was no change in the content of concerns reported during the 5 month data collection period. Early concerns stated, "MY ILP is running the show", and later concerns reported, "My ILP is the only concern I have."

Concerns about School Situation. Concerns about the school situation included concerns about policies, rules or established practlces in the classroom or the school. Nineteen concerns were reported in this category, with most concerns finding interns questioning the "accepted" pollcy in a school or classroom. A concern reported in January was "Our school uses so many dittos, I have textbook/ditto phobia." In February, an intern expressed concern about the "lack of established structures and positive atmosphere in my classroom." The intern had been observing in other classrooms, and was expressing concerns about the establsihed structures and routines in her assigned class. A later concern reported, "I am in a bit of a $1 \mathrm{lmbo}$ situation regarding my place in the class (bouncing back and forth between having a place or being extra luggage). The intern had completed full-time teaching and was concerned about her fitting into the established classroom routine. During February, the highest number ( 7 ) of concerns with the school situation were reported. As this was the 
month before most interns began full-time teaching, this may account for an increase in concerns about the school situation. In March, April, and May, the concerns dropped to 4,1 , and 2 . Interns were involved in teaching full-time and, in most cases, had more control of the school situation, such as furniture arrangement or class schedule. In the later months, interns became more familiar with the school rules and policies, and may have accepted them the longer they were involved with the school. In contrast, student teachers in a traditonal fleld experience may find themself more concerned about the school situation, as they are in this setting for a shorter period of time and have not become as familiar with the established policies and routines. Interns had been in the school since August and were often thought of as "another teacher", rather than a student teacher. Therefore, the intern is more likely to learn the sociological and political structure of the school due to the extended time and responsibilities of the field experience.

Concerns about Classroom Management. Student teachers and beginning teachers relate the most "pressing problem" in teaching is classroom managment (Cruickshank \& Callahan, 1983). In contrast, there were 20 concerns out of the total of 149 reported in the category of classroom management; therefore, interns did not report classroom management as a major concern in this study. This finding supports those of 
Silvernall and Costello (1983), where student teachers and interns reported low levels of concern about classroom management.

Concerns in January. February, and March focused on "gaining control" of the students in order to teach, while later concerns questioned alternative classroom managment strataegles and consequences of these approaches. For example, in January one intern reported "I need to develop a structure of classroom management that is effective." Another intern stated, "Of course my concern is classroom management...how to manage childrens' behavior!" By March, when interns were beginning to teach full-time, 7 concerns about classroom management were reported. Concerns were, "At the moment, I am in the process of tightening my discipline in preparation for the upcoming full-time teaching", or "My concern is discipline. The students are really testing me all over again, even though I've been teaching a lot since January." These interns were concerned about developing effective classroom management techniques in order to "survive" the field experience. In contrast, the May classroom management concerns were fewer, and addressed the phllosophy behind classroom management. For example, an intern stated, "I'm constantly weighing the cholces between having a quiet, strict classroom or having a noisier, more creative classroom." There was a distinct change in the content of concerns within the category of 
classroom management. In the early months, the focus was on basic concerns about surviving and developing a management system that would allow the intern to teach and "get through" a lesson. In the later months, interns were examining the effect of different classroom management styles on the students and their learning. Interns shifted from concerns about developing skills and searching for effective management techniques (what do I do in the class to keep "control"?) to assessing, evaluating, and questioning the rationale and effect of a classroom management style (do different types of classroom management styles and techniques result in different amounts or types of learning?).

Concerns about Subject Knowledge. The number of concerns abut knowledge of subject matter of curriculum was very low ( 3 for the 5 month period). One concern per month was reported in January, February, and March, with 0 concerns reported in April and May. A possible explanation for the low reporting of concerns about knowledge of subject matter may be found in the gradual progression of assuming teaching repsonsibilities in the classroom. Interns had been working in these classrooms since August and had teaching experience in most curriculum areas by January, when the concerns questionnaire was introduced. Also, the interns had completed four months of seminars, with a focus on curriculum content in reading, math, language arts, 
science, and social studies. A January concern was, "I will be full-time teaching soon, and may not be as familiar with all the subjects as I should be." In March, an intern expressed, "I am concerned about keeping up with content as well as evaluation."

Cencerns about Future Empleyment. This category emerged in April, when the identical concerns questionnaire was completed by the interns, and focus abruptly shifted to "finding a teaching job." From January through March future employment was not mentioned. One intern reported a concern about "looking for a teaching job" in April. In May, 10 concerns (the highest number of concerns in a category during May) were focused on finding a teaching job. In the Portland Metropolitan area, securing a teaching position is difficult. Approximately 50\% of the teacher education graduates at Portland State University find a teaching position before the beginning of the school year. Perhaps the intense screening process and the scarcity of teaching positions increased the number of concerns for these interns In this metropolitan area.

Examples of these concerns are, "I'm concerned about the job hunt and interviewing, etc." "getting a job", and "As the end of the year approaches I $f$ ind my concerns are centering on the process of being hiredvertified. I find myself worrying about all these forms, forms, forms." Although the questionnaire addressed concerns with teaching, 
interns expressed numerous concerns about finding a teaching job as a concern during May.

Concerns with Students' Problems, Individual Needs or Abilitieg. Interns expressed no concern ( 0 ) about students' problems, individual needs, or abilities during January and February. In March, April, and May, 1, 2, and 1 concerns were reported. In April, an intern stated, "I am concerned about following up on the low students so they are benefiting from whatever we are doing." During May, an intern expressed, "Students come with such different emotional, social, and academic starting points...some can do so little academically-others so much." Both interns" concerns centered on the student, and the student's individual abilities and needs.

A possible influence on the interns' reporting more concerns-with-self may be found in the instrument. The questionnaire asked, "In relation to your teaching, what are your concerns at this time?" Perhaps, interns interpreted this question to ask about personal concerns, rather than teaching concerns. Therefore, interns may have reported more concerns-with-self.

Concerns with Impact of Instruction on Students. Interns reported concerns about the impact of instruction on students during March, April, and May. Most of the concerns were focused on examining the role of teaching and the effect on students. When asked about teaching concerns in 
March an intern stated, "How to teach students in a way that causes them to increase their ability to take better care of themselves, be able to solve problems on their own, and organize themselves." In April an intern revealed the following concern, "Reaching student's individual learning styles appropriately is one of my largest concerns right now. As I give assignments, I realize I'm not reaching everyone fairly. I'm trying to remedy this." During May, an intern wondered, "How do I teach to address the learning of students as individuals?" These interns viewed the students as individuals and were concerned about providing effective instruction for the students.

\section{Summary of Professional Concerns of Interns}

Introduction. Over the 5 month data collection period of this study, there were 149 concerns reported by interns. During the first two months, no concerns-with-students were reported. In March, April and May, a total of 17 concerns-with-students were expressed. There was a gradual increase of concerns-with-students until May, when a decrease was noted. This corresponds to findings of Silvernail and Costello (1983), who found student teachers shifted back to concerns-with-self at the end of the field experience. In this study, CPEP interns reported concerns about completing ILP activitles and looking for a teaching position during May. These factors may have influenced the 
concerns of the Interns, resulting in a shift toward concerns-with-self at the end of the field experience.

Concerns-with-Self. Of the 149 reported concerns in this study, 132 were concerns-with-self. The highest number of concerns were reported in the category of self-adequacy (44). Interns expressed concern about their self-adequacy during the field experience, when they were expected to assume important responsibilities and demonstrate their teaching abilities. The second most frequent (20 concerns) category of concern was CPEP, specifically the Individualized Learning Plan (ILP) requirements. Interns were involved in numerous activities in order to complete their ILP, which constituted the framework for each intern's professional development plan for the year. Nineteen concerns were expressed about the school situation. Interns were placed in a school situation and had to learn the social and political policies and established routines of their classroom and school setting. There were 19 concerns expressed about classroom management. In March, when most interns were teaching full-time, the highest number of classroom management concerns were reported. Within the category of classroom management, interns shifted their focus from finding effective classroom management ideas to enable them to teach, to reflecting on the relationship between different classroom management styles and students'learning. Fifteen concerns were reported about the 
expectations of the support teacher. Interns were concerned about meeting both expressed and non-expressed expectations, particularly about following the support teacher's style of teaching. Future employment became a concern in April and May. Interns reported a high number of concerns about looking for and obtaining teaching positions. Knowledge of subject matter was the least reported concern of the interns. Possibly due to the extended length of time in the classroom before teaching, and the concurrent presentation of curriculum and subject matter in seminars, interns were minimally concerned with knowledge of subject matter.

\section{Concerns-with-Students. A total of 17 of the 149} concerns were reported about students. In the category of impact of instruction on students, there were 13 concerns reported. Interng reported questioning the impact of their instruction on the learning of the students during March, April, and May. A total of 4 concerns about student's individual needs and abilities were expressed during March, April and May. These concerns focused on individual differences among students. A possible explanation for the low number of reported concerns-with-students may be found in the requirements and demands of the CPEP program. Interns were expected to complete education coursework requirements through seminars, observations, reading, and working in numerous classrooms. These expectations were in addition to participation in the field experience, and may 
have Influenced the number of concerns interns expressed about themselves as students.

\section{INTERNS' SELF-ASSESSMENT OF TEACHING}

\section{Presentation of Data}

Intreduction. The current state of research in the area of teacher self-assessment is very limited (Irvine, 1983), and literature on self-assessment of prospective teachers is sparse. This study examined the self-assessment of interns and the rationale for their assessment. The intensive sample of 6 interns completed a self-assessment form rating their teaching one week each month during the January to May period of their field experience. The form contained a rating scale from 1 to 5 , with 1 the highest rating. A rating of 1 reflects the intern's description of "very satisfied and would make no changes if presented again", to a rating of 5 , which reflects the description of "very dissatisfied, would change everything (see Figure 3 , p. 45). To determine the rationale the interns were using as a basis for the numerical rating, the question "Why?" was also included on this form. Four or five forms were completed each week, depending on the intern's teaching and seminar schedule.

The ratings of individual intern's self-assessment of teaching were averaged for each month, and the total average 
of the Interns' rating per month are presented in Table IV. The highest self-assessment rating of teaching was in April and May, when 3 interns rated their teaching at 1.3. The lowest rating occurred in March, when 1 intern rated her teaching at 3.4 , therefore, the range was 1.3 to 3.4 . The average rating (for the entire group) per month ranged from 1.8 in April and May to 2.2 in January, with a total average for the 5 month period of 2.0. In looking at the average self-assessment rating per intern for the entire 5 month period, the range was from 1.7 (Intern \#5) to 2.5 (Intern \#2).

The answers to the "why" question on the selfassessment of teaching form produced the rationale or content for the numerical ratings. The content of the rationale statements were classified into 4 categories. After reading the rationales, then coding and classifying similar responses, 4 categories emerged (see Table V). These categories included the following: (a) instructional techniques which included references to lesson design and presentation; (b) student learning behavior which included comments such as; "The kids participated and really enjoyed reading the stories today"; (c) self-adequacy which included comments about themself in the role of teacher; (d) classroom management which included specific references to the behavior of the students (i.e., disruptive, oft-task, talking). In order to provide further information about 
TABLE IV

INTERN'S SELF ASSESSMENT OF TEACHING

\begin{tabular}{|c|c|c|c|c|c|c|c|}
\hline & $\$ 1$ & 12 & $\$ 3$ & 14 & 15 & $\$ 6$ & Average \\
\hline January & 1.5 & 2.3 & 2.3 & 2.0 & 2.3 & 2.9 & 2.2 \\
\hline February & 2.0 & 2.3 & 1.5 & 2.3 & 2.0 & 2.0 & 2.0 \\
\hline March & 1.5 & 3.4 & 1.6 & 1.8 & 1.8 & 2.4 & 2.1 \\
\hline Apr Il & 1.6 & 2.0 & 2.3 & 2.3 & 1.3 & 1.8 & 1.9 \\
\hline May &,$^{2.3}$ & 2.5 & 1.3 & 1.5 & 1.3 & 1.8 & 1.8 \\
\hline \multicolumn{8}{|l|}{$\begin{array}{l}\text { Intern's } \\
\text { Average }\end{array}$} \\
\hline Rating & 1.8 & 2.5 & 1.8 & 2.0 & 1.7 & 2.2 & 2.0 \\
\hline
\end{tabular}

\section{Pating Scale}

1 = Very satisfled, would make no changes in lesson

2 = Satisfled, mould make minimal changes in lesson

3 = Acceptable, would make some changes and keep some the same

4 = Dissatisfled, would make mafor changes

5 = Very dissatisfled, would change everything

Intensive Sample of Interns $N=6$ 
TABLE V

CONTENT OF RATIONALE OF INTERNS' SELF-ASSESSMENT OF TEACHING

\begin{tabular}{|c|c|c|c|c|c|c|c|c|c|c|c|c|c|c|c|}
\hline \multirow[t]{2}{*}{ Month } & \multirow[t]{2}{*}{ Total } & \multicolumn{3}{|c|}{$\begin{array}{c}\text { Instructional } \\
\text { Techniques }\end{array}$} & \multicolumn{3}{|c|}{$\begin{array}{l}\text { Student } \\
\text { Learning } \\
\text { Behavior }\end{array}$} & \multicolumn{3}{|c|}{$\begin{array}{c}\text { Self- } \\
\text { Adequacy }\end{array}$} & \multicolumn{3}{|c|}{$\begin{array}{l}\text { Classroom } \\
\text { Management }\end{array}$} & \multicolumn{2}{|c|}{ Total } \\
\hline & & Total & + & - & Total & + & - & Total & + & - & Total & + & - & + & - \\
\hline Jan. & 68 & 26 & 15 & 11 & 22 & 17 & 5 & 13 & 6 & 7 & 7 & 2 & 5 & 40 & 28 \\
\hline Feb. & 40 & 24 & 13 & 11 & 8 & 7 & 1 & 6 & 2 & 4 & 2 & 0 & 2 & 22 & 18 \\
\hline March & 52 & 22 & 9 & 13 & 14 & 6 & 8 & 10 & 1 & 9 & 6 & 2 & 4 & 18 & 34 \\
\hline April & 39 & 21 & 13 & 8 & 12 & 8 & 4 & 4 & 1 & 3 & 2 & 0 & 2 & 22 & 17 \\
\hline May & 38 & 20 & 8 & 12 & 10 & 7 & 3 & 4 & 2 & 2 & 4 & 2 & 2 & 19 & 19 \\
\hline Total & 237 & 113 & 58 & 55 & 66 & 45 & 21 & 37 & 12 & 25 & 21 & 6 & 15 & 121 & 116 \\
\hline
\end{tabular}

$+=$ positive rationale

- = negative rationale

Intensive Sample of Interns

$n=6$ 
interns' selír-assessment ớ teaching, these categories were coded as positive or negative statements about the rationale for the rating. For example, when an intern responded, "Because the kids were really involved in the lesson", the category was student learning behavior and the code was $t$, (positive). Another example was, "I would make changes in the pacing in the lesson", and the category was instructional techniques with a -, (negative) code.

A total of 237 rationale statements related to self-assessment of teaching were reported by the 6 interns during the 5 month period of the study. In January, 68 rationale statements were reported, and in May, 38 rationale statements were expressed. In the 4 categories, 113 (highest amount) of the rationale statements were about instructional techniques, 66 about student learning behavior, 37 about self-adequacy and 21 (lowest amount) focused on classroom management. In looking at the positive and negative dichotomy of the 237 statements, 121 were positive, and 116 were negative. In January, 40 positive rationale statements were expressed; while in March, 18 positive statements were reported. The number of negative statements ranged from 17 in April to 34 in March.

\section{Presentation of Data Analyzed by Month}

Introduction. The self-assessment ratings and rationale for ratings may be related to monthly activities 
in the field experience. A review of Figure \#4, Timeline of CPEP Activites ( $p .51$ ) may provide essential information useful in comparing the monthly ratings to the monthly CPEP activities.

January. The average self-assessment rating for all interns in January was 2.2 . The range was from 1.5 (Intern \#1) to 2.9 (Intern \#6). A total of 68 rationale statements about self-assessment of teaching were expressed, with 40 positive and 28 negative. Of the 68 statements, 26 were about instructional techniques (highest number) and 7 (lowest number) were related to classroom management.

Eebruary. The average self-assessment of teaching was 2.0, with a range of 1.5 (Intern \#3) to 2.3 (Intern \#1 and \#4). Forty rationale statements were expressed in February, with 22 of these positive statements and 18 negative. Instructional techniques was the focus of 24 statements, while the lowest amount was in classroom management, with 2 rationale statements reported.

March. The average of self-assessment of teaching was 2.1, with a range of 1.5 (Intern \#1) to 3.4 (Intern \#2). A total of 50 self-assessment rationale statements were reported; 18 of these were positive and 34 were negative. The highest amount (22) were centered on instructional techniques, and the lowest number ( 6 ) was about classroom management. 
april. During April the average self-assessment rating was 1.9 , with a range of 1.3 (Intern \#5) to 2.3 (Intern \#3 and \#4). Thirty-nine rationale statements for the self-assessement ratings were reported. Twenty-two were positive, and 17 had a negative focus. The highest number (21) were centered on instructional techniques, and the lowest number (2) focused on classroom management.

May. The average self-assessment rating for all interns was 1.8 . The range was 1.3 (Intern \#3 and \#5) to 2.5 (Intern \#2). A total of 38 self-assessment rationale statements were expressed, 19 positive and 19 negative. Instructional techniques were the most frequent focus ( 20 ), and both self-adequacy and $\mathrm{classroom}$ management were the lowest reported rationale (4).

\section{Presentation of Data Analyzed by Intern}

Intern \#1. The average self-assessment rating for Intern \#1 was 1.8 , with a range of 1.5 reported in January and March, to 2.3, reported in May. Intern \#1 expressed a total of 41 rationale statements related to the numerical ratings, with 18 (highest amount) in January and 5 (lowest amount) in April and May. Thiry-two of these statements were positive, and 9 were negative. Of the 41 rationale statements, 16 focused on instructional techniques, 21 on student learning behavior, 3 on self-adequacy, and 1 on classroom management. 
Intern \#2. The average for self-assessment rating of teaching for Intern \#2 was 2.5. This wa. the lowest averaged rating for this group of interns. The range of ratings was from 2.0 in April to 3.4 in March. The 3.4 rating was the lowest monthly rating an intern reported in this study. Intern \#2 reported 48 rationale statements about her assessment of her teaching. Twenty statements expressed positive comments, and 28 were negative. Twenty rationale statements were based on instructional techniques, 11 on student learning behavior, 12 on self-adequacy and 6 on classroom management. This intern expressed self-adequacy as a basis for rationale of self-assessment ratings on her teaching more frequently than the other interns in this group.

Intern \#3. The average for the 5 months of selfassessment ratings on teaching for this intern was 1.8. The range was from 1.3 in May to 2.3 in January and April. The rating of 1.3 was the highest assessment rating an intern gave their teaching. A total of 39 rationale statements were expressed. Twenty-three were positive, and 16 had a negative focus. Twenty of the self-assessment statements were about instructional techniques, 6 about student learning behavior, 6 about self-adequacy, and 7 about classroom management.

Intern \#4. Intern \#4 averaged 2.0 in the selfassessment rating over the 5 month period. The range was 
from 1.5 in May to 2.3 in February and April. Of the 28 reported statements reflecting the rationale for the self-assessment of teaching ratings, 11 were positive, and 17 were negative. Seventeen were centered on instructional techniques, 6 on student learning behavior, 5 on self-adequacy, and 0 on classroom management. The lowest number of rationale statements based on the area of classroom management was 0 in this study.

Intern \#5. The average of the self-assessment ratings on teaching for Intern \#5 was 1.7 , which was the highest average rating in this group of interns. The range was from 1.3 in April and May (the highest monthly average) to 2.3 in January. Forty-four statements were expressed reflecting the rationale for the ratings. Of these, 22 were positive and 22 were negative. Intern \#5 based the self-assessment on instructional techniques with 25 rationale statements, 7 statements about student learning behavior, 8 about self-adequacy, and 4 were focused on classroom management. Intern \#6. Intern \#6 averaged 2.2 on the selfassessment of teaching ratings over te 5 month period. The range was from 1.8 in April and May to 2.9 in January. A total of 35 rationale statements were expressed, with 16 positive, and 19 found to be negative. Sixteen of the 35 rationale statements were related to instructional techniques, 12 about student learning behavior, 4 about self-adequacy, and 3 focused on classroom management. 
Discussion of Findings

Intreduction. The monthly average of the selfassessment of teaching rating ranged from 2.2 in January to 1.8 in May, with an overall average of 2.0. Except for the month of March, a steady incline occurred in the interns' rating of their teaching. A possible explanation for the slight decline in the average rating in March may be due to the timeline of CPEP activities. All of the interns in this sample were teaching full-time in March, and the demands and realities of teaching full-time may have resulted in lower self- assessment ratings. When an intern is teaching for part of a day, the intern has more time to prepare for each lesson, and returns the responsibility for students to the support teacher after teaching for a portion of the day. In contrast, when teaching full-time, the demands on time and energy increase, and the realities of the work load become apparent. The support teacher has moved out of the role as "the" person in charge of the classroom, and interns have assumed the responsibilities for planning and instruction. Success in teaching one or two lessons a day is far different from successfully teaching an entire day or week of teaching. Therefore, in March, when the interns were teaching full-time, their self-assessment ratings of their teaching dropped slightly, perhaps indicating their Involvement in the reality of the demands and responsibllities of full-time teaching. 
Another factor that may have influenced the lower ratings in March was the reported fatigue of the interns. Interns commented about the time and energy full-time teaching required, and how exhausted they felt. Feeling tired and "run-down" may have influenced their self-assessment ratings negatively. An additional factor that may have caused interns to rate their teaching lower in March may be found in the increased number of lessons interns were teaching. With an increase in the number of lessons interns were responsible for, there was more opportunity for interns to find parts of lessons that need improvement.

There were more negative rationale statements in March than in any other month. Of the 53 total statements, 18 were positive, and 34 were negative. All 4 categories contained more negative than positive statements. Interns were expressing negative comments, as well as lower ratings during their full-time teaching period. The realities and demands of day-to-day teaching were revealed through the lower ratings and increased negative comments about their teaching in March.

The overall increase from 2.2 in January to 1.8 in May indicates the interns' gain in satisfaction of their teaching over the 5 month period. The interns were continually gaining experience and education about teaching, as well as receiving feedback about their teaching from 
their supervisor, support teacher, and administrator. The length of the field experience ( 10 months) allowed interns extensive opportunity to practice while "learning-to-teach." The longer period of $t$ ime in a fleld experience may have enabled interns to assess their progress in teaching, seeing changes in their instruction from September to June. An additional factor that may have contributed to an increase in the self-assessment rating of teaching may be found in the content of the small group seminar sessions. This was a time for interns to reflect upon their teaching progress and discuss this with other interns and their supervisor. A non-threatening environment had been established, and both successes and failures in the classroom were openly discussed. These discussions provided an opportunity for interns to listen and learn about other interns' teaching, as well as express their personal thoughts about their own teaching. The process of reflection and discussion produced feedback useful in improving teaching, which may have contributed to the increase in ratings for self-assessment of teaching.

In looking at the average ratings of all interns over the 5 month period, the lowest rating occurred in March, by Intern \#2. The 3.4 rating reflected this intern's self-assessment during the full-time teaching period. All of her raticnale statements were negative in March, including 5 self-adequacy comments. This was the highest 
amount of self-adequacy statements reported by any lntern during 1 month. Intern \#2 stated, "This is one of my most common mistakes-not giving enough background and asssuming the kids know more than they do." The intern was concerned with her instructional techniques, and prefaced this comment with a personal qualification. In contrast, the highest ratings (1.3) occurred in the later months of April and May. Three ratings of 1.3 were reported, with 1 intern (\#5) reporting 1.3 in April and again in May. Although these interns gave themself a high rating numerically, there were both positive and negative statements in their rationale comments. Perhaps, these interns had made improvements in their teaching, yet still saw a need for further improvement. For example, an instructional technique comment made in May by Intern \#5 stated, "I was satisfied with most of my lesson, but I would change how long I did certain aspects of the lesson." Intern \#3 had a self-assessment rating of 1.3 also and reported the following student learning behavior about a lesson, "I was able to get the students really focused and involved." The rationale statements (the answers to "why?" on the self-assessment forms) provided a basis for the interns' rating decisions. In January, more statements were reported than in other months. As January was the first month of the study and interns had not completed this form before, they may have had more rationale statements to express. There 
was a decrease in the number of statements made monthly, except for March. In February, there were 40 rationale statements expressed, with a jump to 52 in March, then a decline to 39 in April and 38 in May. The increase in March may again be related to the timeline, with interns engaged in full-time teaching in March. Interns had "more" teaching to base their assessments on, and may have had more need to express their rationale, increasing the number of responses in March. The decrease of statements made each month from the January to May period may have occurred due to familiarity with the form, and the interns had thought out their rationale for the rating before completing the form. Of the 237 rationale statements, 121 were positive, and 116 were negative. More rationale statements were expressed about instructional techniques than other teaching areas, with 113 statements out of 237 total. Of these, 58 were positive, and 55 were negative. Interns based instructional technique rationale on positive and negative reasons almost equally. CPEP seminars had focused on instructional techniques during several sessions, and the support teachers were also giving the interns information in this area. Instructional techniques are observable, and through seminars, interns had developed a vocabulary to use in discussing these techiques. For example, an intern stated, "I had smooth transitions and the closure went well." The intern had learned the terms "transitions" and "closure" in 
relation to lesson design and instruction, and was able to use this information and behavior to assess her teaching. In implementing a change, a person must first be aware of a behavior and a perception of that behavior (Hartman, 1978). Having a vocabulary and a clear understanding of instructional techniques presented by the support teacher and seminars may have facilitated this awareness and vocabulary with the interns, and may have increased their focus on instructional techniques. The interns had developed a repertoire of effective teaching strategies and were able to measure their personal instructional techniques to this standard.

A total of 66 rationale statements were expressed about student learning behavior, 45 positive and 21 negative. Interns were assessing their teaching on the basis of student learning behavior with over twice as many positive comments than negative about student learning behavior. Perhaps, the Immediate feedback provided by the students was reinforcing to interns, and as a constantly available source of feedback, was depended upon by interns in their self-assessments. Interns could glance around the classroom and observe a student looking like they were enjoying or partlcipating in the lesson, and use this observation as a basis for deciding they had a successful lesson. Examples of positive statements were, "Kids participated and enjoyed making their own books" or "Kids were coming up with lots of 
ldeas during brainstorming." A negatlve statement expressed, "In their present state of mind the students were unable to understand the circumstances I presented them." CPEP seminars had presented information about the relationship between instruction and student learning behavior; thus, interns were aware of the importance of students' participating and working "on-task" during lessons.

Interns expressed a total of 37 rationale statements about self-adequacy: 12 were positive, and 25 were negative, resulting in over twice as many negative comments than positive. Interns were reporting perceptions of themselves and their adequacy in relation to teaching. As they were "learning-to-teach", self doubt and questioning their ability to be successful in this situation arose, and more often with a negative focus. Learning the "ropes" in any new job situation is stressful, including "learning-toteach" in the field experience. Interns are constantly on "display", observed by students, teachers, supervisors, support teachers, and administrators. One intern concluded her self-assessment form with, "I don't know if I can do this job!"

The category with the least amount of rationale statements reported was classroom management, with 21 out of 237 reported statements. Of the 21 statements, 6 were positive ("The lesson went well because of management"), and 
15 were negative ("Classroom management and keeplng them quiet is st 11 the main, underlying problem"). There were over twice as many negative as positive comments about classroom management. Although the literature (Ryan, et al., 1980) finds beginning teachers concerned with classroom management, this group of interns seldom assessed their teaching on the basis of classroom management. A possible explanation might be found in the curriculum in CPEP seminars and feedback from the support teacher and the supervisor. Interns had been presented with classroom management principles and techniques during the school year, both in seminars and in their classrooms. Interns received feedback from their support team about their classroom management and had worked with their classroom management techniques in several classes. The extended period of time in the field experience may also have contributed to fewer statements about classroom management, as CPEP interns had more time to practice classroom management and become more competent in this area. Perhaps, the combination of education and experience in classroom management resulted in raising interns' effectiveness while lowering their concerns in this area.

\section{Discussion of Findings by Month}

January. The average self-assessment rating for January was 2.2 , which was the lowest monthly rating during 
the study. A rating of 2.0 relects a satisfactory lesson, therefore, interns reported that they were satisfied with their teaching, and would make few changes if they presented the same lesson again. Interns based their self-assessment of teaching ratings mainly on instructional techniques and student learning behavior. Of the 68 statements of rationale expressed in January, 26 were about instructional techniques, 22 about student learning behavior, 13 about self-adequacy, and 7 about classroom management. More of these statements were positive than negative. A possible reason for the satisfactory rating in January may be attributed to the length of time interns had already been a "part" of their classroom before this study commenced. Interns began the school year in August with this class and had gradually increased their amount of teaching responsiblity. Interns were now teaching a minimum of several lessons each week. If self-assessment ratings had been reported earlier in the school year, perhaps lower ratings would have occurred in the first months of the study.

Of the 26 instructional techniques listed as rationale statements, 15 were positive ("The small group discussions went very well"), and 11 were negative ("I should make some changes in the pacing of the lesson"). Again, the use of vocabulary that had been presented in seminars was prevalent in these statements. The vocabulary provided a basis for 
expressing comments that contained specific information relating to what components were satisfactory in a lesson or what needed improvement.

Of the 22 rationale statements reporting student learning behavior as a focus for the rating, 15 were positive ("The students were enthusiastic and participated throughout the lesson"), and 7 were negative ("Kids were not tuned-in to the lesson"). Interns relied upon their "reading" of the student learning behavior as an indicator for effectiveness of their teaching more frequently in January than in other months. Interns had not had extensive teaching experience by January and relied on their impressions of students' involvement and interest in lessons as indicators of success in teaching. Several seminar sessions in the fall had focused on actively involving students in learning. Perhaps, interns were using concepts of student learning as measures of success in teaching. In January, interns expressed rationale statements based on self-adequacy 13 times. Of the 13 statements, 6 were positive ("I felt confident about my reading lesson and spelling today"), and 7 were negative ("I was just not prepared to teach this lesson today"). January and March were the months when self-adequacy statements were most frequent. In January, interns were teaching several lessons each week, progressing to teaching several lessons each day. The teaching experience is new, and the interns' thoughts 
about their teaching ability and self-adequacy may have been intertwined with their personal measures of successful teaching.

Classroom management was reported as a basis for self-assessment of teaching 7 times in January. There were 2 positive comments ("Lesson went smoothly in student behavior"), and 5 negative ("I would change some management techniques"). The comments interns made about classroom management were general and did not give specific details about elements of the management techniques or behaviors. Possibly, interns were thinking of classroom management in global terms and not focusing on specific elements.

Eebruary. In February, the average self-assessment rating increased to 2.0 for the 6 interns. The interns reported that their instruction was satisfactory in February, and they would make minimal changes if they presented the same lesson again. Forty statements were expressed as rationale for the numerical rating. Twenty-two were positive, and 18 were negative comments. As in all months, instructional techniques were reported most frequently as rationale for the numerical rating. In February, instructional technique comments were expressed 24 times, with 13 positive ("I combined cognitive and affective aspects, the combination worked well"), and 11 negative ("I think I would re-think the kinds of activities I planned"). This was the highest proportion of reporting instructional 
techniques as the rationale for self-assessment durlng the 5 month period. The reason for the higher proportion of instructional technique comments may be related to the timeline, as interns were working on improving their Instruction before beginning to teach full-time in March. In addition, interns were increasing the amount of time they taught each day, along with Increasing their repertiore of instructional techniques.

During February, 8 rationale statements were expressed about student learning behavior. This was the lowest frequency during the 5 month period. This may be related to the higher number of comments focused on instructional techniques this month, drawing some of the emphasis from other categorles. Also, interns may have discovered that "how students look" may not be an accurate indicator of how much they are learning. Seven of the 8 statements were positive ("Children really seemed to enjoy the challenge of attacking a difficult lesson"), and 1 was negative ("the kids are so tired and not interested in this kind of a lesson at the end of the day").

Comments about self-adequacy as the rationale for self-assessment of teaching decreased during February. Possibly, this is not an area where interns can see immediate improvement, or receive direct feedback and see results in their instruction. Also, interns had gained more experience teaching part-time in the class, and may have 
fele more confident about their instruction now. Two rationale statements were positive ("I was very happy with my reading session"), and 4 were negative ("I hadn't thought in advance of some of the questions and problems the students might have so the lesson didn't go smoothly").

Two comments reflected interns' rationale about classroom management. Both of these were negative comments ("A more structured approach with the students might have been more effective"). There were no changes in the content of the rationale statements since January.

March. The average self-assessment rating on teaching declined slightly in March, to 2.1. This is the month when interns began to teach full-time, and, perhaps, experienced anxiety about assuming total responsibility for all aspects of teaching. The range was from 1.5 to 3.4 , which was the widest spread of ratings during the 5 month period. Perhaps, the onset of full-time teaching influenced some of the interns and their ratings more than others. One low rating of 3.4 significantly decreased the average rating. As this rating tended to be individual more than a group movement, this information will be discussed within the discussion of findings for each intern.

Fifty-two statements of rationale for the ratings were expressed during March. This was an increase from February, and may be related to the timeline of full-time teaching in March. Eighteen statements were positive, and 34 were 
negative. This was the only month were most of the rationale statements were negative. This may be related to the onset of full-time teaching, and the interns acute awareness of their teaching. The support team was observing and giving feedback to interns often during this month, and interns were actively working on improving their teaching. Due to the amount of feedback and suggestions offered to improve the interns' instruction, interns may have also become more aware of the assessment process and may have increased the number of their self-assessment comments during full-time teaching.

The most frequently expressed rationale statements were about instructional techniques. Of the 22 instructional techniques reported, 9 were positive "After evaluating each part of my lesson, I feel it went well and I don't know what I would change"), and 13 were negative ("I would work more on timing and keep the lesson moving at a faster pace"). Looking at the timeline of CPEP finds interns teaching full-time this month, which may have increased their self-critisism and negative rationale statements. Interns were teaching more lessons, which created more opportunities for something to "go wrong" during their teaching. Planning and teaching for an entire day or week opens up more possible situations where improvement in instructional techniques might be necessary. 
Of the 14 Eationale statements using student learning behavior as a basis for self-assessment of teaching, 6 were positive ("Kids were working well"), and 8 were negative ("Kids' attention wandered quite easily"). Again, more negative comments were expressed, which is possibly related to the increased time interns were teaching. Keeping students' attention for an entire day or week, versus students paying attention for a 30 minute lesson created a different teaching situation to assess. Interns seemed to be aware of the students and their reactions and behavior related to instruction. The comments expressed included both general and specific recommendations and statements. Interns reported rationale statements about their self-adequacy 10 times in March. Of these 1 was positive ("I felt very comfortable with the material"), and 9 were negative ("I tried to teach pronouns today"). This was the highest number of negative self-adequacy statements expressed during the study. All interns were teaching full-time now, and were responsible for every aspect of instruction. There were numerous demands on interns, creating pressures and stress. Under increased stress, interns may have become more concerned with their self-adequacy and reported these concerns in their self-assessments.

Classroom management statements were expressed at a higher proportion in March than in any other month. Two 
were positive ("Good classroom management") and 4 were negative ("Management of student behavior could have been approached differently"). Because interns were now responsible for the classroom management during March, they were possibly more aware and critical of this teaching area at this time.

April. The average self-assessment rating during April was 1.9. As a group, interns were increasing their ratings, and expressing more satisfaction with their instruction. There were 38 rationale statements reported, with 22 positive and 17 negative. Both the rating and the number of positive statements increased in April, possibly an indication of interns' thoughts and feelings about successfully completing full-time teaching. After preparing for and completing a major requirement of the field experience, interns may have felt more successful, and expressed this in their ratings and rationale statements.

The most frequent category interns based their self-assessment on continued to be instructional techniques. of the 21 rationale statements expressed about instructional techniques, 13 were positive ("Lesson was well planned and organized"), and 8 were negative ("The flashcards I used were not good"). Interns were reporting more positive rationale statements now, perhaps, due to "surviving" and succeeding the full-time teaching experience. 
Twelve rationale statements dlscussed student learning behavior, with 8 positive " Kids participated through the math lesson") and 4 negative ("Students did not care for the movie"). Again, interns used observations of students" learning behaviors as a tool in assessing their instruction. Perhaps, the continual and immediate feedback provided by students assisted interns in determining their selfassessment.

Four comments were reported about self-adequacy as a rationale for the self-assessment rating in April. One was positive ("My visualization in the music lesson went even better than I had expected") and 3 negative ("The circumstances were beyond my control"). The number of statements in this category declined from the preceding 3 months, indicating interns were basing their self-assessment more on instructional techniques and student learning behavior. Also, as interns gained more experience in "learning-to-teach", they may have become more self-confident and had fewer concerns about self-adequacy. of the 2 rationale statements based on classroom management, none ( 0 ) were positive and 2 were negative. There was no significant change noted in the content of rationale, and the frequency decreased slightiy from the previous months.

May. The average self-assessment rating increased to 1.8 in May. The group of interns tended to rate their 
teaching slightly hlgher each month durling the study. Length of time in the field experience, as well as gaining more success in teaching may have influenced the interns in their self-assessment ratings. Interns had now completed 9 months in the classroom and their full-time teaching requirement. As this was an extended field experience, interns may have been able to see progress in their teaching, and possibly expressed this in their self-assessments. Thirty-eight rationale statements were expressed, with 19 positive and 19 negative. Interns continued to make both positive and negative statements about their teaching during the study, perhaps, indicating their awareness of the Importance of feedback in improving their teaching.

Again, instructional techniques were the basis for most of the self-assessment comments. Eight of these were positive ("I had an effective set and closure") and 12 were negative ("I would have perfected the wording of my questions during discussion"). May and March were the only months when more negative than positive were reported about instructional techniques. Perhaps, as interns were approaching the end of the field experience, they were scrutinizing their teaching, attempting to find "pieces" that could be improved. Most interns were teaching part-time and may have spent more time reflecting on their 
teaching in an attempt to íind specíic areas for improvement.

Ten rationale statements were based on student learning behavior. Seven were positive "The kids were fully focused and involved"), and 3 were negative ("Students did not apply the scenarios to personal life situations"). The frequency of using student learning behavior as a rationale for self-assessment remained fairly constant during the last 4 months of the study. Therefore, interns used their interpretations of student learning behavior during their instruction as one basis for self-assessment. Interns' attention was focused on students, and they noticed students' actions and responses while teaching. Several seminar sessions included "monitoring students' learning", and interns had been involved in learning techniques to use in monitoring. Perhaps, they applied this information from seminar into their classroom teaching, and consequently. reported student learning behavior as rationale for self-assessment.

Self-adequacy comments were reported as rationale for self-assessment of teaching 4 times during May. Two were positive ("I was able to get the students involved today"), and 2 were negative ("I am still feeling my management of the research projects is poor. I have asked for advice"). When interns reported negative self-adequacy rationale statements, they were aware of the instructional areas that 
needed lmprovement, and how to work for improvement. The frequency of using self-adequacy as a rationale for rating teaching declined in the last two months of the study. A possible explanation may be interns were now looking for feedback about their teaching in instructional techniques and student learning behavior. Because of their successful experiences in teaching, they had gained self-confidence in relation to their instruction and were not as concerned about self-adequacy now.

In May, the established trend of classroom management used least frequently as rationale for rating interns' teaching remained consistent. Four of the 38 rationale statements expressed classroom management information. Of these, 2 were positive ("When the students are working individually and I want to control bodies and keep kids on task I am going to keep them in the classroom and have a waiting list for frequently needed resources"), and 2 were negative ("I still don't have a reliable strategy for (classroom management"). No significant changes were found in this category during May.

\section{Discussion of Data by Intern}

Intern \#1. The average of this intern's self assessment of teaching was 1.8 (see Table VI). The highest rating occurred early in the study, and lowest rating was in the last month. The intern gained more experience in 
TABLE VI

SELF-ASSESSMENT PROF ILE OF INTERN औ

\begin{tabular}{|c|c|c|c|c|c|c|c|c|c|c|c|c|c|c|c|c|}
\hline \multirow[t]{2}{*}{ Month } & \multirow{2}{*}{$\begin{array}{l}\text { Rating } \\
\text { Average }\end{array}$} & \multicolumn{3}{|c|}{$\begin{array}{c}\text { Instructional } \\
\text { Techniques }\end{array}$} & \multicolumn{3}{|c|}{$\begin{array}{l}\text { Student } \\
\text { Learning } \\
\text { Behavior }\end{array}$} & \multicolumn{3}{|c|}{$\begin{array}{c}\text { Self- } \\
\text { Adequacy }\end{array}$} & \multicolumn{3}{|c|}{$\begin{array}{l}\text { Classroom } \\
\text { Management }\end{array}$} & \multicolumn{3}{|c|}{ Total } \\
\hline & & Total & + & - & Total & + & - & Total & + & - & Total & + & - & Total & + & - \\
\hline Jan. & 1.5 & 4 & 4 & 0 & 10 & 9 & 1 & 3 & 3 & 0 & 1 & 0 & 1 & 18 & 16 & 2 \\
\hline Feb. & 2.0 & 4 & 3 & 1 & 3 & 3 & 0 & 0 & 0 & 0 & 0 & 0 & 0 & 7 & 6 & 1 \\
\hline Mar. & 1.5 & 2 & 0 & 2 & 4 & 3 & 1 & 0 & 0 & 0 & 0 & 0 & 0 & 6 & 3 & 3 \\
\hline April & 1.6 & 3 & 1 & 2 & 2 & 2 & 0 & 0 & 0 & 0 & 0 & 0 & 0 & 5 & 3 & 2 \\
\hline May & 2.3 & 3 & 1 & 2 & 2 & 1 & 1 & 0 & 0 & 0 & 0 & 0 & o & 5 & 2 & 3 \\
\hline TOTAL & 1.8 & 16 & 9 & 7 & 21 & 18 & 3 & 3 & 3 & 0 & 1 & 0 & 1 & 41 & 32 & 9 \\
\hline
\end{tabular}

$+=$ positive rationale

- = negative rationale 
teaching and received more feedback from others about her teaching as she progressed through the field experience. This may have influenced her in becoming more realistic and, perhaps, more accurate in her self-assessment ratings, as well as more aware of "what" constitutes effective instruction. In January, over half of her rationale statements focused on student learning behavior. She was assessing her teaching according to student involvement and student enjoyment of lessons. In contrast, during May most of the rationale statements were about instructional techniques, demonstrating a shift in the basis for her self-assessment. Perhaps, Intern \#1 discovered the value and relationship of effective instructional techniques in students' learning. While student involvement and enjoyment of lessons is important, student learning is not dependant upon this criteria. These factors may have caused this intern to shift the focus to instructional techniques and assess her teaching more critically at the end of the study. During the 5 months, Intern \#1 expressed 41 rationale statement about her self-assessment of teaching. Thirty-two were positive, and 9 were negative. The rationale statements were more positive in January and February than in the later 3 months. In May, she reported 2 positive and 3 negative comments about her teaching. This finding again supports the possibility that interns moved toward more 
realistic and accurate self-assessments later in the field experjence.

In January, Intern \#1 reported 4 statements about instructional techniques as rationale for self-assessment, and all 4 were positive. An example of an early statement expressed about instructional techniques was, "The lesson itself went $0 . K$., the kids had to cooperate to solve the brainstorming problems." In May, this intern reported more negative than postive comments about instructional techniques, stating, "I should have allotted more time for discussing the calendar and student's drawing." She became more critical of her instruction while offering specific suggestions for improvement.

The category of student learning behavior was most frequently cited as rationale for self-assessment. In January, she reported 10 of the 18 comments in the category of student learning behavior. This intern was relying on feedback from the students' behavior as an indicator of her success in teaching, particulary in the earlier months. In the later months of April and May, less than half of her comments were about student learning behavior, as the focus of her self-assessment rationale shlfted to instructional techniques. On the 21 student learning behavior comments, 18 were positive ("Kids were enthusiastic in this lesson"), and 3 were negative ("I could sense boredom during the lesson"). A possible explanation for the high number of 
positive statments might be that thls Intern was looklng for students that appeared interested or enthusiastic about the lesson and then developed her self-assessment from these selected behaviors.

Intern \#1 expressed few rationale statements about self-adequacy or classroom management. There was little to discuss in this area, except that Intern \#1 relied infrequently upon self-adequacy or classroom management as self-assessment rationale.

Intern \#2. Intern \#2 reported the lowest average self-assessment ratings during the study at 2.5 (see Table VII). The highest rating this intern reported was 2.0 , which was lowest of all interns' highest ratings. The lowest rating was 3.4 , which was the lowest rating reported during the study. The lowest rating occurred in March, when the intern began teaching full-time. In this same month the intern reported 14 negative comments about self-assessment of teaching and no positive comments. The lower ratings tended to occur during the month when an increase in the frequency of reporting negative statements occurred. Therefore, the rating reflected the self-assessment rationale statements of this intern. In contrast, during April, when the highest rating of 2.0 was reported, the intern reported 9 positve statements and 2 negative, again supporting the finding of a relationship between content of rationale statements and the numerical rating of intern's 
TABLE VII

SELF-ASSESSMENT PROF ILE OF INTERN $\$ 2$

\begin{tabular}{|c|c|c|c|c|c|c|c|c|c|c|c|c|c|c|c|c|}
\hline \multirow[t]{2}{*}{ Month } & \multirow{2}{*}{$\begin{array}{l}\text { Rating } \\
\text { Average }\end{array}$} & \multicolumn{3}{|c|}{$\begin{array}{c}\text { Instructlonal } \\
\text { Techniques }\end{array}$} & \multicolumn{3}{|c|}{$\begin{array}{l}\text { Student } \\
\text { Learning } \\
\text { Behavior }\end{array}$} & \multicolumn{3}{|c|}{$\begin{array}{c}\text { Self- } \\
\text { Adequacy }\end{array}$} & \multicolumn{3}{|c|}{$\begin{array}{l}\text { Classroom } \\
\text { Management }\end{array}$} & \multicolumn{3}{|c|}{ Total } \\
\hline & & Total & + & - & Total & + & - & Total & + & - & Total & + & - & Total & + & - \\
\hline Jan. & 2.3 & 3 & 2 & 1 & 4 & 4 & 0 & 2 & 1 & 1 & 0 & 0 & 0 & 9 & 7 & 2 \\
\hline Feb. & 2.3 & 3 & 2 & 1 & 0 & 0 & 0 & 2 & 1 & 1 & 1 & 0 & 1 & 6 & 3 & 3 \\
\hline Mar. & 3.4 & 5 & $\mathbf{0}$ & 5 & 3 & 0 & 3 & 5 & 0 & 5 & 1 & 0 & 1 & 14 & 0 & 14 \\
\hline Apr 11 & 2.0 & 6 & 5 & 1 & 4 & 3 & 1 & 1 & 1 & 0 & 0 & 0 & 0 & 11 & 9 & 2 \\
\hline May & 2.5 & 2 & 0 & 2 & 0 & 0 & 0 & 2 & 0 & 2 & 4 & 2 & 2 & 8 & 2 & 6 \\
\hline TOTAL & 2.5 & 19 & 9 & 10 & 11 & 7 & 4 & 12 & 3 & 9 & 6 & 2 & 4 & 48 & 20 & 38 \\
\hline
\end{tabular}

$+=$ positive rationale

- = negative rationale 
teaching. Whlle this intern was self-critical and noted many areas where changes would improve a lesson, through participant observation the investigator observed satisfactory and above satisfactory teaching by Intern \#2. Perhaps, the lower rating reflected a personal trait of this intern toward self-criticism, as well as the personal behavior of searching for specific changes that would improve future instruction.

A total of 48 rationale statements were expressed, with 20 positive and 28 negative. The most frequently reported rationale comments were about instructional techniques. Nine were positive ("I taught an aerobics class which covered all the basicg I intended"), and 10 were negative ("I should have given them a minimum expectation for each (ategory"). The comments contained specific information related to instruction, and noted what components made a lesson successful or not successful.

Student learning behavior was the basis for rationale of self-assessment from 11 statements: 7 were positive ("The kids did not have trouble thinking up things to $d r a w ")$, and 4 were negative ("In their present state of mind, students are unable to understand the information"). This was the only category where the intern reported more positive than negative statements, perhaps, relying upon student learning behavior for more positive feedback about teaching. 
Rationale statements focused on seli-adequacy were more frequently reported by Intern \#2 than any other intern. Personal feelings of self-adequacy in teaching may have influenced the intern's self-assessment ratings, resulting in lower numerical ratings. Of the total 12 self-adequacy statements, 3 were positive ("I am satisfied with what I did"), and 9 were negative ("I must remember there are more things to consider than just academics, I made a big mistake"). When Intern \#2 discussed possible lesson changes, comments about the intern's personal involvement were included often, which increased the number of self-adequacy rationale statements. Also, an individual trait of Intern \#2 was self-reflection, which included expressing thoughts about her confidence and ability to teach. Possibly, due to these individual traits, Intern \#2 reported more rationale statements about self-adequacy.

Of the 48 total rationale statements expressed by Intern \#2, 6 focused on classroom management. Two were positive ("To keep the kids busy I had them come up one at a time and play an instrument"), and 4 were negative ("Our kids were totally distracted all day"). Classroom management as a rationale for self-assessment was used infrequently by Intern \#2, which was a consistent finding for the entire group of interns.

Intern \#3. The average self-assessment rating for Intern \#3 was 1.8 (see Table VIII). The highest rating 
TABLE VIII

SELF-ASSESSMENT PROF ILE OF INTERH

\begin{tabular}{|c|c|c|c|c|c|c|c|c|c|c|c|c|c|c|c|c|}
\hline \multirow[t]{2}{*}{ Month } & \multirow{2}{*}{$\begin{array}{l}\text { Rating } \\
\text { Average }\end{array}$} & \multicolumn{3}{|c|}{$\begin{array}{c}\text { Instructional } \\
\text { Techniques }\end{array}$} & \multicolumn{3}{|c|}{$\begin{array}{l}\text { Student } \\
\text { Learning } \\
\text { Behavior }\end{array}$} & \multicolumn{3}{|c|}{$\begin{array}{c}\text { Self- } \\
\text { Adequacy }\end{array}$} & \multicolumn{3}{|c|}{$\begin{array}{l}\mathrm{Cl} \text { assroom } \\
\text { Management }\end{array}$} & \multicolumn{3}{|c|}{ Total } \\
\hline & & Total & + & - & Total & + & - & Total & + & - & Total & + & - & Total & + & - \\
\hline Jan. & 2.3 & 6 & 2 & 4 & 3 & 3 & 0 & 1 & 0 & 1 & 1 & 1 & 0 & 11 & 6 & 5 \\
\hline Feb. & 1.5 & 3 & 2 & 1 & 0 & 0 & 0 & 0 & 0 & 0 & 1 & 0 & 1 & 4 & 2 & 2 \\
\hline Mar. & 1.6 & 5 & 4 & 1 & $\mathbf{0}$ & 0 & 0 & 2 & 1 & 1 & 3 & 1 & 2 & 10 & 6 & 4 \\
\hline Apr 11 & 2.3 & 4 & 3 & 1 & 0 & 0 & 0 & 1 & 0 & 1 & 2 & 0 & 2 & 7 & 3 & 4 \\
\hline May & 1.3 & 2 & 1 & 1 & 3 & 3 & 0 & 2 & 2 & 0 & 0 & 0 & 0 & 7 & 6 & 1 \\
\hline TOTAL & 1.8 & 20 & 12 & 8 & 6 & 6 & 0 & 6 & 3 & 3 & 7 & 2 & 5 & 39 & 23 & 16 \\
\hline
\end{tabular}

$+=$ positive rationale

- = negative ratlonale 
occurred in May, along with the highest proportion (5 out of 7) of positive rationale statements reported. The repeated incidence of higher numerical ratings occurring during months when higher proportion of positive rationale statements are reported supports the finding of a relationship between the content of the rationale statements and the self-assessment rating. A total of 39 rationale statements were expressed during the 5 month period, with 23 positive and 16 negative, resulting in more positive than negative comments reported by Intern \#3. Over half of the rationale statements were focused on instructional techniques, with 12 positive ("Planning was thorough and lesson went well"), and 8 negative ("I could have shortened the discussion to make more time for experiments"). The rationale comments reflected direction for the intern to use in improving instruction.

A total of 6 comments were expressed using student learning behavior as rationale for self-assessment. All 6 were positive and clearly described the students' behavior ("The students experimented with the science equipment and discovered some properties of magnetism"). A possible explanation for the high proportion of positive comments may be found in the personal character of Intern \#3. This intern expressed strong desires to succeed in the field experience to others during seminars. This desire may have influenced the intern to seek out and notice the positive 
student learning behavior in order to reiniorce successes in instruction.

Of the 6 rationale statements reported about self-adequacy, 3 were positive ("I was able to get the lesson finished"), and 3 were negative ("I felt unsure of some parts of today's lesson"). With limited statements about self-adequacy and and equal division of positive and negative comments, there are no significant findings noted in this area.

Intern \#3 expressed 7 rationale statements about classroom management during the 5 months. Two of the classroom management statements were positive ("The lesson went smoothly in student behavior"), and 5 were negative ("I would change how I dealt with some student behaviors"). Of the 7 statements, 3 were reported in March, when the intern began to teach full-time, indicating classroom management was more of a focus during March than other months. During May, there were no statements reported about classroom management, and this was when Intern \#3 was completing full-time teaching. Perhaps, the intern was satisfied with classroom management techniques and was now more concerned about other areas of instruction.

Intern \#4. The average of the self-assessment of teaching by Intern \#4 was 2.0 (see Table IX). This intern began full-time teaching late in March, although she had taught several lessons each day beginning in January. The 
TABLE IX

SELF-ASSESSMENT PROF ILE OF INTERN $\$$

\begin{tabular}{|c|c|c|c|c|c|c|c|c|c|c|c|c|c|c|c|c|}
\hline \multirow[t]{2}{*}{ Month } & \multirow{2}{*}{$\begin{array}{l}\text { Rating } \\
\text { Average }\end{array}$} & \multicolumn{3}{|c|}{$\begin{array}{c}\text { Instructional } \\
\text { Techniques }\end{array}$} & \multicolumn{3}{|c|}{$\begin{array}{l}\text { Student } \\
\text { Learning } \\
\text { Behavior }\end{array}$} & \multicolumn{3}{|c|}{$\begin{array}{c}\text { Self- } \\
\text { Adequacy }\end{array}$} & \multicolumn{3}{|c|}{$\begin{array}{l}\text { Classroom } \\
\text { Management }\end{array}$} & \multicolumn{3}{|c|}{ Total } \\
\hline & & Total & + & - & Total & + & - & Total & + & - & Total & + & - & Total & + & - \\
\hline Jan. & 2.0 & 4 & 3 & 1 & 2 & 1 & 1 & 0 & 0 & 0 & 0 & 0 & 0 & 6 & 4 & 2 \\
\hline Feb. & 2.3 & 5 & 2 & 3 & 2 & 2 & 0 & 2 & 0 & 2 & 0 & 0 & 0 & 9 & 4 & 5 \\
\hline Mar. & 1.8 & 3 & 0 & 3 & 1 & 0 & 1 & 0 & 0 & 0 & 1 & 0 & 1 & 5 & 0 & 5 \\
\hline Apr 11 & 2.3 & 1 & 0 & 1 & 1 & 1 & 0 & 2 & 0 & 2 & 0 & 0 & 0 & 4 & 1 & 3 \\
\hline May & 1.5 & 4 & 2 & 2 & 0 & 0 & 0 & $\mathbf{0}$ & 0 & 0 & 0 & 0 & 0 & 4 & 2 & 2 \\
\hline TOTAL & 2.0 & 17 & 7 & 10 & 6 & 4 & 2 & 4 & 0 & 4 & 1 & 0 & 1 & 28 & 11 & 17 \\
\hline
\end{tabular}

$+=$ positive rationale

- = negative rationale 
highest self-assessment ratlng occurred in May, when the intern was spending the majority of tlme observing in other classrooms and teaching infrequently. Also, as this intern had completed full-time teaching and gained teaching experience, this may have been reflected in the selfassessment.

Twenty-eight rationale statements were expressed by Intern \#4, 11 were positive, and 17 were negative. In March and May, when the highest ratings were recorded, Intern \#4 reported the highest proportion of negative statements. The finding of more frequent positive statements related to higher ratings did not continue with this intern. Possibly, the intern was basing the numerical rating on more information than reported in the rationale statements. Instructional technique comments were the most frequently reported rationale for self-assessment. Several seminar sessions had presented Instructional techniques, and in addition, the support teacher worked specifically on this area with the intern. This may have increased this intern's awareness of the significance of effective instructional techniques in successful teaching. Seventeen comments were expressed, 7 positive ("The response group technique worked will"), and 10 were negative (I should have included an essay in the test"). All of the comments the intern reported contained specific information applicable to 
improving classroom instruction, both in early and later months.

A total of 6 comments were expressed about student learning behavior, with 4 positive "I want students to read for enjoyment") and 2 negative ("One student kept

disagreeing with me during the irony discussion"). Intern \#4 was aware of the student learning behavior and reported specific illustrations.

Of the 4 self-adequacy comments expressed regarding self-assessment of teaching, all were negative ("I didn't think to collect outlines soon enough"). The comments were all closely related to instructional techniques, which was the major area this intern based the rationale for self-assessment upon.

Classroom management was mentioned infrequently (1) in the self-assessment rationale statements, and was coded as a negative statement.

Intern \#5. Intern \#5 reported the highest selfassessment rating (1.7) of the group of subjects. A total of 44 rationale statements were expressed, with 22 positive and 22 negative (see Table X). Over half of these contained instructional technique comments. Thirteen were positive ("Reading went smoothly and the objective was met easily"), and 12 were negative ("Social studies needed to be shortened. I packed too much in for the time allotted"). Possibly, the extensive presentations in seminars about 
TABLE $X$

SELF-ASSESSMENT PROF ILE OF INTERN 5

\begin{tabular}{|c|c|c|c|c|c|c|c|c|c|c|c|c|c|c|c|c|}
\hline \multirow[t]{2}{*}{ Month } & \multirow{2}{*}{$\begin{array}{l}\text { Rating } \\
\text { Average }\end{array}$} & \multicolumn{3}{|c|}{$\begin{array}{c}\text { Instructional } \\
\text { Techniques }\end{array}$} & \multicolumn{3}{|c|}{$\begin{array}{l}\text { Student } \\
\text { Learning } \\
\text { Behavior }\end{array}$} & \multicolumn{3}{|c|}{$\begin{array}{c}\text { Self- } \\
\text { Adequacy }\end{array}$} & \multicolumn{3}{|c|}{$\begin{array}{l}\text { Classroom } \\
\text { Management }\end{array}$} & \multicolumn{3}{|c|}{ Total } \\
\hline & & Total & + & - & Total & + & - & Total & + & - & Total & + & - & Total & + & - \\
\hline Jan. & 2.3 & 6 & 2 & 4 & 1 & 1 & 0 & 4 & 2 & 2 & 3 & 1 & 2 & 14 & 6 & 8 \\
\hline Feb. & 2.0 & 5 & 2 & 3 & 1 & 0 & 1 & 2 & 1 & 1 & 0 & 0 & 0 & 8 & 3 & 5 \\
\hline Mar. & 1.8 & 5 & 3 & 2 & 1 & 1 & 0 & 2 & 0 & 2 & 1 & 1 & 0 & 9 & 5 & 4 \\
\hline Apr Il & 1.3 & 3 & 3 & 0 & 3 & 2 & 1 & 0 & 0 & 0 & 0 & 0 & 0 & 6 & 5 & 1 \\
\hline May & 1.3 & 6 & 3 & 3 & 1 & 0 & 1 & 0 & 0 & 0 & 0 & 0 & 0 & 7 & 3 & 4 \\
\hline TOTAL & 1.7 & 25 & 13 & 12 & 7 & 4 & 3 & 8 & 3 & 5 & 4 & 2 & 2 & 44 & 22 & 22 \\
\hline
\end{tabular}

$+=$ positive rationale

- = negative rationale 
instructional techniques along with the experienced reality of the importance of effective instructional techniques may have influenced this intern to report a high number of statments in this area. Intern \#5 reported specific information about "why" a lesson was effectlve or ineffective, using the vocabulary presented in seminars.

There were 7 rationale statements expressed about student learning behavior, 4 positive ("Kids participated and were interested in subtraction regrouping"), and three negative "The kids were a little stir-crazy at the end of the lesson"). Although the category of student learning behavior was used less frequently than others as rationale for self-assessment, the intern was aware of student learning behavior in the class and included this in developing rationale for self-assessment ratings.

Ejght statements about self-adequacy were reported as rationale for self-assesment ratings. Three were positive ("I feel good about some things today"), and 5 were negative ("I'm not exactly sure what to do different"). The comments were based on intuition or feelings about the lesson, which reflected the personality of this intern. Intern \#5 was a sensitive person and frequently discussed her feelings about students and her teaching during seminars.

Classroom management was reported as rationale for self-assessment 4 times, 2 positive ("Today the kids were a lot better than normal") and 2 negative ("There are a lot of 
management techniques that I could have changed to make it go even smoother"). This was a minor basis for

self-assessment for Intern \#5, and significant $f$ indings were not noted in this area.

Intern \#6. Intern \#6 had an average self-assessment rating of 2.2 (see Table XI). There was a general increase in the ratings during the study, except for a slight decrease in March). This intern was teaching full-time from February through June, so the decrease would not have been related to beginning full-time teaching. As the number of negative statements were lowest in March, this is also not an explanation for the decrease. A total of 35 statements were expressed as rationale for the self-assessment ratings. Sixteen were positive, and 19 were negative. There were more negative statements reported in January, when the lowest rating was recorded. This was the month when this intern was preparing to teach full-time, and the reality of accepting this responsibility may have influenced the ratings in January.

The rationale statements contained instructional technique comments in 16 of the 35 total statements. Seven were positive ("The lesson was fast-paced and kept the students thinking"), and 9 were negative ("I would change the lesson by leaving out the spelling test"). The comments included specific information about the effectiveness or 
TABLE XI

SELF-ASSESSMENT PROF ILE OF INTERN 6

\begin{tabular}{|c|c|c|c|c|c|c|c|c|c|c|c|c|c|c|c|c|}
\hline \multirow[t]{2}{*}{ Month } & \multirow{2}{*}{$\begin{array}{l}\text { Rating } \\
\text { Average }\end{array}$} & \multicolumn{3}{|c|}{$\begin{array}{c}\text { Instructional } \\
\text { Technlques }\end{array}$} & \multicolumn{3}{|c|}{$\begin{array}{l}\text { Student } \\
\text { Learning } \\
\text { Behavior }\end{array}$} & \multicolumn{3}{|c|}{$\begin{array}{c}\text { Self- } \\
\text { Adequacy }\end{array}$} & \multicolumn{3}{|c|}{$\begin{array}{l}\mathrm{Cl} \text { assroom } \\
\text { Management }\end{array}$} & \multicolumn{3}{|c|}{ Total } \\
\hline & & Total & + & - & Total & + & - & Total & + & - & Total & + & - & Total & + & - \\
\hline Jan. & 2.9 & 3 & 1 & 2 & 2 & 0 & 2 & 3 & 1 & 2 & 2 & 0 & 2 & 10 & 2 & 8 \\
\hline Feb. & 2.0 & 4 & 2 & 2 & 2 & 2 & $\mathbf{0}$ & 0 & 0 & 0 & 0 & 0 & o & 6 & 4 & 2 \\
\hline Mar. & 2.4 & 2 & 2 & 0 & 3 & 3 & 0 & 1 & 0 & 1 & 0 & 0 & 0 & 6 & 5 & 1 \\
\hline Apr11 & 1.8 & 4 & 1 & 3 & 1 & 0 & 1 & 0 & $\mathbf{0}$ & $\mathbf{0}$ & 1 & 0 & 1 & 6 & 1 & 5 \\
\hline May & 1.8 & 3 & 1 & 2 & 4 & 3 & 1 & 0 & 0 & 0 & 0 & 0 & 0 & 7 & 4 & 3 \\
\hline TOTAL & 2.2 & 16 & 7 & 9 & 12 & 8 & 4 & 4 & 1 & 3 & 3 & 0 & 3 & 35 & 16 & 19 \\
\hline
\end{tabular}

+ = positive ratlonale

- = negative rationale 
ineffectiveness of each lesson. This intern made valid suggestions that would improve future instruction.

Twelve rationale statements focused on student learning behavior, with 8 positive ("Reading the article in groups helped the low-level readers"), and 4 negative ("The students couldn't understand or use the forms"). Intern \#6 illustrated student learning behavior with specific reasons for the success or failure in a lesson.

Four statements of rationale about self-adequacy were included, 1 was positive ("I saw light bulbs go off during this activity-it felt good"), and 3 were negative ("I was very disoriented from being out of the class for 7 days"). With few statements expressed in this area, there were no significant findings uncovered.

Of the 3 rationale statements expressed about classroom management, all 3 were negative. For example, the intern stated, "Classroom management and keeping them quiet is still the main underlying problem." Intern \#6 reported classroom management as a problem in the rationale statements, yet the frequency of these statements was low. Perhaps, the intern intentionally excluded these thoughts on the self-assessment forms, or did not feel they provided a basis for assessing teaching. 


\section{Summacy of Self-Assessment of Teaching}

The average self-assessment of teaching rating for all interns in this group was 2.0 , which reflects a satisfactory rating with minimal changes needed if the lesson were to be presented again. The range of ratings was from 1.7 to 2.5 . These scores again reflect satisfactory ratings of the interns' teaching. Although the ratings tended to increase with the amount of teaching experience, individual differences were noted during the 5 month period of the study :

Irvine (1983) reports self-assessment of teaching may not be useful, as discrepancies exist between actual practice and reported activites. Therefore, the perception of the individual may influence the self-assessment rating and rationale in conjunction with "what really happened" in the classroom. While this may have occurred in this study, the focus was not on the accuracy of the self-assessment, but on how interns assessed themself, and the rationale used for assessment.

In looking at the rationale interns used for self-assessment, 237 rationale statements were expressed. Of these 237 statements, 113 focused on instructional techniques. This was the most frequent rationale interns relied upon in determining their self-assessment rating as a group, within each month, and for each intern. 
Instructional techniques were the major source of teaching behavior interns used in rating their teaching. Student learning behavior was reported as the rationale for self-assessment 66 times. Interns were aware of student learning behavior and included this in their comments. Self-adequacy was reported as a rationale for self-assessment 37 times, with 25 of these comments negative. While interns did not rely frequently upon self-adequacy as a major rationale for self-assessment, it did contribute to the rating of interns' teaching. The lowest number of rationale statements in a category were about classroom management. Thus, classroom management was a minor influence in determining interns' self-assessment ratings.

Interns' statements reflected slightly more positive than negative comments. Although the interns generally reported that they were satisfied with their teaching, a large number of negative statements were expressed. A possible explanation for this finding may be found in examining the rationale statements. When a statement expressed a need for a change, the statement was coded negative, and if the statement reported no changes were necessary, the statement was coded as positive. If the statement was negative, interns generally reported "how" and "what" needed to be changed in order to improve the instruction. The interns offered constructive criticism 
about their teaching. During the study, interns reported assessing their teaching during times of the month when data was not being collected. The interns were practicing self-assessment, and attributed this learning to the introduction of the self-assessment process implemented by the participant observer. Interns also reported implementing ideas and changes in their teaching that had originated from the self-assessment process. As a participant observer in this study, most of the ideas expressed would produce desireable results when instituted in teaching. 
CHAPTER V

CONCLUSIONS, IMPLICATIONS, AND RECOMMENDATIONS

\section{INTRODUCTION}

This study examined the "learning-to teach" process in an alternative teacher education program. The general sample included 22 interns enrolled in the Cooperative Professional Education Program (CPEP) at Portland State University, and the intensive sample included 6 interns from this group. Through observations, interviews, and questionnaires, interns provided qualitative and quantitative information that created a comprehensive, holistic picture of "learning-to-teach". Three major questions were addressed to probe the field experience:

1. To what sources of influence do the interns attribute their learning of specific teaching behaviors and ideas?

2. What are the professional concerns of interns, and are there changes in concerns as they progress through the field experience?

3. How do interns assess their teaching as they progress through the field experience, and what is the rationale for the assessments? 
Following are conclusions based on indings from each question. Reviewing the program components of the Cooperative Professional Education Program (CPEP) may produce a more accurate understanding of the conclusions. Components such as extended field experience, concurrent seminars, and multiple teaching and observation experiences may have influenced the findings. In addition, implications, and recommendations derived from these findings will be presented.

SOURCE OF INFLUENCE ON INTERNS' TEACHING BEHAVIORS AND IDEAS

The findings of this study related to source of influence on prospective teachers differ from those existing in the literature. Haberman reports that cooperating teachers are the major source on influence on student teachers (1983). In this study, multiple sources of influence were reported, with seminars found to be the major source of influence on interns' teaching behavior. CPEP interns had completed a minimum of education courses before entering the CPEP program and were involved in learning subject area knowledge, elements of instruction, and classroom management in seminars (see Appendix). The content of CPEP seminars differed from seminars in traditional programs. Goodman (1983) finds the most frequent function of seminar is collaboration and support of student teachers in their field experience. While this 
function occurred in CPEP seminars, the major purpose was to provide interns with pedagogical knowledge, understanding, and skills. The seminar schedule was developed to present information in a sequenced curriculum. Therefore, the influence of seminar on interns' teaching was derived from both the content and scheduling of seminars.

Support teachers were rated as the second most influential source of interns' teaching behaviors and ideas. Teaching behaviors most likely to be influenced by support teachers are classroom routines and subject matter. A review of the literature (e.g.. Freibus, 1977; Karmos \& Jacko, 1977; Seperson \& Joyce, 1973) regarding influences on prospective teachers found most of the research reports cooperating teachers as the major influence on student teachers. In this study, while support teachers were reported to be an influence, they were not the major influence. CPEP interns observed in many classrooms during the school year and taught with several teachers. In addition, the interns were encouraged to "try out" different instructional approaches through seminar content. Interns experienced several different "models" of instruction, while a traditional field experience is restricted to one model, the cooperating teacher. As a result, CPEP interns were involved in a wide range of teaching experiences and were not as strongly influenced by the support teacher as student teachers in traditional programs. Increasing exposure to a 
greater number of models during the ileid experience lessened the lmpact from any ene source of influence. Interns in this study reported "self" as an additional source of influence on their teaching. No literature was found presenting information about prospective teachers' "self" as a source of influence on their teaching behavior or ideas. CPEP interns designated "self" as a frequent source of influence. The extended field experience provided an opportunity for interns to analyze, synthesize, and integrate teaching ideas from many sources. During this process, interns were able to personalize teaching ideas; therefore, they attributed the ideas as coming from "self." The "self" is a large and rich reservoir of ideas. Teaching preservice teachers how to tap into this reservoir should be included in teacher education curriculum, acknowledging that each person's ideas have worth and value (J. D. Lind, personal communication, June 26, 1987).

\section{PROFESSIONAL CONCERNS OF INTERNS}

The professional concerns of CPEP interns gradually moved toward concerns-with-students during the field experience, followed by a slight decrease in the final month of the field experience. The results of this study support the findings of Silvernail and Costello (1983) and Fuller, Parsons, and Watkins (1973), who report student teachers 
return the focus of concerns to "self" towards the end of the field experience.

Interns, like student teachers, share the common "dual" role of both student and student teacher during the field experience. In Fuller's later studies (1973), the reversal of concerns back to concerns-with-self was assumed to be related to student teachers' return to the student role. Student teachers reported concerns about grades, college requirements, and other college related concerns. CPEP interns are also students, and reported concerns about completing program requirements along with future employment. These concern patterns are similar to those found in research literature describing teacher development at the preservice level.

\section{SELF-ASSESSMENT OF INTERNS}

The average self-assessment of teaching rating for the group was 2.0 , whilch reflects a satisfactory rating, with minimal changes needed in the lesson. The average of the group ratings tended to increase slightly over the 5 month period, although individual intern's ratings varied.

Interns reported "thinking about their teaching" in terms of self-assessment. They attributed the effects of reflection and analysis to the use of the self-assessment process in this study. On-going self-evaluation as 
conducted in this study may initlate the internalization of a self-assessment process.

The individual ratings of intern's teaching were influenced by their personal traits. Several interns were self-critical, while others tended to be satisfied and rated themselves consistently high. This was demonstrated both in their ratings and rationale statements. Higher frequency of positue rationale statements generally corresponded to higher ratings, although examination at an individual level yields a more accurate account of the self-assessment. The participant observer/supervisor noted many of the self-assessment ratings were higher or lower than her ratings. The interns who were self-critical continually rated their teaching with lower scores than the score the supervisor would have recorded, while other interns consistently rated themself higher than their instruction warranted. Each intern brought personal perspectives into the self-assessment exercise and relied upon individual "standards" for the assessment. Therefore, the value of the self-assessment process lies in the development of reflective habits at a preservice level rather than as a comparison or measure of effectiveness or success in teaching. 


\section{IMPLICATIONS}

\section{Source of Influence}

This study found multiple sources of influence on interns' teaching behavior, due to the wide range of experiences included in CPEP. If we want prospective teachers to develop the ability to analyze and evaluate teaching strategies, and to develop a range of teaching styles and strategies to accomodate a range of learners, then teacher education programs must include opportunities for additional experiences to occur during the "learning-toteach" process. Exposing student teachers to one model (the cooperating teacher) encourages imitation for "survival" purposes. In contrast, CPEP interns had extended time to try out a range of observed models and develop personal instructional styles and strategies based on several sources of influence. Providing interaction with multiple "models" of instruction and allowing time for personal interpretation while "learning-to-teach" can promote the development of a range of strategies and a more individualized instructional style.

\section{Professional Concerns of Interns}

Extending the field experience (in this study, to 9 months) did not alter the movement in level of concern in prospective teachers. Moving through concern levels may be similar to moving through developmental levels. People 
advance to the next stage or level when they are "ready" for the move. Spending more time in the field experience did not cause interns to move toward concerns-with-students earlier than students in a traditional program. Until "self" concerns are acknowledged and addressed, prospective teachers can not be expected to move to concerns-withstudents. Resolving concerns-with-self during the field experience with the assistance of university and school-based personnel may enable prospective teachers to move to the next stage of concerns.

\section{Self-Assessment}

Due to the impact of the self-assessment process from this study, interns reported incorporating self-assessment of their teaching into their repertoire. Interns reported using their personal feedback for improvement in their instruction. Prospective teachers can be taught to assess and evaluate their teaching, and can be taught how to implement assessment feedback to improve their teaching. Teacher education programs should include instruction and practice in self-assessment and the process of change and improvement in teaching, especially when prospective teachers have the opportunity to directly apply the information.

In the "real world" of education, teachers receive scant feedback from outside sources; thus, the self- 
assessment process will facllitate teachers in gaining feedback and information about their instruction. The self-assessment feedback becomes the foundation for improvement in instructional skills. Encouraging analysis of instruction and the building of future instructional decisions on such feedback develops an ethos of lifelong "learning-to-teach."

\section{RECOMMENDATIONS}

\section{Program Development}

The conclusions and implications from this study lead to the following recommendations for possible changes in teacher education programs.

1. Adding multiple observations and teaching experiences during the field experience component of teacher education provides multiple sources of influence for professional development of preservice teachers. Educating teachers to analyze and evaluate instructional "models" can change the "learning-to-teach" process from the traditional model of imitation to a model of selection, synthesis, and individual interpretation. This level of "learning-toteach" requires reflective abilities.

2. Including instruction in self-assessment, rationales for use, and analysis strategies, with the promotion of regular practice in teacher education programs has long term effects. Preparing teachers with the ability 
to reflect upon their instruction and the impact of instruction results in teachers who are more likely to continue professional growth and improvement.

3. Assessing and modifying the sequence and content of seminars during the field experience is essential. Seminars were reported to be the major source of influence on CPEP interns' teaching behavior. In light of this finding, analysis of both seminar content and the sequence of this content is warranted in order to utilize the potential of seminars in developing the teaching of prospective teachers.

4. Addressing and supporting prospective teachers' concerns should occur during the field experience. Reflecting on and resolving concerns-with-self in conjuction with presentations about levels of concerns may influence the movement toward concerns-with-students.

\section{Euture Study}

Since the literature on alternative teacher education programs is not extensive and since more questions about the field experience have been raised than answered, there are many possibilities for future research. In advance of responding to calls for major changes in teacher education programs, further research examining and describing the "learning-to-teach" process is essential. The following recommendations and research questions have been selectd to 
expand the findings of this study, in examining and exploring "learning-to-teach".

Qual itat ive Research of Teacher Educat ion Programs.

The majority of research completed in teacher education and more specifically in field experiences has been quantitative in nature. Most studies of the field experience have relied upon pre- and post-test surveys (Popkewitz, Tabachnick \& Zeichner, 1979). In order to report an accurate portrayal of the field experience, observational and field-based methods must be employed. The field experience is complex and consists of numerous interrelated components; thus, it must be studied as a dynamic process. Researching "pieces" of the field experience will not unfold the actual "learning-to-teach" process. Studying the entire process requires a combination of study strategies.

In addition, research methodology must be designed that allows for "unanticipated events as well as anticipated events" (Tabachnick, 1981) to emerge from the study. Many of the findings in this study were unanticipated, and emerged due to the structure of the study's methodology and content of the data. Methods which allow for emergent findings as well as studying the process over a period of time are recommended. 
Besearch Questlons for Future Study.

1. Do sources of influence on teaching change significantly after preservice teachers complete the field experience and enter the teaching profession?

2. Do inservice teachers who completed alternative extended programs move sooner to concerns-with-students in their first years of teaching than inservice teachers who completed traditional programs with 10-12 weeks of field experience?

3. If preservice teachers learn self-assessment processes during the field experience, does the practice continue in the induction phase of teaching?

4. Further investigation of thus $f$ ar reported influence of the university supervisor is warranted. Most studies have examined this influence in relation to student teachers' instruction. Observation of the supervisors' influence on the entire field experience and examination of the content of supervisors' conferences will provide a more accurate and comprehensive description of the supervisors' influence.

5. What impact do individual characteristics of prospective teachers have on "learning-to-teach"? In this study there were significant differences among interns on their self-assessments ratings and rationale statements, concerns, and reported sources of influence. Future studies that continue to attend to individual characteristics of 
preservice teachers will provide essential Information to strengthen teacher education programs.

6. What are the relationships between seminar content and preservice teachers' instructional behavior? Examining the source of influence on teaching in relation to seminar content may provide additional information about the application of seminar curriculum into the field experience.

\section{SUMMARY OF IMPLICATIONS AND RECOMMENDATIONS}

Implications from this study pointed to the need to expose prospective teachers to multiple "models" of instruction, and provide for application of these models during the field experience. Secondly, addressing and supporting prospective teachers' professional concerns may facilitate the movement to concerns-with-students. Finally, integrating self-assessment procedures, and the purpose of self-assessment of teaching into the teacher education curriculum enables prospective teachers to evaluate their teaching and make improvements based on their selfassessment. Implementing these implications in teacher education programs promotes reflection of teaching beliefs and knowledge.

Recommendations for program development included suggestions derived directly from the three implications. In addition, the fourth recommendation stressed the need to 
analyze the content and sequence of seminars, as seminars provide a major source of influence on preservice teachers' instructional behavior.

Utilizing qualitative techniques in examining teacher education programs was recommended for future study. Employing research methods that allow for emergent $f$ indings, field-based studies, and studying the process over a period of time will provide an accurate portrayal of "learning-toteach."

Additional recommendations for future study included following the program development recommendations into the first years of teaching, and assessing the impact or changes in sources of influence, professional concerns, and self-assessment. Investigating the influence of the university supervisor on the entire field experience through observations and content analysis was suggested. Examining individual characteristics of preservice teachers and the impact of these individual differences in "learning-toteach" was a further recommendation. The final recommendation proposed exploring the relationship between seminar content and preservice teachers' instruction.

Following these recommendations will result in information significant to curriculum development and the context of teacher education programs. An important consideration is the recomnendation to incorporate teaching of "reflection" in teacher education curriculum. Preparing 
teachers who have the abllity to reflect upon their teaching beliefs and knowledge creates teachers who have moved beyond the level of "imitation" and "survival", and are able to create personal "models" of teaching. Combining this recommendation with those for future study will produce information useful for those responsible for teacher education programs and policy development. The response to the calls for reform in teacher education is to base improvements in teacher education programs on current research rather than tradition. 


\section{REFERENCES}

Applegate, J. H. \& Lasley, T. J. (1982). Cooperating teachers' problems with preservice field experience students. Journal of Teacher Education, $33(2), 15-18$.

Bogdan, R. C. \& Biklen, S. K. (1982). Qualitative research for education: An introduction to theory and methods. Boston: Allyn and Bacon.

Campbell, D. (1978). Qualitative knowing in action research. In M.Brenner, P. Marsh, \& M. Brenner (Eds.), The social contexts of method, New York: St. Martins.

Carl, M. E. (1985). Cooperative Professional Education Program. phase ene. Portland, OR: Portland State University.

Carnegie Forum on Education and the Economy. (1986). A nation prepared: Teachers for the 21st century. New York: Carnegie Forum on Education and the Economy, Carnegie Foundation.

Clift, R. \& Warner, A. (1986). University contributions to the education of teachers. Journal of Teacher Education, 37(2), 32-36.

Cohn, M. A. (1981). A new supervision model for linking theory to practice. Journal of Teacher Education, $32(3), 26-30$.

Combs, A., Blume, R., Newman A., \& Wass, H. (1978). The professional education of teachers: A humanistic approach to teacher preparation. Boston: Allyn and Bacon.

Conant, J. (1963). The education of American teachers. New York: McGraw-Hill.

Corrigan, D. C. (1981). Creating conditions for professional practice: Education's unfinished agenda. Journal of Teacher Education, 32(2), 26-32.

Cruikshank, D. R. \& Armal ine, W. D. (1986). Field experiences in teacher education: Considerations and recommendations. Journal of Teacher Education, 37(3), 34-40. 
Cruikshank, D. R. \& Callahan, R. (1983). The other side of the desk: Stages and problems of teacher development. The Elementary School Journal, 83, (3), 250-259.

Davies, D. \& Amershak, K. (1969). Student teaching. In R. Ebel (Ed.). The encyclopedia of educational research (pp. 1376-1387). New York: McMillan.

Denemark, G., \& McDonald, J. (1967). Pre-service and in-service education of teachers. Review of Educational Research, 37, 233-248.

Doyle, W. (1977). Learning the classroom environment: An ecological analysis. Journal of Teacher Education, $28(6), 51-55$.

Driscoll, A. \& Strouse, J. (1986). Portland State University's Cooperative Professional Education Program: A Teacher Education Alternative. Portland, OR: Portland State University.

Egbert, R. L. (1985). The practice of preservice teacher education. Journal of Teacher Education, 36(1), 16-22.

Emans, R. (1983). Implementing the knowledge base: Redesigning the function of cooperating teachers and college supervisors. Journal of Teacher Education, $34(3), 14-18$.

Feiman, S. (1979). Technique and inquiry in teacher edaucation: A curricular case study. Curriculum Inquiry, 9, 63-79.

Friebus, R. (1977). Agents of socialization involved in student teaching. Journal of Educational Research, 70, 263-368.

Fuller, F. (1969). Concerns of teachers: A developmental conceptualization. American Educational Research Journal, $6(2), 207-226$.

Fuller, F. F. (1971). Relevance for teacher education: A teacher concerns model. Aust in: Research and Development Center for Teacher Education, University of Texas.

Fuller, F. F., Parsons, J. S., \& Watkins, J. (1973). Concerns of teachers: Research and reconceptualization. Austin: Research and Development Center for Teacher Education, University of Texas. 
Geertz, C. (1973). Thick Description: Toward an interpretive theory of culture. In C. Geertz (Ed.), The interpretation of cultures: Selected essays by Clifford Geertz. New York: Basic Books.

Gehrke, N. (!981). Rationales for field experiences in the professions. In C. Webb, N. Gehrke, P. Ishler \& A. Mendoza (Eds.), Exploratory field experiences in teacher education (pp. 1-7). Reston, VA: Association of Teacher Educators.

Glaser, B. G. (1978). Theoretical sensitivity: Advances in the methodology of grounded theory. Mill valley, CA: Sociology Press.

Glaser, B. G., \& Strauss, A. L. (1967). The discovery of grounded theory: Strategies for gual itative research. Chicago: Aldine.

Goodlad, J. I. (1984). A place called school. New York: McGraw-Hill.

Goodman, J. (1983). The seminar's role in the education of student teachers: A case study. Journal of Teacher Education, 34(3), 44-49.

Green, J. \& Wallat, C. (1981). Ethnography and language in educational settings. New Jersey: Ablex.

Griffin, G., Barnes, S., Hughes, R., O’Neal, S., Defino, M. E., Eotwards, S. A., \& Hukil1, H. (1983). Clinical presservice teacher education: Final report of a descriptive study. Aust in, TX: University of Texas Research \& Development Center for Teacher Education.

Guba, E. (1978). Toward a methodology of natural istic inquiry in equational evaluation. (Center for the Study of Evaluation Monograph No. 8). Los Angeles, CA: University of California Graduate School of Education.

Haberman, M. (1983). Research on preservice laboratory and clinical experiences: Implications for teacher education. In K. R. Howey \& W. Gardner, The education of teachers: A look ahead (pp. 98-117). New York: Longman Press.

Hall, G. E. \& Hord, S. M. (1981). A national agenda for research in teacher education for the $1980 \mathrm{~s}$. Journal of Teacher Education, $32(2), 4-8$. 
Hartman, C. L. (1978). A longitudinal look at self-appraisal strategies. Journal of Teacher Education, 29(5), 11-12.

Holmes Group Report. (1986). Tomorrow's teachers: A report of the Holmes Group. East Lansing, MI: The Holmes Group.

Howey, K. R. (1977). Preservice teacher education: Lost in the shuffle? Journal of Teacher Education, $28(2)$, 26-28.

Howey, K. R. (1983). Teacher education: An overview. In K. R. Howey \& W. Gardner, The education of teachers: A look ahead (pp. 6-37). New York: Longman Press.

Howey, K. R. \& Gardner, W. (1983). The education of teachers: A look ahead. New York: Longman Press.

Iannaconne, L. (1963). Student teaching: A transitional stage in the making of a teacher. Theory inte Practice, 2. 73-80.

Irvine, J. J. (1983). The accuracy of pre-service teachers' assessments of their classroom behaviors. Journal of Research and Development in Education, 17(1), 25-31.

Issac, S. (1971). Handbook in research and evaluat ion. San Diego, CA: Edits.

Joyce, B. \& Clift, R. (1984). The Phoenix agenda: Essential reform in teacher education. Educational Researcher, 13(4), 5-18.

Joyce, B., Yarger, S., \& Howey, X. (1977). Preservice teacher education. Palo Alto, CA: Center for Educational Research, Stanford University.

Karmos, A. H. \& Jacko, C. M. (1977). The role of significant others during the student teaching experience. Journal of Teacher Education, 28(5), 51-55.

Keppel, F. (1986). A field guide to the land of teachers. Phi Delta Kappan, 68(1), 18-24.

Koehler, V. (1985). Research on preservice teacher education. Journal of Teacher Education, $36(1), 23=30$.

Lincoln, Y. S. \& Guba, E. G. (1985). Naturalistic inquiry. Beverly Hills, CA: Sage. 
Lipton, A. \& Lesser, E. (1978). Teacher training at Stony Brook: A model for conflict. Journal of Teacher

Education, 29(6), 57-60.

Lortie, D. (1975). School teacher. Chicago, IL: University of Chicago Press.

Lutz, F. W. \& Ramsey, M. A. (1974). The use of anthropological field methods in education. Educational Researcher, $3(10)$, 5-9.

Magoon, A. J. (1977). Constructivist approaches in educational research. Review of Educational Research, 4. 651-693.

Miles, M. B. \& Huberman, A. M. (1984). Qualitative data analysis: A sourcebook of new methods. Beverly Hills, CA: Sage.

Mosher, R. \& Purpel, D. (1972). Supervision: A reluctant profession. Boston: Houghton-Mifflin.

National Commission on Excellence in Education. (1983). A nation at risk. Washington, DC: U. S. Department of Education.

Ogbu, J. U. (1978). School ethnography: A multilevel approach. Anthropology and Education Quarterly, $2(1)$, 3-29.

Patty, A. H. (1973). Classroom teachers will replace college supervisors. Contemporary Education, $44(3)$, 179-183.

Peck, R. \& Tucker, J. (1973). Research on teacher education. In R. Travers (Ed.), The second handbook of research on teaching (pp. 940-978). Chicago: Rand-McNally.

Popkewitz, T. (1977, April). Ideology as a problem of teacher education. A paper presented at the annual meeting of American Educational Research Association, New York.

Popkewitz, T., Tabachnick, B., \& Zeichner, K. (1979). Dulling the senses: Research in teacher education. Journal of Teacher Education, 30(5), 52-60.

Rist, R. C. (1980). Blitzkreig ethnography: On the transformation of a method into a movement. Educational Researcher, 9, 8-10. 
Rogers, V. (1984). Qualitative research--Another way of knowing. In P. L. Hosford (Ed.), Using what we know about teaching. Alexandria, VA: Association for Supervision and Curriculum Development.

Ryan, K., Newman, K., Mager, G., Applegate, J., Lasley, T., Flora, R., \& Johnston, J. (1980). Biting the apple: Accounts of first year teachers. New York: Longman.

Salzillo, F., \& Van Fleet, A. (1977). Student teaching and teacher education: A sociological model for change. Journal of Teacher Education, 28(1), 27-31.

Sanders, J. (1974). Towards a rationale for practice teaching. Teacher Education, 18-23.

Sarason, S., Davidson, K., \& Blatt, B. (1962). The ereparation of teachers: An unstudied problem in eqducation. New York: John Wiley.

Schalock, D. (1983). Methodological considerations in future research and development in teacher education. In K. Howery \& W. Gardner (Eds.), The education of teachers: A look ahead. New York, NY: Longman Press.

Schatzman, L. \& Strauss, A. (1970). Field research: Strateqies for a natural socialization. Englewood Cliffs, NJ: Prentice-Hall.

Scriven, M. (1972). Objectivity and subjectivity in educational research. In L. G. Thomas (Ed.), Philesophical redirections in educational research, the seventy-first handbook (Part 1). Chlcago: The University of Chicago Press.

Seperson, M. A. \& Joyce, B. (1973). Teaching styles and student teachers as related to those of their cooperating teachers. Educational Leadership Research Supplement, 146-151.

Silberman, C. (1971). Crisis in the classroom. New York: Random House.

Silvernail, D. \& Costello, M. (1983). The Impact of student teaching and internship porgrams on preservice teachers/pupil control perspectives, anxiety levels and teaching concerns. Journal of Teacher Education, 34(4), 32-36.

Spindler, G. D. (1982). Doing the ethnoaraphy of schooling, New York: Holt, Rinehart \& Winston. 
Tabachnick, B. R. (1981). Teacher education as a dynamic social event. In B. R. Tabachnick, T. Popkewitz \& B. Bszekely (Eds.), Studying teaching and learning: Trends in Soviet and American research. New York: Praeger.

Tabachnick, B. R., Popkewitz, T. S., \& Zeichner, K. M. (1979-1980). Teacher education and the professional perspectives of student teachers. Interchange, 10(4), 12-29.

Tabachnick, B. R, \& Zeichner, K. (1984). The impact of the student teaching experience on the development of teaching perspectives. Journal of Teacher Education, 3다 $(6), 28-36$.

Tuckman, B. W. (1972). Conducting educational research. New York, NY: Harcourt Brace Jovanoch.

Veldman, D. J. (1970). Pupil evaluation of student teachers and their supervisors. Journal of Teacher Education, 21(2), 165-167.

Warren, D. (1985). Learning from experience: History and Teacher Education. Educational Researcher, 14(10), 5-12.

Heick, K. E. (1968). Systematic observational methods. In Gardner Lindzey \& Elli lot Aronson (Eds.). The handbook of social psychology (2nd ed. Vol,2), Menlo Park, CA: Addison-Wesley.

Wilson, S. (1977). The use of ethnographic techniques in educational research. Review of Educational Research. 47, 245-265.

Wittrock, M. C. (Ed.). (1986). Handbook of research on teaching (3rded.). New York: McMillan.

Wolcott, H. (1973). The man in the principal's office: An ethnography, New York: Holt, Rinehart \& Winston,

Wright, J. P., Silvern, S. B., \& Burkhalter, B. B. (1982). An evaluation of teacher input in fleld-based instruction. Jeurnal of Research and Development in Education, 15(2), 34-37.

Yee, A. H. (1969). Do cooperating teachers influence the attitudes of student teachers? Journal of Educational Psychelogy, 60(4), 327-332. 
Zeishner, K. (1978). The student teaching experience. Teacher Education, $1(1), 58-61$.

Zeichner, K. (1980). Myths and realitites: Field-based experiences in preservice teacher education. Journal of Teacher Education, $31(6), 45-55$.

Zeichner, K. (1981). Reflective teaching and field-based experience in teacher education. Interchange, 12(4), $1-23$.

Zeichner, K. (1984). The ecology of field experience: Toward an understanding of the role of field experience in teacher development. Paper presented at annual meeting of the Association of Teacher Educators.

Zeichner, K. M. \& Liston, D. P. (1987). Teaching student teachers to reflect. Harvard Educational Review, 57(1), $2-48$.

Zeichner, K. \& Tabachnick, B.R. (1981). Are the effects of university teacher education 'washed out' by school experience? Journal of Teacher Education, 32(3), 7-11.

Zimpher, N. L., deVoss, G. G., \& Nott, D. L. (1980). A closer look at university student supervision. Jeurnal of Teacher Education, 31(4), 11-15.

Zohorik, J. A. (1981). Using insights in education. Journal of Teacher Education, 32(2), 10-13.

Zahorik, J. A. (1986). Acquiring teaching skills, Journal of Teacher Education, 37(2), 21-25. 
APPENDIX

SEMINAR SCHEDULE FOR

COOPERATIVE PROFESSIONAL EDUCATION PROGRAM

$1986-1987$ 
Aug. $24 \& 25$

A.M. \& P.M. Inservice Days (Included observation techniques, and an overview of (PEP)

Sept. 5

A.M. \& P.M. Instructional Theory

Sept. 12

A.M. \& P.M. Instructional Theory

Sept. 19

A.M.

Reading Instruction

P.M.

Instructional Theory

Sept. 26

A.M.

Reading Instruction

P.M.

Instructional Theory

Oct. 3

A.M.

Reading Instruction

P.M.

Classroom Management

Qct. 10 Professional Inservice Day

Oct. 17

A.M.

Reading Instruction

P.M.

Instructional Theory

Qet. 24

A.M.

Reading Instruction

P.M.

Instructional Theory into Practice

Qct. 31

A.M.

Reading Instruction

Nov. 7

A.M.

Reading Instruction

P.M.

Math Instruction, Elementary School Level

Nov, 14

A.M.

Reading Instruction

P.M.

Math Instruction, Elementary School Level

Nov, 21

A.M.

Elementary Math Seminar (Math Their Way Program)

P.M.

Math Instruction, Elementary School Level

Nov, 28 Hol i day 


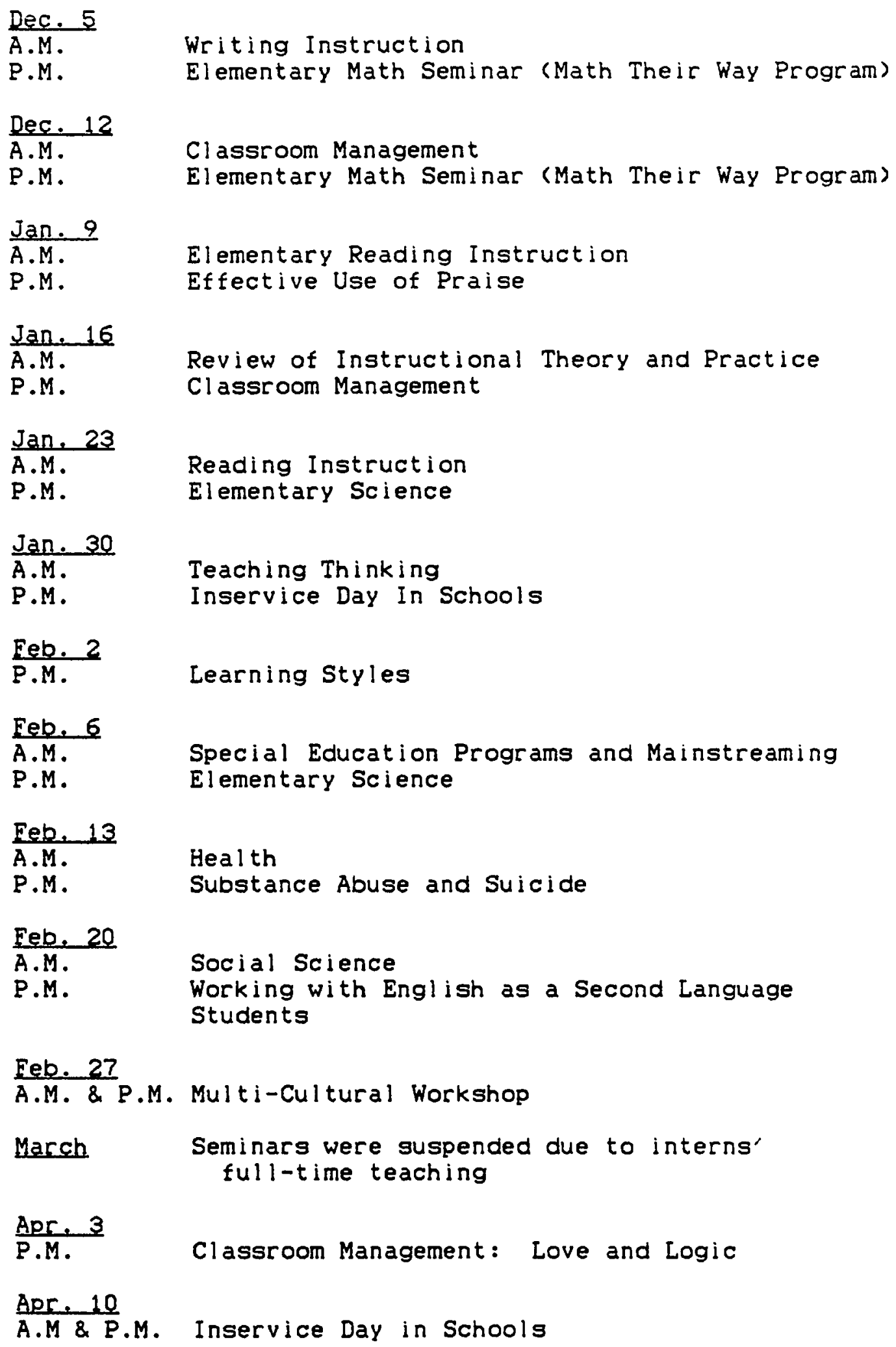




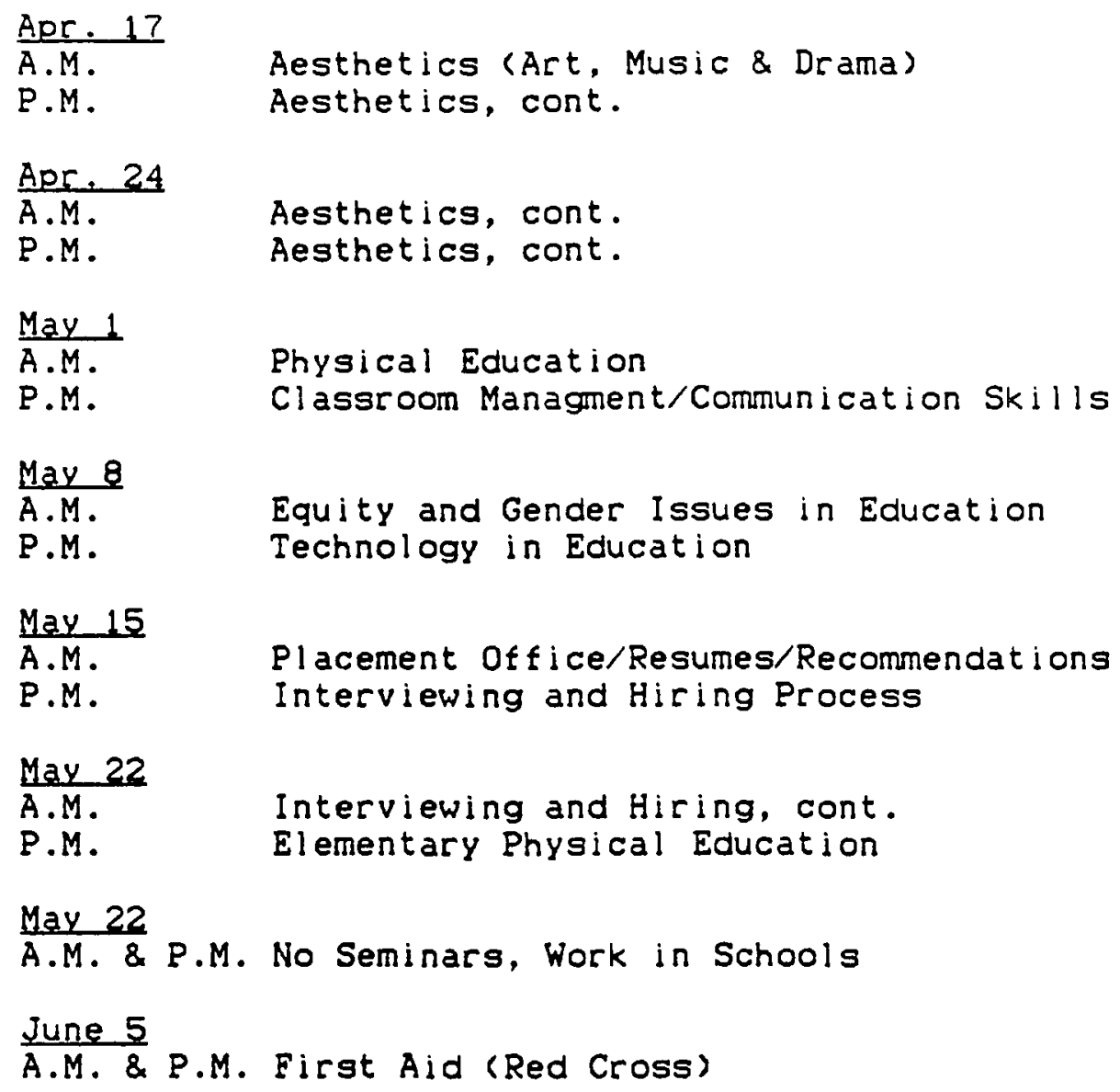

May 22

A.M.

P.M.

Interviewing and Hiring, cont. Elementary Physical Education

May 22

A.M. \& P.M. No Seminars, Work in Schools

June 5

A.M. \& P.M. First Aid (Red Cross) 